\title{
Early rheumatoid arthritis
}

Clinical aspects of new classification criteria and modern treatment strategies

\author{
Thesis by \\ Lena Bugge Nordberg
}

2019

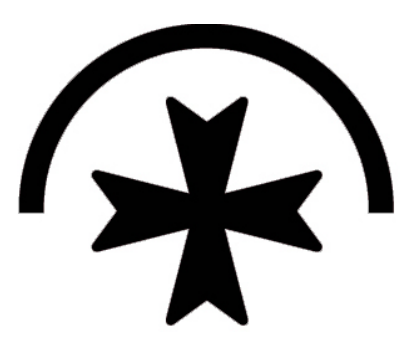

Diakonhiemmet Hospital

Department of Rheumatology

Oslo, Norway

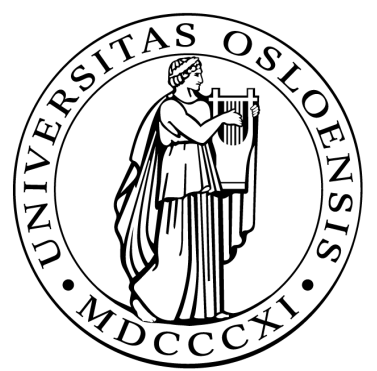

University of Oslo

Faculty of Medicine

Oslo, Norway 
(C) Lena Bugge Nordberg, 2019

Series of dissertations submitted to the Faculty of Medicine, University of Oslo

\section{ISBN 978-82-8377-528-0}

All rights reserved. No part of this publication may be reproduced or transmitted, in any form or by any means, without permission.

Cover: Hanne Baadsgaard Utigard.

Photo cover: Nicolas Tourrenc.

Print production: Reprosentralen, University of Oslo. 


\section{Contents}

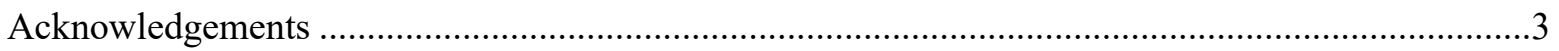

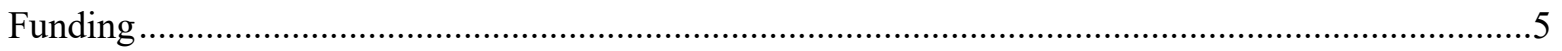

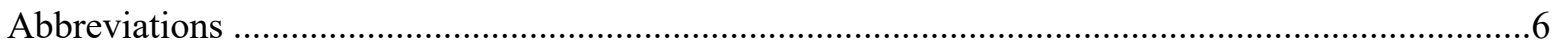

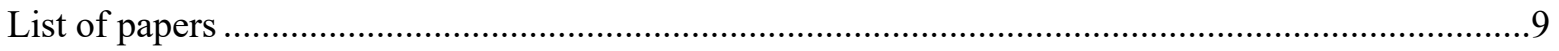

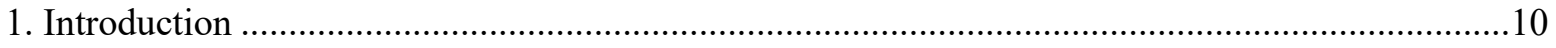

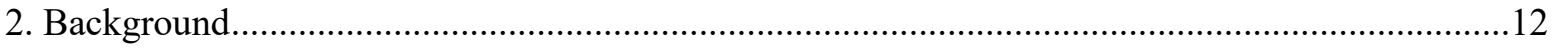

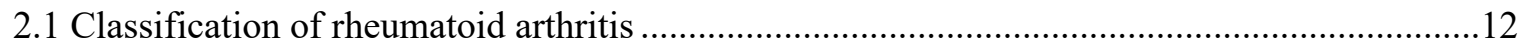

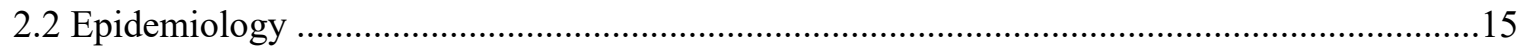

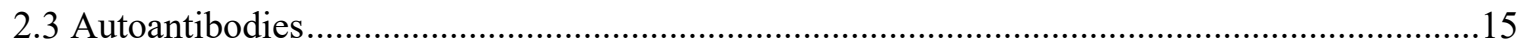

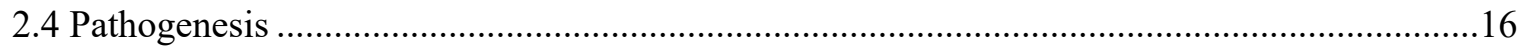

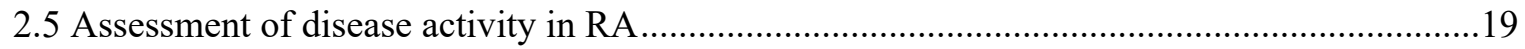

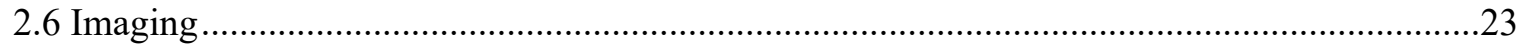

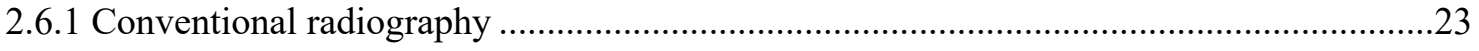

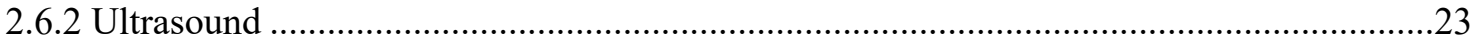

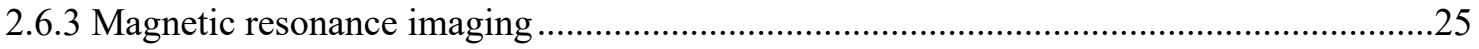

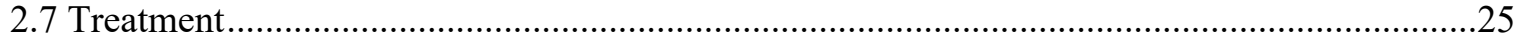

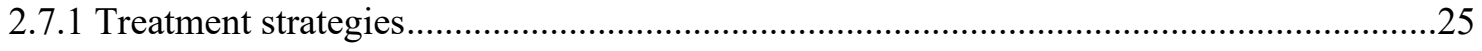

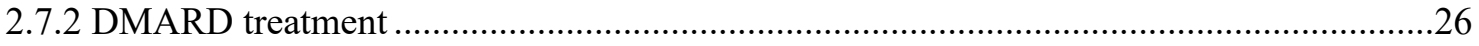

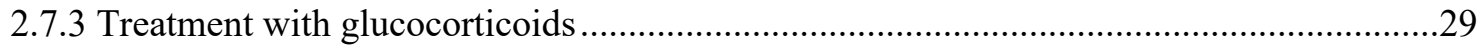

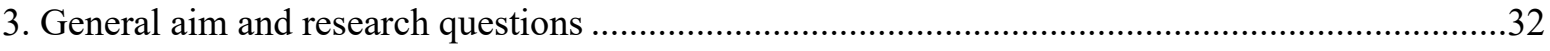

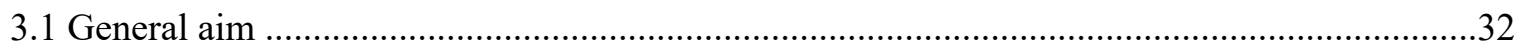

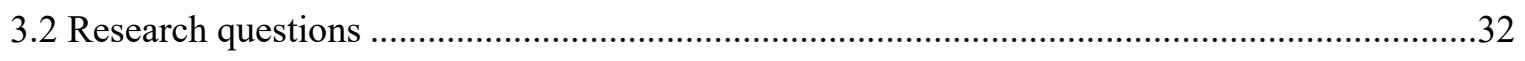

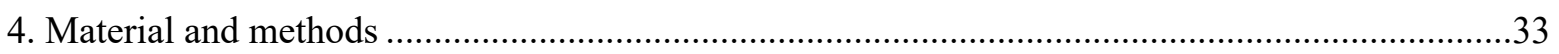

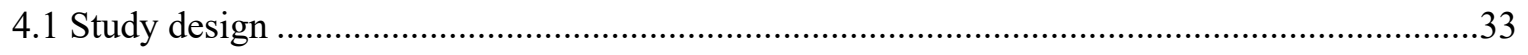

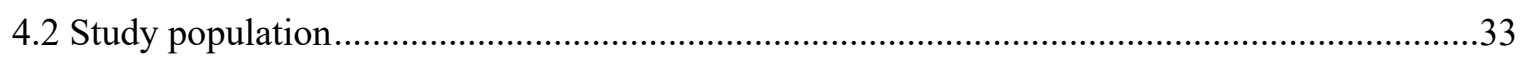

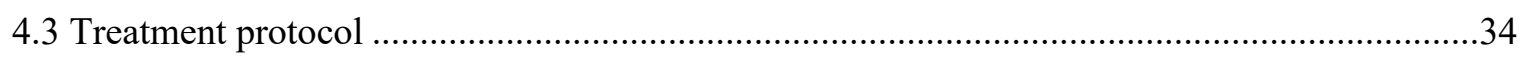

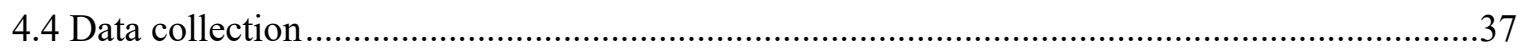

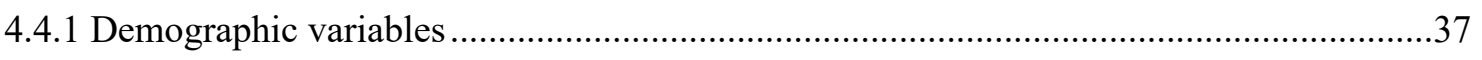

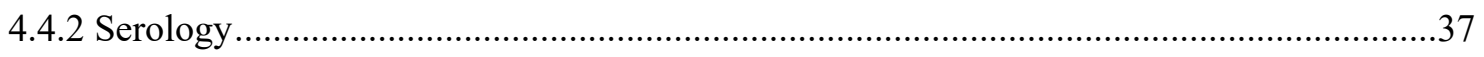

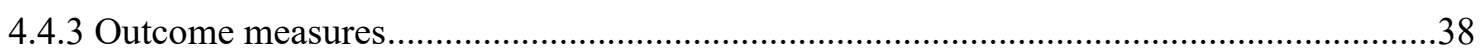

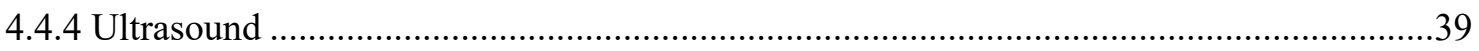




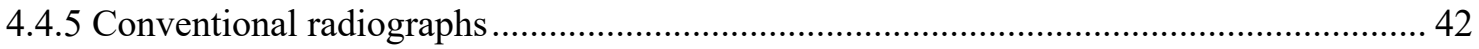

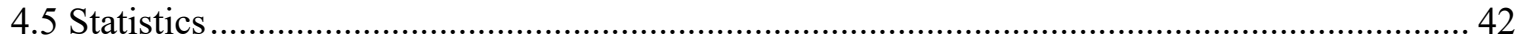

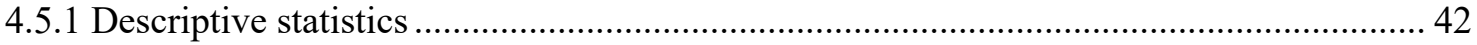

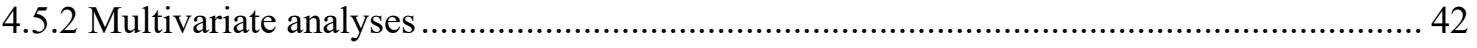

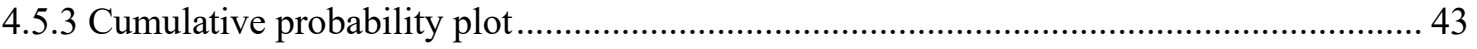

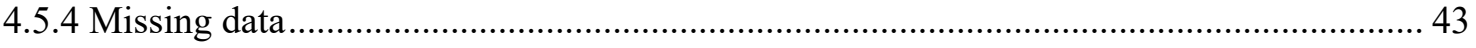

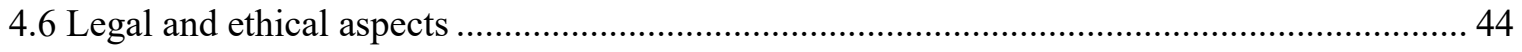

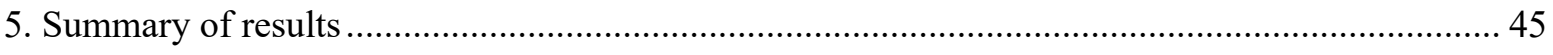

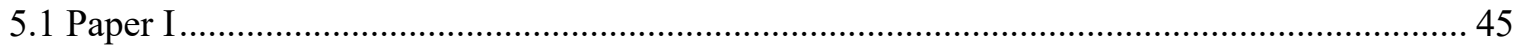

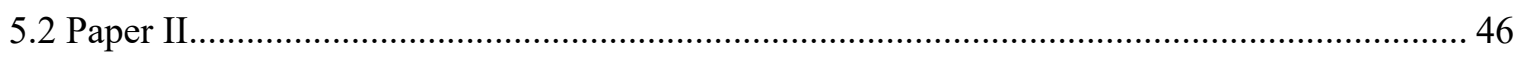

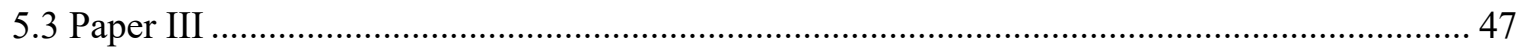

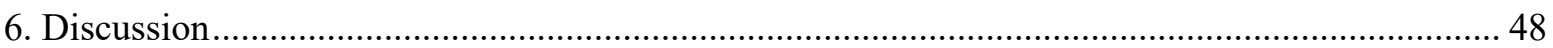

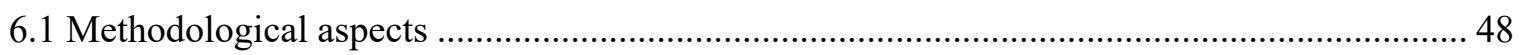

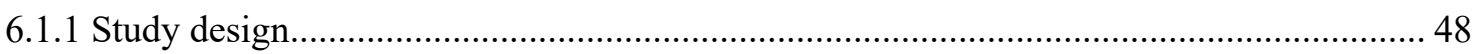

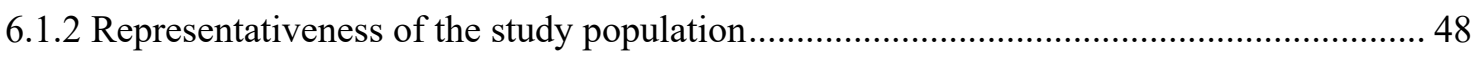

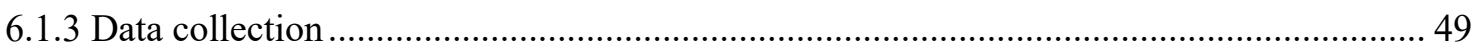

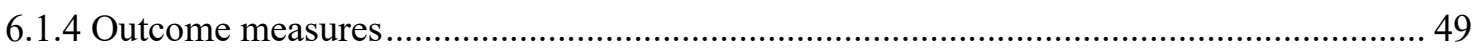

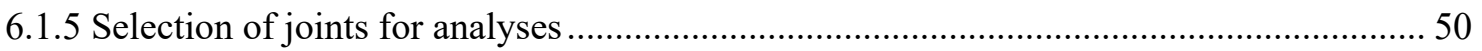

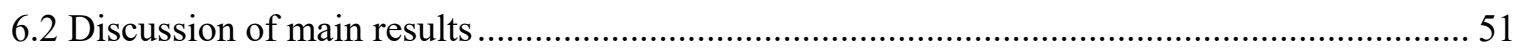

6.2.1 Ultrasound power Doppler and subsequent clinical joint swelling .................................. 52

6.2.2 Identification of joints that may benefit from intra-articular injections ............................ 52

6.2.3 Ultrasound-guided compared to palpation-guided injection procedure ............................. 54

6.2.4 Clinical presentation of seronegative and seropositive RA.............................................. 55

6.2.5 Disease course of seronegative compared to seropositive RA ........................................... 56

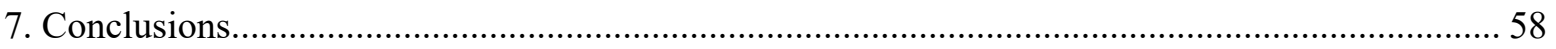

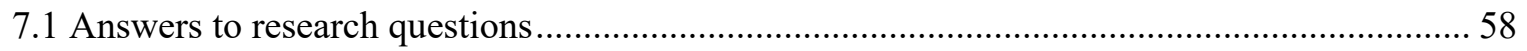

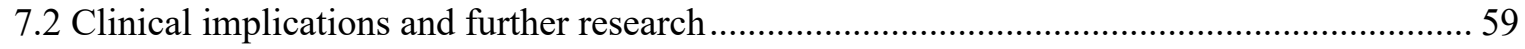

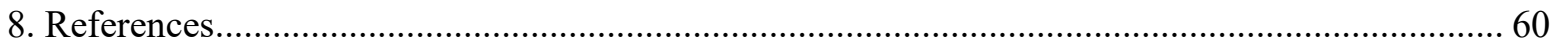

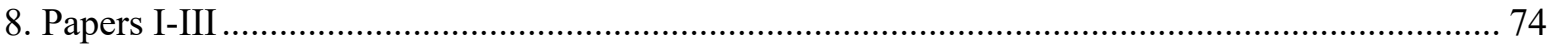




\section{Acknowledgements}

The work included in this thesis would not have been possible without the contribution of a large number of people to whom I am sincerely greatful.

I have had the best supervisor team anyone could wish for. My warm thanks go to my main supervisor professor Espen A. Haavardsholm, and co-supervisors Siri Lillegraven, Elisabeth Lie and professor Tore K. Kvien.

Espen has an extensive knowledge and an ability to carry out small and large projects in a brilliant way. When I have had my moments of panic, he has always seemed calm, and reassured me that "this is going to work out fine". Also, I appreciate that we share the same sense of humor. Espen, thank you for being a great supervisor, your scientific and social cleverness is extraordinary.

Siri has given me endless support and encouragement. When I ask for her advice, it feels like no question is a bad question, and she always has a solution to any problem. She is the best scientific writer I know of and she has lifted the quality of my work. On top of that, she has a heart of gold. Siri, thank you for being my supervisor, and for being a good friend.

Elisabeth's intelligence and kindness make her a great supervisor and colleague. I value her attention to detail and her vast knowledge, and I am truly grateful for our conversations on academic and not so academic issues. Elisabeth, thank you for all the help you have given me and for our friendship.

Tore's scientific expertise combined with encouraging and constructive supervision has meant a lot. His advice is always worth listening to. Tore, thank you for being my supervisor, and for creating such a great place to work.

Anna-Birgitte, although not being a formal supervisor, you have helped me so much. Thank you for valuable advice and thank you for all our good conversations.

Furthermore, I am grateful to all my co-authors. I want to thank Hilde Berner Hammer, Professor Till Uhlig and professor Desiree van der Heiide for valuable input. To Inge, Joe and Øyvind, thank you for making statistics understandable and surprisingly fun (most of the time). Your statistical expertise and advice have been invaluable.

My PhD period would not have been the same without all my great colleagues in the "Villa". Ulf, Alexander, Inger Jorid, Maria J, Ellen, Gina, Eirik I, Vibeke, Grunde, Pernille, Øystein, Ingrid, Brigitte, Silvia, Elisabeth M, Karen, Maria M, Marte SH, Silje, Eirik K, Sella, Ida, Guro, Anne Grete, Karen H, Gunnhild Anita and Kristin, thank you for creating an inspiring, fun and friendly place to work. A special thanks to my roommate, ARCTIC fellow and friend, Nina, for good scientific and non-scientific conversations, and for sharing "ups and downs" in research and personal life. I also want to thank my good friend and colleague Marthe Maehlen, who made me apply for the position as a PhD student at Diakonhjemmet.

Furthermore I want to express my gratitude to my good colleagues in the clinic who now support and guide me in my early clinical work. Kjetil and Lars, thank you for wise answers to my endless questions, I admire your patience and your positivity. 
Additionally I want to thank the patients who voluntarily participated in the ARCTIC trial and investigators and research nurses who have dedicated time and effort. A special thank goes to Ellen Moholt, Camilla Fongen and our monitor Bjørn Solvang. I am also thankful to Diakonhjemmet Hospital for the excellent support they provide their researchers, and the University of Oslo for facilitating my $\mathrm{PhD}$ project.

Finally, I want to thank my friends and family for reminding me every day that there are more important things to life than a doctoral degree. To my parents and "bonus" parents, my sisters, grandparents and my family-in-law for all your love, support and encouragement.

To my dear husband and best friend, Jens Aksel, and my children, Birger, Gustav and Marie, thank you for giving me moments of happiness every day. Each one of you means everything to me. 


\section{Funding}

This PhD-fellowship was funded by the Research Council of Norway. Institutional support was provided by the administration at Diakonhjemmet Hospital.

The ARCTIC trial was supported by the Research Council of Norway, the South-Eastern Norway Regional Health Authority, the Norwegian Rheumatism Association, and investigator initiated research grants from AbbVie, UCB, Pfizer, MSD and Roche. Siemens Healthcare and GE Healthcare provided technical support regarding standardisation of ultrasound equipment.

The funders of the studies have not been involved in study design, data collection, data analyses, data interpretation, or writing of the manuscripts. 


\section{Abbreviations}

ACPA

ACR

Anti-CCP

ARCTIC

CDAI

CI

CRP

DAS

DIP

DMARD

ECU

ESR

EQ-5D

EULAR

GCP

GSUS

HAQ

HLA

Ig

IL

JAK

MCP

MRI

MTP

MTX

OMERACT

OR

PDUS
Anti-Citrullinated Peptide Antibodies

American College of Rheumatology

Antibodies to Cyclic Citrullinated Peptide

Aiming for Remission in rheumatoid arthritis: a randomised trial

examining the benefit of ultrasonography in a Clinical TIght Control

regimen

Clinical Disease Activity Index

Confidence Interval

C-Reactive Protein

Disease Activity Score

Distal InterPhalangeal

Disease Modifying AntiRheumatic Drug

Extensor Carpi Ulnaris

Erythrocyte Sedimentation Rate

EuroQol-5 Dimensions

EUropean League Against Rheumatism

Good Clinical Practice

Grey Scale UltraSound

Health Assessment Questionnaire

Human Leucocyte Antigen

Immunoglobulin

InterLeukin

JAnus Kinase

MetaCarpoPhalangeal

Magnetic Resonance Imaging

MetaTarsoPhalangeal

MethoTreXate

Outcome Measures in Rheumatology

Odds Ratio

Power Doppler UltraSound 


$\begin{array}{ll}\text { PGA } & \text { Patient Global Assessment } \\ \text { PIP } & \text { Proximal InterPhalangeal } \\ \text { PhGA } & \text { Physician Global Assessment } \\ \text { PROMIS } & \text { Patient-Reported Outcomes Measurements Information System } \\ \text { RA } & \text { Rheumatoid Arthritis } \\ \text { RAID } & \text { Rheumatoid Arthritis Impact of Disease } \\ \text { RAMRIS } & \text { Rheumatoid Arthritis Magnetic Resonance Imaging Score } \\ \text { RCT } & \text { Randomised Controlled Trial } \\ \text { RF } & \text { Rheumatoid Factor } \\ \text { SD } & \text { Standard Deviation } \\ \text { SDAI } & \text { Simplified Disease Activity Index } \\ \text { SF-36 } & \text { Short-Form 36 } \\ \text { SJC } & \text { Swollen Joint Count } \\ \text { TJC } & \text { Tender Joint Count } \\ \text { TNF } & \text { Tumor Necrosis Factor } \\ \text { US } & \text { Ultrasound } \\ \text { VAS } & \text { Visual Analogue Scale } \\ \text { vdHSS } & \text { van der Heijde-modified Sharp Score }\end{array}$




\section{List of papers}

I. L. B. Nordberg, S. Lillegraven, A. B. Aga, J. Sexton, E. Lie, H.B. Hammer, I. C. Olsen, T. Uhlig, D. van der Heijde, T. K. Kvien, E. A. Haavardsholm. The impact of ultrasound on the use and efficacy of intra-articular glucocorticoid injections in early rheumatoid arthritis: Secondary analyses from a randomized trial examining the benefit of ultrasound in a clinical tight control regimen. Arthritis Rheumatol 2018;70(8):1192-9.

II. L. B. Nordberg, S. Lillegraven, E. Lie, A. B. Aga, I. C. Olsen, H. B. Hammer, T. Uhlig, M. K. Jonsson, D. van der Heijde, T. K. Kvien, E. A. Haavardsholm and the ARCTIC working group. Patients with seronegative RA have more inflammatory activity compared with patients with seropositive $R A$ in an inception cohort of DMARD-naïve patients classified according to the 2010 ACR/EULAR criteria. Annals of the Rheumatic Diseases 2017;76(2):341-5.

III. L. B. Nordberg, S. Lillegraven, A. B. Aga, J. Sexton, I. C. Olsen, E. Lie, H. B. Hammer, T. Uhlig, D. van der Heijde, T. K. Kvien, E. A. Haavardsholm. Comparing the disease course of patients with seronegative and seropositive rheumatoid arthritis fulfilling the 2010 ACR/EULAR classification criteria in a treat-to-target setting: 2-year data from the ARCTIC trial. RMD Open 2018;4(2):e000752. 


\section{Introduction}

Rheumatoid arthritis (RA) is one of the most prevalent chronic inflammatory diseases in the world, affecting about 24.5 million people as of 2015 (1). The disease primarily affects joints, typically presenting with symmetric inflammation of the small joints of hands and feet, potentially resulting in joint damage and loss of function. RA may also lead to extraarticular manifestations, including rheumatoid nodules, pulmonary involvement and vasculitis, and comorbidities, such as cardiovascular disease (2). The first acknowledged description of the disease is found in a doctoral thesis by Dr. Landré-Beauvais (1772-1840) published in 1800 (3). However, descriptions of signs and symptoms indicative of RA have also been found in ancient texts, such as in the writings of Hippocrates (4).

Identification of rheumatoid factor (RF) (5) and later of anti-citrullinated protein antibodies (ACPA) (6) led to the recognition of the subgroups of seropositive and seronegative rheumatoid arthritis, and serological status has become an important diagnostic and prognostic factor (7). Seronegative RA has been considered to represent a milder form of the disease, associated with less radiographic damage (8-12). New American College of Rheumatology (ACR)/European League Against Rheumatism (EULAR) classification criteria for RA, published in 2010, have led to a redefinition of the patient population by increased weighting of serology (13). Knowledge is limited regarding the presentation and disease course in seropositive versus seronegative RA patients classified according to the 2010 ACR/EULAR criteria.

During the last 20 years new treat-to-target strategies with the use of disease-modifying antirheumatic drugs (DMARDs) have led to greatly improved outcomes in RA $(2,14)$. Early initiation of intensive treatment with effective drugs, have made clinical remission and prevention of radiological damage achievable for many patients. In addition to DMARDs, systemic glucocorticoids and intra-articular glucocorticoid injections of inflamed joints are often included in treat-to-target strategies. Injections are performed with or without ultrasound guidance. Knowledge regarding the efficacy of intra-articular injections and the impact of using ultrasound in injection therapy is limited. 
New treatment strategies with novel therapeutics, application of modern imaging methods and development of new classification criteria have changed the concept of early RA. The aim of this thesis is to assess some of the clinical aspects of modern treatment and new classification criteria, focusing on ultrasound and intra-articular injections, and the presentation and disease course of seronegative and seropositive RA patients classified according to new ACR/EULAR classification criteria. 


\section{Background}

\subsection{Classification of rheumatoid arthritis}

The development of classification criteria for rheumatoid arthritis (RA) has provided a common approach to disease definition in research. Classification criteria enable standardised recruitment of patients into studies and can be used for guidance in clinical practice (13).

Before 2010, the classification of RA was based on fulfillment of the 1987 ACR criteria (15) (Table 1). These criteria were developed in RA patients with established disease and some of their components, especially the presence of rheumatoid nodules, are rare in early RA. Early treatment is important for the prognosis of RA, and the 1987 criteria have been shown to have poor sensitivity for classification of patients with early disease $(16,17)$. The need for improved sensitivity was one of the main reasons for the development of the 2010 ACR/EULAR classification criteria (13) (table 2). The 2010 criteria put great emphasis on RF and ACPA status. While seropositive patients can fulfill the criteria with only one affected joint, more than 10 involved joints are required for seronegative patients to fulfill the criteria. The new criteria demonstrate better sensitivity in patients with early disease compared to the old criteria and appear to result in an increased prevalence of classifiable RA with a milder disease course (18). The 2010 criteria have been shown to identify fewer patients with seronegative disease compared to the 1987 criteria (19). 
Table 1 The 1987 ACR classification criteria for RA*

\begin{tabular}{|c|c|}
\hline Criterion & Definition \\
\hline 1. Morning stiffness & $\begin{array}{l}\text { Morning stiffness in and around the joints, } \\
\text { lasting at least } 1 \text { hour before maximal } \\
\text { improvement }\end{array}$ \\
\hline 2. Arthritis of 3 or more joint areas & $\begin{array}{l}\text { At least } 3 \text { joint areas simultaneously have had } \\
\text { soft tissue swelling or fluid (not bony } \\
\text { overgrowth alone) observed by a physician. } \\
\text { The } 14 \text { possible areas are right or left PIP, } \\
\text { MCP, wrist, elbow, knee, ankle, and MTP } \\
\text { joints }\end{array}$ \\
\hline 3. Arthritis of hand joints & $\begin{array}{l}\text { At least } 1 \text { area swollen (as defined above) in a } \\
\text { wrist, MCP, or PIP joint }\end{array}$ \\
\hline 4. Symmetric arthritis & $\begin{array}{l}\text { Simultaneous involvement of the same joint } \\
\text { areas (as defined in 2) on both sides of the body } \\
\text { (bilateral involvement of PIPs, MCPs, or MTPs } \\
\text { is acceptable without absolute symmetry) }\end{array}$ \\
\hline 5. Rheumatoid nodules & $\begin{array}{l}\text { Subcutaneous nodules, over bony prominences, } \\
\text { or extensor surfaces, or in juxtaarticular } \\
\text { regions, observed by a physician }\end{array}$ \\
\hline 6. Serum rheumatoid factor & $\begin{array}{l}\text { Demonstration of abnormal amounts of serum } \\
\text { rheumatoid factor by any method for which the } \\
\text { result has been positive in } 4 \% \text { of normal control } \\
\text { subjects }\end{array}$ \\
\hline 7. Radiographic changes & $\begin{array}{l}\text { Radiographic changes typical of rheumatoid } \\
\text { arthritis on posteroanterior hand and wrist } \\
\text { radiographs, which must include erosions or } \\
\text { unequivocal bony decalcification localised in or } \\
\text { most marked adjacent to the involved joints } \\
\text { (osteoarthritis changes alone do not qualify) }\end{array}$ \\
\hline
\end{tabular}


Table 2 The 2010 ACR/EULAR classification criteria for $R A^{*}$

\begin{tabular}{|l|c|}
\hline Criterion (score range) & Score \\
\hline JOINTS $(0-5) \dagger$ & 0 \\
\hline 1 large joint & 1 \\
\hline $2-10$ large joints & 2 \\
\hline $1-3$ small joints (large joints not counted) & 3 \\
\hline $4-10$ small joints (large joints not counted) & 5 \\
\hline$>10$ joints (at least one small joint) & \\
\hline SEROLOGY (0-3) & 0 \\
\hline Negative RF AND negative ACPA & 2 \\
\hline Low positive RF OR low positive ACPA & 3 \\
\hline High positive RF OR high positive ACPA & \\
\hline SYMPTOM DURATION (0-1) & 0 \\
\hline$<6$ weeks & 1 \\
\hline$\geq 6$ weeks & 1 \\
\hline ACUTE PHASE REACTANTS (0-1) & 0 \\
\hline Normal CRP AND normal ESR & \\
\hline Abnormal CRP OR abnormal ESR & \\
\hline
\end{tabular}

* The criteria apply to patients with at least one joint with clinical synovitis not related to a specific aetiology. A patient must achieve a score of 6 or more points to be classified as RA (13). In the presence of erosions typical of rheumatoid arthritis, no other points are needed for classification (20).

$\dagger$ Joint involvement includes any tender or swollen joints, except from DIP of hand and feet, CMC1, MTP1, and MRI/ultrasound may be used to determine a more complete joint involvement. Joints defined as "small": MCP, MTP, PIP, IP, wrist. Joints defined as "large": Shoulder, elbow, hip, knee and ankle (21). 


\subsection{Epidemiology}

RA has a prevalence of 0.5 to $1.1 \%$ in the adult population in developed countries, including Norway, with lower incidence rates in Southern Europe than in Northern America and Northern Europe (primarily based on the 1987 classification criteria for RA) (22-24). The global prevalence of RA has been stable during the last decades, whereas disability-adjusted life years have increased from 3.3 million in 1990 to 4.8 million in 2010 due to population growth and increased aging (25). RA incidence increases with age, and more women than men are affected (3:1 female to male ratio) (26-28).

Mortality is increased in patients with RA compared to the general population, partly explained by an increased incidence of cardiovascular disease, infections and cancer (29, 30). Studies have, however, indicated a decrease in mortality over the last decades, probably due to earlier diagnosis and improvements in RA treatment (30-32).

\subsection{Autoantibodies}

Seropositive RA is characterised by the presence of autoantibodies in serum. The first recognised autoantibody in RA patients was rheumatoid factor (RF), described by Waaler in 1939 (5). RF is an antibody directed against the Fc part of immunoglobulin $G(\operatorname{IgG})$. The role of RF in RA pathogenesis is unclear, but it is involved in mechanisms of macrophage activation and induction of cytokine activation $(2,33)$. A majority of RA patients have detectable RF in their sera $(11,34,35)$, but RF is also found in patients with other autoimmune and infectious diseases, and also in the healthy population (36). Around 5\% of healthy 50 year old individuals and $10-25 \%$ of healthy 70 year old individuals have been reported to be positive for RF (37). Sensitivity and specificity of RF for RA vary between studies. A meta-analysis from 2010 found an overall sensitivity of $70 \%$ and specificity of $79 \%$. In analyses restricted to studies of early RA, sensitivity was $56 \%$ and specificity was $86 \%$ (35). 
In the 1960s and 70s, new autoantibodies highly specific for RA were described, first the antiperinuclear factor antibody (APF) (38), followed by the discovery of anti-keratin antibodies (AKA) (39). These antibodies were the first members of the now well-known ACPA family. Widespread diagnostic use of ACPAs was delayed due to uncertainty about their antigenic target and complex technical requirement for their detection. Advances in the biological understanding of ACPAs and the development of enzyme-linked immunosorbent assay (ELISA) tests for detecting them, have made ACPA the most important diagnostic biomarker in RA $(35,40)$. ACPAs are autoantibodies directed against different citrullinated peptides and proteins including vimentin, $\alpha$-enolase, fibronectin, fibrinogen, histones, and type II collagen, associated with activation of immune responses (2).

In the year 2000 the anti-cyclic citrullinated peptide (anti-CCP) ELISA test was described, developed to determine the presence of ACPAs. It incorporated a cyclic peptide variant containing citrulline as antigenic substrate in ELISA and was found to be highly specific for RA (40). The specificity of ACPA (by use of the anti-CCP test) is higher than for RF, while sensitivity is similar. The overall specificity and sensitivity of ACPA for RA has been estimated to $95 \%$ and $67 \%$ respectively, while in early RA specificity has been estimated to $96 \%$ and sensitivity to $58 \%(35)$.

More recently, anti-carbamylated and acetylated peptide autoantibodies have also been identified in RA patients $(41,42)$. Around $20 \%$ of patients with seronegative RA have been shown to have anti-carbamylated protein antibodies, which are associated with more severe joint damage (41).

\subsection{Pathogenesis}

The cause of RA remains unknown, but insights regarding the pathogenesis has increased in recent years contributing to the development of new effective therapeutics and treatment strategies (43). RA is a multifactorial disease, where genetic and environmental factors both play a role (figure 1). Twin studies have shown a genetic contribution to RA of 
approximately $60 \%$ (44). In a large register study from Sweden, the heritability of RA was estimated to around $50 \%$ for seropositive and $20 \%$ for seronegative disease (45).

A number of genetic risk factors for RA have been identified. Some of the most important RA risk alleles have been found in the human leukocyte antigen (HLA)-DRB1 region. Certain alleles in this region, strongly associated with seropositive RA, encode for an identical amino acid sequence in the peptide-binding groove, termed the shared epitope (46). Multiple single nucleotide polymorphisms outside the HLA region are also associated with RA. In recent years genome-wide association studies have identified around 100 RA risk genes (47). Many of the identified genes associated with seropositive RA are involved in immune regulation, including nuclear factor $\kappa \mathrm{B}-$ dependent signalling (e.g., TRAF1-C5 and c-REL) and T-cell stimulation, activation, and functional differentiation (e.g. PTPN22 and CTLA4) $(43,48)$. Genetic risk factors for seronegative RA have been less studied. There is evidence of partial genetic overlap for seropositive and seronegative disease, however several differences have been identified $(28,49,50)$. Seronegative RA has been shown to be associated with HLA-DRB3 (51) and with several genes outside the HLA region (52).

Environmental risk factors for seropositive RA include cigarette smoking and low socioeconomic status $(43,53)$. A meta-analysis has shown a $40 \%$ higher risk for developing RA among ever-smokers compared to never-smokers (54). A strong gene-environment interaction has been shown between smoking and HLA-DR shared epitope genes with regard to the risk of developing ACPA positive RA. A study by Klareskog et al reported a relative risk among ACPA positive persons for RA of 21 in smokers carrying two copies of the shared epitope gene compared with nonsmokers without the risk gene. The risk of RA in smokers without the risk gene and in non-smokers with the risk gene was also increased, but markedly less (55).

Other potential environmental risk factors include silica dust and other airway exposures, periodontal disease, gastrointestinal dysbiosis and infectious agents (porphyromonas gingivalis, Epstein-Barr virus, cytomegalovirus, proteus species, and Escherichia coli) (2). Long term breastfeeding, oral contraceptives and alcohol consumption have been identified as possible protective factors for developing seropositive RA (56). Knowledge about environmental risk factors for seronegative rheumatoid arthritis is more limited. Obesity has 
been identified as a possible risk factor (57). High birth weight and age at menarche of 15 years or more have been associated with an increased risk of both seronegative and seropositive RA (57-59).

It is not known where in the body immune activation in RA occurs, possibly local tissue stress in the lung, oral mucosa and/or the gastrointestinal tract, can lead to modifications of self-peptides with subsequent antibody formation (60). Signs of immune activation have been shown in the lung tissue of patients with early RA strengthening the hypothesis of immunization in the lungs (61). Furthermore, secretory IgA antibodies against cyclic citrullinated peptides in RA patients are associated with inflammatory activity and smoking (62).

RF, ACPA and also other autoantibodies, including anti-carbamylated and acetylated peptides, may lead to immune activation in RA, but the mechanisms are only partly understood. Seronegative and seropositive RA have a similar clinical presentation possibly caused by a common inflammatory pathway. Activation of the immune system in both seropositive and seronegative disease leads to leucocyte infiltration into the synovium. Leucocytes, cytokines, and immune complexes stimulate macrophages and fibroblast-like synoviocytes to produce pro-inflammatory cytokines (like TNF- $\alpha$, IL-1, IL-6, IL-15, and IL23 ) resulting in synovial inflammation, chondrocyte activation and cartilage destruction. Activated fibroblasts and leucocytes can upregulate expression of RANK ligand, leading to osteoclastogenesis and bone destruction $(2,48)$. 


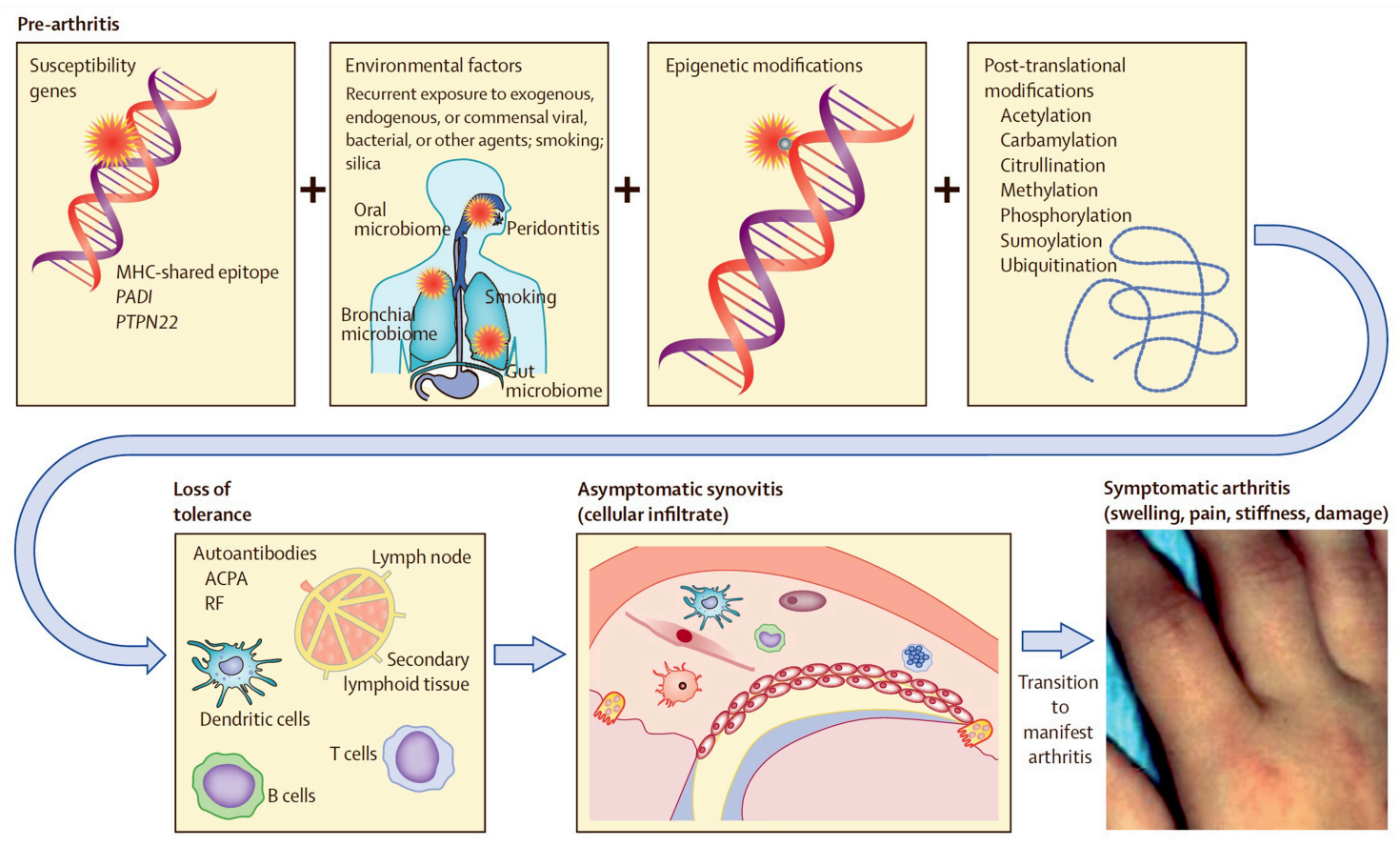

Figure 1: In a genetically predisposed host with susceptibility genes, environmental insults, epigenetic modifications, and post-translational modifications can lead to loss of tolerance with subsequent asymptomatic synovitis, ultimately leading to clinically overt arthritis. ACPA=autoantibodies against citrullinated peptides. RF=rheumatoid factor. First published by Smolen et al in the Lancet, 2016 (2). Reprinted with permission from Elsevier.

\subsection{Assessment of disease activity in RA}

Assessment of disease activity is essential in the follow-up of RA patients, to evaluate the treatment efficacy, and to monitor the course of the disease. In 1993 an ACR committee validated and proposed a core set of disease activity measures for RA clinical trials (63). Since the introduction of this core set, measurement of outcomes in RA trials have become more consistent (64). The core set consists of a tender joint count, a swollen joint count, the patient's assessment of pain, the patient's global assessment of disease activity (PGA) and the physician's global assessments of disease activity (PhGA), the patient's assessment of physical function and a laboratory evaluation of an acute-phase reactant. These measures have been shown to capture improvement in RA and many of them predict long-term outcomes (i.e. physical disability, radiographic damage and death) (63). 
The most commonly used swollen joint counts are 66, 44 and 28 swollen joints (65-67). Joint tenderness is usually assessed by the 68 and 28 tender joint counts, and the Ritchie Articular Index $(65,66,68)$.

Patient's and physician's global assessments of disease activity are usually based on visual analogue scales (VAS) (0-10 or 0-100 mm), measuring the overall way RA affects the patient at a point in time (69). Pain is the most prominent symptom in RA patients, it is usually assessed by the patient on a VAS (70).

Acute phase reactants commonly assessed in RA patients include the Erythrocyte Sedimentation Rate (ESR) and C-reactive protein (CRP). CRP and ESR are elevated in patients with active disease and decline with disease improvement. Elevated acute phase reactants have been shown to be associated with a poor prognosis, but they are not considered to be sensitive prognostic markers (71).

No individual outcome measure can reflect all aspects of RA, making them ineligible as single endpoint measures in clinical trials (72). Therefore, the use of composite measures, in which single measures are combined into a composite index, are recommended to asses disease activity in RA $(72,73)$. The most commonly used measures are the disease activity score (DAS) $(67,74)$, the modified disease activity score that includes 28 joints (DAS28) (75), the simplified disease activity index (SDAI) (76) and the clinical disease activity index (CDAI) (77). These composite measures are based on tender and swollen joint counts, the PGA, acute phase reactants (except from CDAI), and, for SDAI and CDAI also the PhGA. The composite measures provide numerical scales reflecting disease activity and they can be used to classify different states of disease activity (high, moderate, low, remission) (2).

In modern treatment of RA, the treatment target is remission (or at least low disease activity if remission is not a realistic goal). Remission can be defined as no signs and symptoms of active disease (73). In clinical trials remission is usually defined by use of the described composite measures or by the ACR/EULAR Boolean remission criteria (78). The remission cut-points for each composite measure are listed in table 3. 
Table 3 Disease activity composite measures and ACR/EULAR Boolean remission criteria

\begin{tabular}{|c|c|c|}
\hline $\begin{array}{l}\text { Composite } \\
\text { measure }\end{array}$ & Components & Remission cut-point \\
\hline DAS & 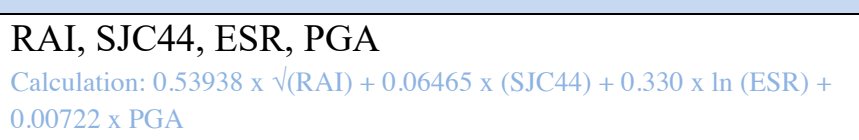 & $<1.6$ \\
\hline DAS28 & $\begin{array}{l}\text { ESR, } 28 \text { swollen joint count, } 28 \text { tender joint count, } \\
\text { PGA } \\
\text { Calculation: } 0.56 \times \sqrt{ }(\text { TJC28) }+0.28 \times \sqrt{ }(\text { SJC2 } 2)+0.70 \times \log (\text { ESR })+0.014 \\
\times \text { PGA }\end{array}$ & $<2.6$ \\
\hline SDAI & $\begin{array}{l}\text { CRP, SJC28, TCJ28, PGA, PGA } \\
\text { Calculation: CRP [mg/dl] + SJC28 + TJC28+ PGA + PGA }\end{array}$ & $\leq 3.3$ \\
\hline CDAI & $\begin{array}{l}\text { SJC28, TJC28, PGA, PhGA } \\
\text { Calculation: SJC28 + TJC28 + PGA + PhGA }\end{array}$ & $\leq 2.8$ \\
\hline $\begin{array}{l}\text { ACR/EULAR } \\
\text { Boolean } \\
\text { remission criteria }\end{array}$ & CRP, swollen joint count, tender joint count, PGA & $\begin{array}{c}\mathrm{SJC} \leq 1 \text { and } \\
\mathrm{TJC} \leq 1 \text { and } \\
\mathrm{PGA} \leq 1 \text { and } \\
\mathrm{CRP}[\mathrm{mg} / \mathrm{l}] \leq 10\end{array}$ \\
\hline
\end{tabular}

Abbreviations: ACR: American College of Rheumatology, CDAI: Clinical Disease Activity Index, CRP: C-reactive protein, DAS: Disease Activity Score, DAS28: Disease Activity Score with 28 joints, ESR: Erythrocyte Sedimentation Rate, EULAR: European League Against Rheumatism, PGA: Patient Global Assessment, PhGA: Physician Global Assessment, RAI: Ritchie Articular index, SDAI: Simplified Disease Activity Index, SJC28=swollen joint count with 28 joints. PGA and PhGA are evaluated by use of a visual analogue scale $(0-100 \mathrm{~mm}$ in DAS and DAS28, 0-10 $\mathrm{cm}$ in CDAI, SDAI and Boolean).

ACR and EULAR have also each recommended definitions of response to treatment for use in RA clinical trials. ACR response evaluates the patient's percentage of improvement in core set variables during the study (79), while the EULAR response classifies patients into non- responders, moderate responders and good responders, depending on improvement and level of DAS or DAS28 achieved (80).

Physical function is an important indicator of health and it is measured in most studies of RA. One of the most widely used instruments for measurement of physical function is the Health Assessment Questionnaire (HAQ). It queries the ability of performing 20 activities of daily living by four response categories, ranging from 0 (best) to 3 (worst) (81). Many modified versions of HAQ have been developed, including the Patient-Reported Outcomes Measurement Information System (PROMIS) physical function (82). Another widely used instrument for measuring physical function is the physical function component of the Short Form-36 Health survey (SF-36) (83). 
Health related quality of life can be assessed by use of the EuroQol-5 Dimensions (EQ-5D), a standardised generic instrument using three levels of severity in five dimensions with values based on preference weights with a range from 1 (best possible health), to 0 (death) to -0.59 (worse than death) (84).

A relatively new instrument for measuring the impact of RA, is the Rheumatoid Arthritis Impact of Disease (RAID) score. This is a patient-derived composite score assessing seven important domains of the impact of rheumatoid arthritis (85). 


\subsection{Imaging}

Imaging has an important role in diagnosis and follow-up of patients with RA, both in clinical practice and in research. Structural progression is mainly assessed by conventional radiography, while inflammation is assessed by ultrasound and magnetic resonance imaging (MRI) (86). According to the EULAR recommendations for the use of joint imaging in clinical management of RA, conventional radiography, MRI and ultrasound can be useful in diagnosis, monitoring of disease activity and progression, and prediction of joint damage (87).

\subsubsection{Conventional radiography}

Conventional radiographs of hands and feet is the gold standard for assessment of structural damage in RA, both in clinical practice and in clinical trials (88). In research, radiographs are scored for the presence and progression of erosions and joint space narrowing. One of the most widely used scoring methods is the van der Heijde-modified Sharp score (vdHSS), which includes scoring of hands and feet. It provides separate scores for erosions (range 0280 ) and joint space narrowing (range 0-168), and a total score is calculated as the sum of the two (range 0-448) (89). Radiographic damage assessed by vdHSS is associated with impaired physical function, both in early and established RA (90).

\subsubsection{Ultrasound}

Musculoskeletal ultrasound is increasingly used in the management of RA (91). It is a valid and reliable tool for evaluation of joint and tendon inflammation and it can to a certain extent visualise cartilage and erosions in patients with RA (92).

Ultrasound is sound waves with frequencies higher than the upper audible limit of human hearing. When used for imaging in medicine, a transducer generates ultrasound waves and discharges them into the body. A reflected echo is created at boundaries in or between tissues, with amplitude depending on the difference in density and speed properties of the tissues. The transducer receives the reflected sound waves and they are converted into images. The image resolution improves with higher frequencies, while penetration is better with lower frequencies. In musculoskeletal ultrasound, linear probes with frequencies between 5 and $20 \mathrm{MHz}$ are mainly used (93). 
Ultrasound has no ionising radiation, and it provides immediate information. Synovitis is usually evaluated for the presence of grey-scale and power Doppler activity. Grey-scale provides morphological information of the anatomic structures while power Doppler visualises vascularisation (94). Ultrasound may also be used as a tool to guide intra-articular injections, as will be described in more detail below.

Grey scale and power Doppler are usually scored semi-quantitatively from 0 to 3 for each mode in each joint $(95,96)$. One widely used 0-3 semi-quantitative scoring system for joint effusion, synovial thickening and bone change in finger and toe joints was published in 2003 (96). In Norway most rheumatologists use a validated 0-3 semi-quantitative scoring system for power Doppler and grey scale in 32 joints, published in 2011 by Hammer et al, with an ultrasound atlas as reference (95). This scoring system has also been used in international studies $(97,98)$. Recently the European EULAR-Outcomes Measures in Rheumatology (OMERACT) combined score was proposed, which is also a semiquantitative score from 0-3 for Doppler and synovial hypertrophy (grey scale) $(99,100)$.

There is no consensus on the minimal number of joints and tendons to be included in a global assessment of ultrasound inflammation (101). Several reduced joint scores have been proposed (102-107).

The real-time nature of ultrasound image acquisition makes it more operator-dependent compared with other imaging modalities. Standardisation of the scanning procedures is therefore important in clinical practice and in research. EULAR has recently proposed a consensus-based guide on standardised procedures for ultrasound imaging in rheumatology, including instructions on patient position, probe placement and scanning method (94).

Ultrasound is a useful tool to detect subclinical inflammation in RA, but the addition of structured ultrasound assessment to a treat to target tight control strategy did not improve patient outcomes in the ARCTIC trial or in the TaSER trial $(108,109)$. However, ultrasound may still be of importance in diagnosis and in procedures such as intra-articular injections, also it can improve our understanding of the disease process in RA. 


\subsubsection{Magnetic resonance imaging}

MRI visualises joint destruction (erosions, joint space narrowing) and joint- and tendon inflammation (synovitis, bone marrow edema, tenosynovitis). MRI bone marrow oedema has been shown to be a predictor for future joint damage $(110,111)$. In clinical trials, MRI features are usually scored by the OMERACT RA MRI scoring system (RAMRIS) (112, $113)$.

MRI is primarily used in RA for diagnostic purposes and as an outcome measure in clinical trials. The recently published Imagine RA trial showed no benefit of using MRI to guide treatment of RA in a treat-to-target setting (114).

\subsection{Treatment}

\subsubsection{Treatment strategies}

During the last decades new treatment strategies have improved outcomes in RA and remission has become an achievable goal for many patients. An international task force has published recommendations for implementation of a strategic approach to reach optimal outcomes, and EULAR and ACR have formulated evidence-based recommendations for pharmacological treatment of RA $(14,73,115)$. The recommendations are summarised in the following section.

The ultimate treatment goal is to maximise long-term health-related quality of life through symptom control, prevention of structural damage, normalisation of function and participation in social and work-related activities. Inflammation is responsible for the clinical symptoms, joint damage, disability and comorbidity in RA. Therefore, reversal of inflammation is the major therapeutic target (14).

Early suppression of inflammation, at a stage when the disease process can still be reversible or at least modifiable, is described as a "window of opportunity" (116-118). It has been shown that patients with early disease respond better to treatment compared with 
patients with longer disease duration (119). The exact time frame of this "window of opportunity" is not known, 12 weeks has been suggested (120).

During the last thirty years, this important change in RA treatment practice has been implemented, moving from step-up-therapy, with low initial drug doses, to more aggressive treatment, starting early with higher doses of effective drugs $(121,122)$.

The recommended RA treatment strategy include regular and frequent assessment of disease activity ("tight control") to steer treatment, and treatment should be intensified in order to reach the goal of remission or low disease activity if remission is not possible ("treat-totarget") (14).

Several studies have shown that tight control leads to better outcomes than routine patient care follow-up (123-128). Frequent monitoring (every 1-3 months) is therefore recommended during periods of active disease, and treatment should be escalated if there is no improvement or if the treatment target is not reached $(14,115)$. Early initiation of effective drugs, tight control and treat-to-target has shown convincing clinical and radiographic benefits (123-131).

\subsubsection{DMARD treatment}

The cornerstone in RA treatment is DMARDs $(14,132)$. DMARDs can be divided into synthetic (conventional and targeted) and biological (original and biosimilar) (14). Over the past two decades new pharmacological treatment options and new treatment strategies have dramatically improved the outcomes of RA $(122,133,134)$.

Methotrexate (which is a conventional synthetic DMARD) is considered the anchor drug in RA treatment. Since the first reported application in RA in 1962 (135), methotrexate has become the most frequently prescribed drug and several studies have demonstrated that it reduces inflammation and inhibits radiographic progression (136-138). Methotrexate is a folate inhibitor, it prevents purine and pyrimidine synthesis, which are essential in the synthesis of DNA and RNA, thereby resulting in impaired proliferation of lymphocytes, inhibiting the inflammatory process in RA (138). Methotrexate in combination with bridging glucocorticoids are recommended by EULAR as the initial therapy choice in RA and should be started as soon as possible if no contraindications are present. In patients who 
do not respond to methotrexate within three months, therapy should be changed. If the patient has low risk of progressive disease, changing to another conventional DMARD or adding a second conventional DMARD is recommended. In patients with unfavorable prognostic factors, a biological or targeted synthetic DMARD should be added (14).

The use of biological DMARDs has greatly improved management of RA during the last 15-20 years. Biological DMARDs directly target molecules and cells involved in the pathogenesis of RA. The most important targets in current treatment are tumor necrosis factor- $\alpha$, interleukin-6 (IL-6) receptor, B-cells (depletion of CD20+ B-cells) and T-cells (inhibition of T-cell co-stimulation from antigen-presenting cells). Methotrexate in combination with a biologic DMARD has been shown superior to methotrexate alone in terms of reducing inflammation and inhibiting joint damage $(2,138-140)$. The different synthetic and biological DMARDs are presented in table 4. 
Table 4 Overview of disease-modifying antirheumatic drugs (DMARDs)

\begin{tabular}{|c|c|c|}
\hline Type & Drug & Mechanism of action \\
\hline \multirow{4}{*}{$\begin{array}{l}\text { Conventional } \\
\text { synthetic DMARDs }\end{array}$} & Methotrexate & Inhibits purine and pyrimidine synthesis \\
\hline & Sulfasalazine & $\begin{array}{l}\text { Not completely known (different } \\
\text { antiinflammatory and } \\
\text { immunosuppressive properties have } \\
\text { been demonstrated, suggesting a } \\
\text { multifactorial basis of therapeutic } \\
\text { action) }\end{array}$ \\
\hline & Hydroxychloroquine & $\begin{array}{l}\text { Not completely known. Induces } \\
\text { apoptosis and decreases chemotaxis }\end{array}$ \\
\hline & Leflunomide & Inhibits pyrimidine synthesis \\
\hline \multirow{2}{*}{$\begin{array}{l}\text { Targeted synthetic } \\
\text { DMARDs }\end{array}$} & Baricitinib & Janus Kinase inhibitor \\
\hline & Tofacitinib & Janus Kinase inhibitor \\
\hline \multirow[t]{9}{*}{ Biologic DMARDs } & Abatacept & Selective T-cell co-stimulator blocker \\
\hline & Adalimumab & TNF alpha inhibitor \\
\hline & Anakinra & IL-1 receptor inhibitor \\
\hline & Certolizumab pegol & TNF alpha inhibitor \\
\hline & Etanercept & Soluble TNF alpha inhibitor \\
\hline & Golimumab & TNF alpha inhibitor \\
\hline & Infliximab & TNF alpha inhibitor \\
\hline & Rituximab & $\begin{array}{l}\text { Chimeric monoclonal antibody against } \\
C D 20 \text { on B-cells }\end{array}$ \\
\hline & Tocilizumab & IL-6 receptor inhibitor \\
\hline
\end{tabular}

Abbreviations: DMARD: Disease modifying anti rheumatic drug, TNF: tumour necrosis factor, IL: Interleukin 
In general, the same treatment strategies are recommended for seropositive and seronegative RA patients. However, it has been suggested that seronegative patients should be treated less aggressively than seropositive patients, which is also reflected in the EULAR treatment recommendations by earlier start of biologic DMARD in the presence of RF or ACPA (14, 141). Knowledge is limited regarding response to therapy in seronegative compared to seropositive patients. In a study of early RA patients receiving DAS-steered DMARD treatment, response and remission rates were similar in ACPA negative and ACPA positive early RA patients, but with more radiographic progression in ACPA positive patients (12). Seropositivity has been associated with a better response to methotrexate (142), abatacept (143) and rituximab (144), while similar response in seronegative and seropositive patients was shown in a study of patients receiving tocilizumab (145).

\subsubsection{Treatment with glucocorticoids}

Glucocorticoids have potent anti-inflammatory effects and have been central in the treatment of inflammatory arthritis for decades.

Systemic treatment with glucocorticoids in addition to treatment with DMARDs has been shown to relieve clinical signs and symptoms and inhibit radiographic progression of RA $(146,147)$. According to the EULAR treatment recommendations, short-term glucocorticoids should be used when initiating or changing conventional DMARDs, but should be tapered as rapidly as clinically feasible (preferably within three months) to avoid potential adverse effects (14). The most important adverse effects include osteoporosis, diabetes mellitus, cardiovascular diseases, infections, weight gain, and myopathy (148). Systemic glucocorticoids can be administered orally, intramuscularly or intravenously, but there is no consensus on the optimal route of administration or dose regimen (14).

Intra-articular glucocorticoid injections are often part of RA treatment, but the use varies considerably between countries. In Norway, glucocorticoid injections constitute a central part of RA treatment and they are performed regularly (149). Studies have indicated that the addition of intra-articular glucocorticoid injections results in better clinical outcomes (150154). Two studies have shown that intra-articular glucocorticoid injections in combination with methotrexate in treat-to-target strategies of early RA result in high remission rates. However, there were no control groups without injections in these studies $(150,155)$. 
Studies have shown that inflammatory activity assessed by ultrasound decreased after intraarticular glucocorticoid injections $(156,157)$, while another study found no ultrasound or MRI imaging improvements after injections (158). Intra-articular glucocorticoid injections have been associated with few side effects and have also been shown to protect against periarticular bone loss in RA $(159,160)$. Local treatment is considered to have fewer adverse effects than systemic glucocorticoid treatment, although there is a small risk of local adverse effects, e.g. skin hypopigmentation, subcutaneous atrophy, tendon rupture, osteonecrosis and infection (161).

Ultrasound is increasingly applied in RA management, and the use of ultrasound to guide intra-articular injections is standard practice in several countries. Ultrasound guidance is performed indirectly by skin surface marking or under direct sonographic needle guidance (162) (figure 2).
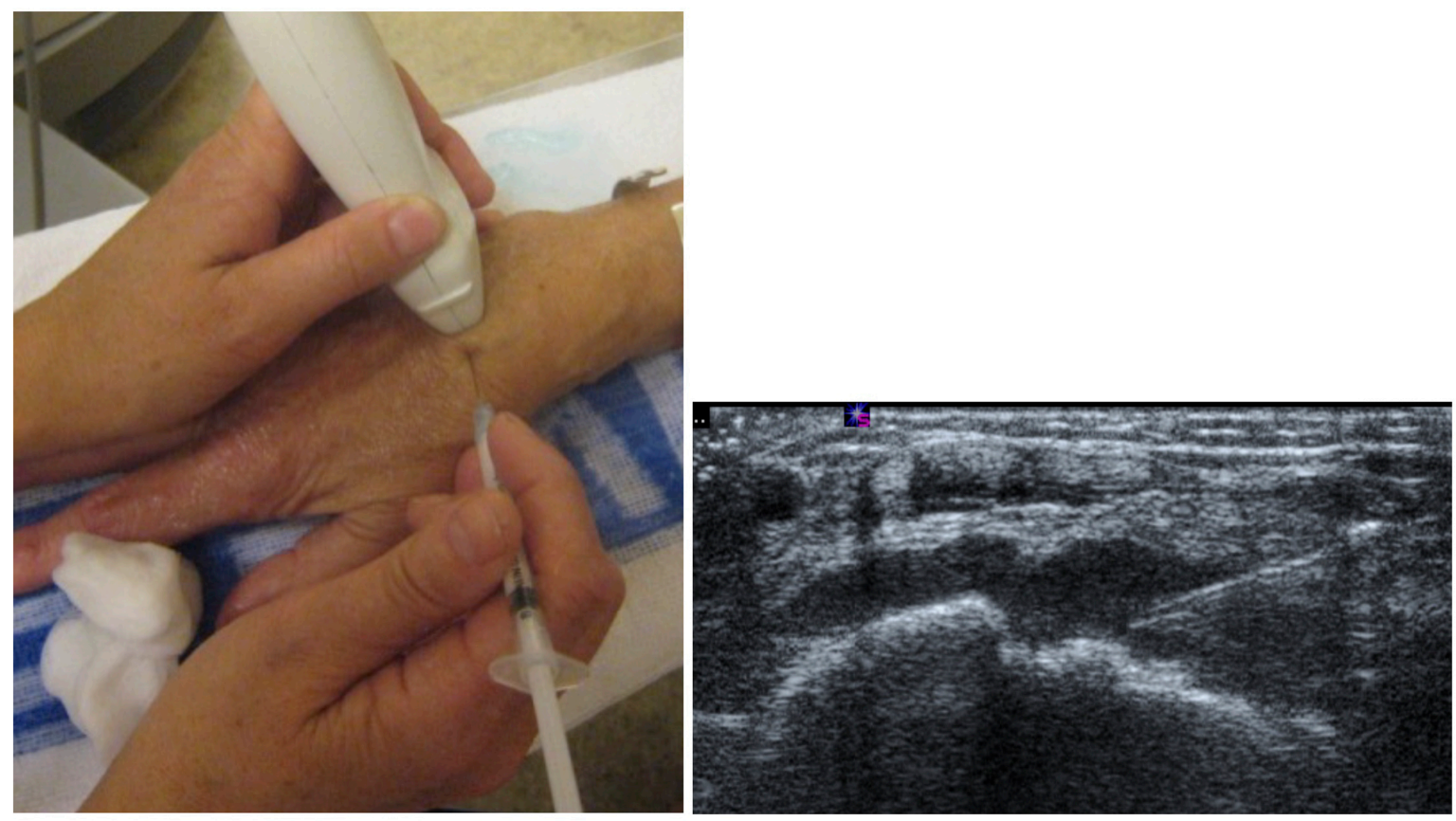

Figure 2. Ultrasound guided injection in intercarpal joint. Images courtesy of Dr. Hilde Berner Hammer. 
Several studies, clinical and cadaveric, have demonstrated better accuracy with ultrasoundguided compared to palpation-guided injection procedures (163-165). Studies are limited and results are conflicting when it comes to whether use of ultrasound guidance improves clinical outcomes $(163,165)$. One study has shown that sonographic needle guidance improves clinical outcomes of intra-articular injections for inflammatory arthritis (166). Another study has shown greater improvement in pain and shoulder function with ultrasound-guided compared to palpation-guided injections for painful shoulder (167). However, a Cochrane review was unable to show any advantage in terms of clinical outcomes in patients who received ultrasound-guided glucocorticoid injection for shoulder disorders, compared to landmark-guided or intramuscular injections (168).

Ultrasound can also be used as a tool to decide whether to inject a joint or not (169). There is a discrepancy between clinical and ultrasound assessment of synovitis at the joint level (170), but knowledge is limited about how this affects selection of, and ultimately the effect of injections in RA joints. 


\section{General aim and research questions}

\subsection{General aim}

The general aim of this thesis was to examine aspects of modern RA treatment and consequences of new classification criteria for RA, focusing on the efficacy of intraarticular glucocorticoid injections, the value of ultrasound and the presentation, and disease course of RA patients classified according to the 2010 ACR/EULAR criteria.

\subsection{Research questions}

- Does ultrasound power Doppler activity predict clinical joint swelling? (Paper I)

- Is the combination of ultrasound and clinical examination better at identifying joints that will benefit from intra-articular injections compared to identification by clinical examination alone? (Paper I)

- Do ultrasound-guided and palpation-guided injection procedures differ in efficacy? (Paper I)

- How is the clinical presentation of seronegative and seropositive RA when patients are classified according to the 2010 ACR/EULAR criteria? (Paper II)

- Is there any difference in disease severity between seronegative and seropositive RA patients classified according to the 2010 ACR/EULAR criteria after two years of treat-to-target DMARD therapy? (Paper III)

- How do seronegative RA patients classified according to the 2010 ACR/EULAR criteria respond to modern treatment compared to seropositive patients? (Paper III) 


\section{Material and methods}

\subsection{Study design}

Data from the ARCTIC (Aiming for Remission in rheumatoid arthritis: a randomised trial examining the benefit of ultrasound in a Clinical TIght Control regimen) study was used for analyses of all papers in this thesis. The study is registered in the ClinicalTrials.gov database (NCT01205854).

In the ARCTIC study early RA patients were randomised 1:1 to follow-up with or without ultrasound. The trial was designed to assess whether the additional use of ultrasound information to guide treatment decisions and targeting therapy towards imaging remission would lead to improved outcomes compared to conventional tight control treatment. Patients were assessed at $0,1,2,3,4,6,8,10,12,14,16,20$ and 24 months. The primary outcome was a composite of sustained clinical remission, absence of swollen joints and inhibition of joint damage. The main results from the ARCTIC trial showed similar outcomes in the two arms, concluding that an ultrasound tight control strategy was not superior to a conventional tight control strategy (108). In many of the analyses in the current thesis, data from the two strategy arms are pooled and analysed together, as clinical and radiographic outcomes were similar in the two arms after two years. In this thesis the ARCTIC data are mainly used as an inception cohort of DMARD-naïve RA patients receiving treat-to-target tight control therapy during two years of follow-up.

\subsection{Study population}

Early RA patients were recruited from 11 rheumatology centres in Norway between 2010 and 2013. All patients fulfilled the 2010 ACR/EULAR classification criteria for RA and 
were DMARD naïve with indication for DMARD treatment (full inclusion/exclusion criteria in table 5). All patients provided written informed consent.

Table 5 Inclusion and exclusion criteria in the ARCTIC trial

\begin{tabular}{|c|c|}
\hline Inclusion criteria & Exclusion criteria \\
\hline Male or non-pregnant, non-nursing female & Abnormal renal function \\
\hline$>18$ years and $<75$ years of age & Abnormal liver function \\
\hline $\begin{array}{l}\text { Patients classified as having RA according to } \\
2010 \text { ACR/EULAR criteria }\end{array}$ & $\begin{array}{l}\text { Major co-morbidities as outlined in the } \\
\text { protocol }\end{array}$ \\
\hline $\begin{array}{l}\text { Disease duration less than } 2 \text { years (defined as } \\
\text { time from } 1^{\text {st }} \text { patient reported joint swelling) }\end{array}$ & Leukopenia and/or thrombocytopenia \\
\hline $\begin{array}{l}\text { Indication for DMARD-treatment, as decided } \\
\text { by the treating rheumatologist }\end{array}$ & $\begin{array}{l}\text { Inadequate birth control conception, } \\
\text { pregnancy, and/or breastfeeding }\end{array}$ \\
\hline The patient has taken no prior DMARD & Indications of active tuberculosis \\
\hline $\begin{array}{l}\text { Patients able and willing to give written } \\
\text { informed consent and comply with the } \\
\text { requirements of the study protocol }\end{array}$ & $\begin{array}{l}\text { Psychiatric or mental disorders, alcohol } \\
\text { abuse, other substance abuse, language } \\
\text { barriers, other factors making adherence to } \\
\text { the study protocol impossible }\end{array}$ \\
\hline
\end{tabular}

Abbreviations: ACR: American College of Rheumatology, DMARD: disease modifying antirheumatic drug, EULAR: European League Against Rheumatism, RA: rheumatoid arthritis

\subsection{Treatment protocol}

All patients were treated according to the same DMARD escalation algorithm (table 6). The decision to adjust medication was based on level and change in DAS (table 7). In the ultrasound arm the physician should overrule the DAS based decision and proceed to the next treatment regimen if indicated by the ultrasound score. In both arms, clinically swollen joints were treated with intra-articular glucocorticoids (triamcinolone hexacetonide). In the 
ultrasound strategy arm, joints with power Doppler activity should be injected as well, and the injections were performed with ultrasound needle guidance. In the conventional strategy arm, injections were palpation-guided. All intra-articular injections were performed by experienced rheumatologists. In both arms, injections in tender joints (without swelling or power Doppler activity) were not allowed. Injections could be performed at all visits and maximum dosage triamcinolone hexacetonide per visit was $80 \mathrm{mg}$, distributed across joints as decided by the treating rheumatologist. 
Table 6 Treatment protocol in the ARCTIC trial

\begin{tabular}{|c|c|}
\hline $\begin{array}{c}\text { Visit } \\
\text { (months) }\end{array}$ & Treatment if no response (if response continue treatment at present step, see table 7) \\
\hline $1(0)$ & $\begin{array}{l}\text { A. Monotherapy* }+ \text { prednisolone: } \\
\text { 1. Methotrexate } 15 \mathrm{mg} / \text { week, increase by } 2.5 \mathrm{mg} \text { every } 2^{\text {nd }} \text { week to target dose } 20 \mathrm{mg} / \text { week, i.e. week } \\
1+215 \mathrm{mg} \text {, week } 3+417.5 \mathrm{mg} \text {, week } 5-820 \mathrm{mg} \\
\text { 2. Concomitant folic acid } 5 \mathrm{mg} / \text { week }(1 \mathrm{mg} 5 / 7 \text { days or } 5 \mathrm{mg} \mathrm{x} 1 / \text { week) } \\
\text { 3. Prednisolone } 15 \mathrm{mg} \text { week } 1,10 \mathrm{mg} \text { week } 2,7.5 \mathrm{mg} \text { week } 3,5 \mathrm{mg} \text { week } 4+5,2.5 \mathrm{mg} \text { week } 6+7 \\
\text { 4. Calcium supplement } 1000 \mathrm{mg} \text { x } 1 \text { (while on prednisolone) }\end{array}$ \\
\hline $2(1)$ & $\begin{array}{l}\text { A. Monitor start-up regimen (no changes in medication allowed unless due to } \mathbf{A E} \text { )* } \\
\text { Joint injections allowed as indicated according to treatment arm }\end{array}$ \\
\hline $3(2)$ & $\begin{array}{l}\text { A. Optimise monotherapy* } \\
\text { Increase methotrexate to } 25-30 \mathrm{mg} / \mathrm{week} \\
\text { Or increase sulphasalazine/hydroxychloroquine/leflunomide dose }\end{array}$ \\
\hline $4(3)$ & $\begin{array}{l}\text { A. Monitor start-up regimen (no changes in medication allowed unless due to } \mathbf{A E})^{*} \\
\text { Joint injections allowed as indicated according to treatment arm. }\end{array}$ \\
\hline $5(4)$ & $\begin{array}{l}\text { B. Triple combination therapy (or other combination therapy if methotrexate not tolerated): } \dagger \\
\text { 1. Add sulphasalazine, step up over } 4 \text { weeks to } 500 \mathrm{mg} 2 \times 2 \text { and } \\
\text { 2. Add hydroxychloroquine } 200 \mathrm{mg} 1 \times 2\end{array}$ \\
\hline $6(6)$ & $\begin{array}{l}\text { B. Optimise triple combination therapy: } \uparrow \\
\text { Add prednisolone } 7.5 \mathrm{mg} 1 \times 1\end{array}$ \\
\hline $7(8)$ & $\begin{array}{l}\text { C. DMARD } \$ \text { and } \mathbf{1}^{\text {st }} \text { biologic: } \\
\text { 1. Highest tolerable dose methotrexate and } \\
\text { 2. Add } 1^{\text {st }} \text { biologic (according to current Norwegian recommendations) } \\
* \text { Or sulphasalazine/hydroxychloroquine/leflunomide if methotrexate not tolerated }\end{array}$ \\
\hline $8(10)$ & $\begin{array}{l}\text { C. DMARD and } 1^{\text {st }} \text { biologic: } \\
\text { Adjust dose/interval of } 1^{\text {st }} \text { biologic }\end{array}$ \\
\hline $9(12)$ & $\begin{array}{l}\text { D. DMARD }+ \text { and } 2^{\text {nd }} \text { biologic: } \\
\text { Switch to } 2^{\text {nd }} \text { biologic (according to current Norwegian recommendations) }\end{array}$ \\
\hline $10(14)$ & $\begin{array}{l}\text { D. DMARD } \$ \text { and } 2^{\text {nd }} \text { biologic: } \\
\text { Adjust dose/interval of } 2^{\text {nd }} \text { biologic }\end{array}$ \\
\hline $11(16)$ & $\begin{array}{l}\text { E. DMARD } 4 \text { and } 3^{\text {rd }} \text { biologic: } \\
\text { Switch to } 3^{\text {rd }} \text { biologic (according to current Norwegian recommendations) }\end{array}$ \\
\hline $12(20)$ & $\begin{array}{l}\text { E. Optimise DMARD and } 3^{\text {rd }} \text { biologic plus prednisolone: } \\
\text { Adjust dose/interval of } 3^{\text {rd }} \text { biologic and/or add prednisolone } 7.5 \mathrm{mg}\end{array}$ \\
\hline $13(24)$ & F. Continue medication according to standard clinical care \\
\hline
\end{tabular}

* If methotrexate is not tolerated, switch to subcutaneous methotrexate, then continue according to scheme. In case of adverse event (AE) or not tolerated even in low dose subcutaneous, switch to sulphasalazine or hydroxychloroquine monotherapy (standard dosage) if low disease activity, or leflunomide $20 \mathrm{mg}$ in case of moderate or high disease activity (loading dose 40mg x 1 for 3 days, then $20 \mathrm{mg}$ per day).

$\dagger$ In patients with high disease activity and risk factors for progressive joint destruction (ACPA or RF-positive and either erosions on CR or baseline RAMRIS bone marrow oedema score $>2$ ) a rescue option is available which includes moving to the next step, i.e. introduce $1^{\text {st }}$ biologic (treatment $\mathrm{C}$ at visit $\#$, without prescribing treatment $\mathrm{B}$ ).

\# In case of no tolerance for any synthetic DMARD, this can be omitted if the biologic DMARD chosen has indication for monotherapy (e.g. tocilizumab).

$\int$ Requirement for adding biologic: There must be objective signs of ongoing inflammation, i.e. either elevated $\mathrm{ESR} / \mathrm{CRP}$ ( $>\mathrm{UNL}$, and not due to other disease/infection) or $\mathrm{SJC} \geq 1$ (or PD score $>1$ in US arm). 
Table 7 ARCTIC decision rules*

\begin{tabular}{|lllll|}
\hline & $\begin{array}{l}\text { Current } \\
\text { DAS }\end{array}$ & No response $\dagger$ & Response $\dagger$ & $\begin{array}{l}\text { Reached target } \\
\text { (DAS }<1.6)\end{array}$ \\
\hline $\begin{array}{l}\text { Conventional } \\
\text { tight control }\end{array}$ & $\leq 2.4$ & Change in DAS $<0.6$ & Change in DAS $\geq 0.6$ & $\begin{array}{l}\text { DAS }<1.6 \text { and no swollen } \\
\text { joints }\end{array}$ \\
\cline { 2 - 5 } & $>2.4$ & Change in DAS $<1.2$ & Change in DAS $\geq 1.2$ & \\
\hline $\begin{array}{l}\text { Ultrasound } \\
\text { tight control }\end{array}$ & $\leq 2.4$ & $\begin{array}{l}\text { Change in DAS }<0.6 \text { or } \\
<10 \% \text { decrease in US } \\
\text { total score }\end{array}$ & $\begin{array}{l}\text { Change in DAS } \geq 0.6 \\
\text { and }>10 \% \text { decrease in } \\
\text { US total score }\end{array}$ & $\begin{array}{l}\text { DAS }<1.6 \text { and no swollen } \\
\text { joints and no joints with } \\
\text { power Doppler synovitis }\end{array}$ \\
\cline { 2 - 5 } & $>2.4$ & $\begin{array}{l}\text { Change in DAS }<1.2 \text { or } \\
<20 \% \text { decrease in US } \\
\text { total score }\end{array}$ & $\begin{array}{l}\text { Change in DAS } \geq 1.2 \\
\text { and } \geq 20 \% \text { decrease in } \\
\text { US total score }\end{array}$ & \\
\hline Action & Change therapy & $\begin{array}{l}\text { Continue current } \\
\text { medication }\end{array}$ & $\begin{array}{l}\text { Continue current } \\
\text { medication }\end{array}$ \\
\hline
\end{tabular}

* To be applied at all visits except visit 2 (1 month) and visit 4 (3 months), as two months between treatment adjustments was considered appropriate.

$\dagger$ Irrespective of response clinically swollen joints should be injected when indicated, up to the maximum allowed dosage per visit ( $80 \mathrm{mg}$ triamcinolone hexacetonide). In the ultrasound tight control group joints with PD-signal on ultrasound is an additional target.

\subsection{Data collection}

\subsubsection{Demographic variables}

The data collection in the ARCTIC trial included demographic variables such as age, gender, co-morbidities, weight, height, smoking status, education and work status. The basic demographic variables gender and age were included in all papers of this thesis.

\subsubsection{Serology}

Sera were collected in a biobank, and RF and ACPA were analysed at the same laboratory by enzyme-linked immunosorbent assay (ELISA) and fluorescence enzyme immunoassay (FEIA), respectively. A positive test was defined as any value $\geq 10 \mathrm{IU} / \mathrm{ml}$ for ACPA and $\geq 25$ $\mathrm{IU} / \mathrm{ml}$ for RF. 


\subsubsection{Outcome measures}

A number of outcome measures were recorded at baseline and during follow-up. The outcome measures utilised in the papers of this thesis are shown in table 8 .

Table 8 Outcome measures included in paper I-III

\begin{tabular}{|l|c|c|c|}
\hline Outcome measures & Paper I & Paper II & Paper III \\
\hline 44 swollen joint count & $\mathrm{x}$ & $\mathrm{x}$ & $\mathrm{x}$ \\
\hline Ritchie articular index & $\mathrm{x}$ & $\mathrm{x}$ & $\mathrm{x}$ \\
\hline ESR and CRP & $\mathrm{x}$ & $\mathrm{x}$ & $\mathrm{x}$ \\
\hline Physician's global assessment of disease activity $^{*}$ & $\mathrm{x}$ & $\mathrm{x}$ & $\mathrm{x}$ \\
\hline Patient's global assessment of disease activity $^{*}$ & $\mathrm{x}$ & $\mathrm{x}$ & $\mathrm{x}$ \\
\hline Patient pain assessment $^{*}$ & & $\mathrm{x}$ & $\mathrm{x}$ \\
\hline Patient fatigue assessment $^{*}$ & & $\mathrm{x}$ & $\mathrm{x}$ \\
\hline PROMIS physical function & $\mathrm{x}$ & $\mathrm{x}$ & $\mathrm{x}$ \\
\hline SF-36 & & $\mathrm{x}$ & $\mathrm{x}$ \\
\hline EQ-5D & $\mathrm{x}$ & $\mathrm{x}$ & $\mathrm{x}$ \\
\hline RAID score & & $\mathrm{x}$ & \\
\hline Composite outcome measures & & & \\
\hline DAS & $\mathrm{x}$ & $\mathrm{x}$ & $\mathrm{x}$ \\
\hline ACR/EULAR Boolean remission & & & $\mathrm{x}$ \\
\hline EULAR response & & & $\mathrm{x}$ \\
\hline ACR response & & & $\mathrm{x}$ \\
\hline Imaging & $\mathrm{x}$ & $\mathrm{x}$ & $\mathrm{x}$ \\
\hline Ultrasound & & $\mathrm{x}$ \\
\hline Conventional radiographs of hands and feet & & \\
\hline Abrevios & & & \\
\hline
\end{tabular}

Abbreviations: ESR: Erythrocyte Sedimentation Rate, CRP: C-Reactive Protein, PROMIS:

Patient-Reported Outcomes Measurements information, SF-36: Short Form 36, EQ-5D: EuroQol-5

Dimensions, RAID: Rheumatoid Arthritis Impact of Disease, DAS: Disease Activity Score, ACR:

American College of Rheumatology, EULAR: European League Against Rheumatism, VAS:

Visual analogue scale.

*Scored on a 0-100 mm VAS scale 


\subsubsection{Ultrasound}

An extensive ultrasound examination was performed. The joints and tendons examined were: Metacarpophalangeal (MCP) 1-5, proximal interphalangeal (PIP) 2-3, radiocarpal, intercarpal, distal radio-ulnar, elbow, knee, talocrural, metatarsophalangeal (MTP) 1-5, extensor carpi ulnaris tendon and tibialis posterior tendon bilaterally (figure 3). Ultrasound examinations were performed according to a validated $0-3$ semi-quantitative scoring system for both grey scale ultrasound and power Doppler that has shown good inter- and intraobserver reliability (95) (figure 4).

In paper II, which was written prior to publication of the main results from the ARCTIC trial, we included in the ultrasound total scores all the 36 joints and 4 tendons examined. In paper I and III, we decided to use the same total score of 32 joints as in the main ARCTIC publication (bilateral PIP2-3 and tendons were not included). However, all 36 joints were included in analyses at the joint level in paper I.

All sonographers underwent systematic training. Siemens Antares or GE Logiq E9 machines with linear probes were used, and power Doppler and a number of other parameters were standardised and adjusted according to the device used (171).

In the ultrasound strategy arm, patients underwent ultrasound examination at all visits. Patients in the conventional arm were examined by ultrasound at baseline, 12 and 24 months, and both patient and the treating physician were blinded for results. All patients were assessed for clinical joint swelling at all visits, with clinical joint examination performed prior to any ultrasound examination. 


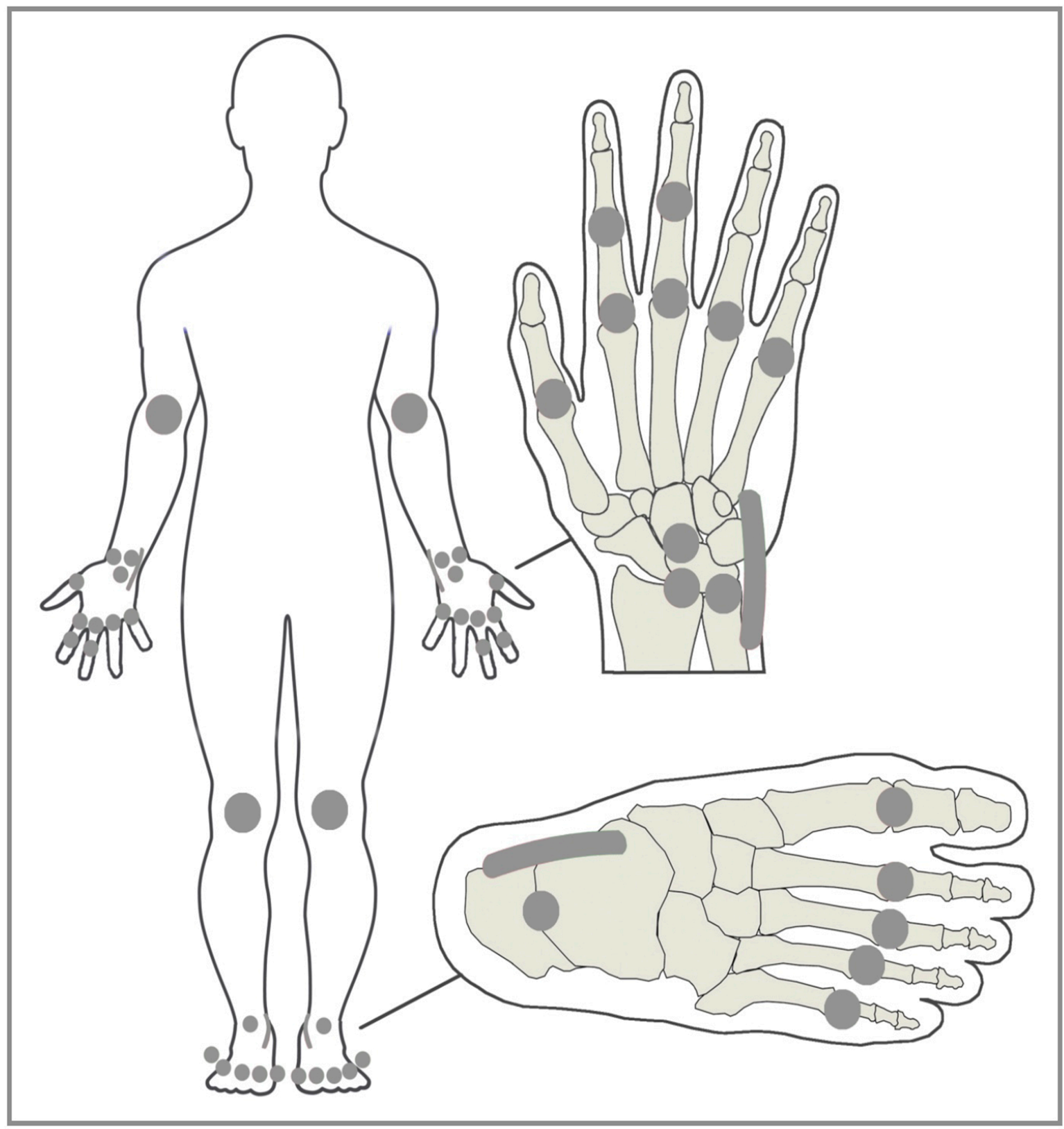

36 joints and 4 tendons examined by ultrasound: Metacarpophalangeal (MCP) 1-5, proximal interphalangeal (PIP) 2-3, radiocarpal, intercarpal, distal radioulnar, elbow, knee, talocrural, metatarsophalangeal (MTP) 1-5, extensor carpi ulnaris (ECU) tendon and tibialis posterior (TP) tendon bilaterally. Image courtesy of Dr. Anna-Birgitte Aga. 
Figure 4: Excerpt from the reference atlas used in the ARCTIC study

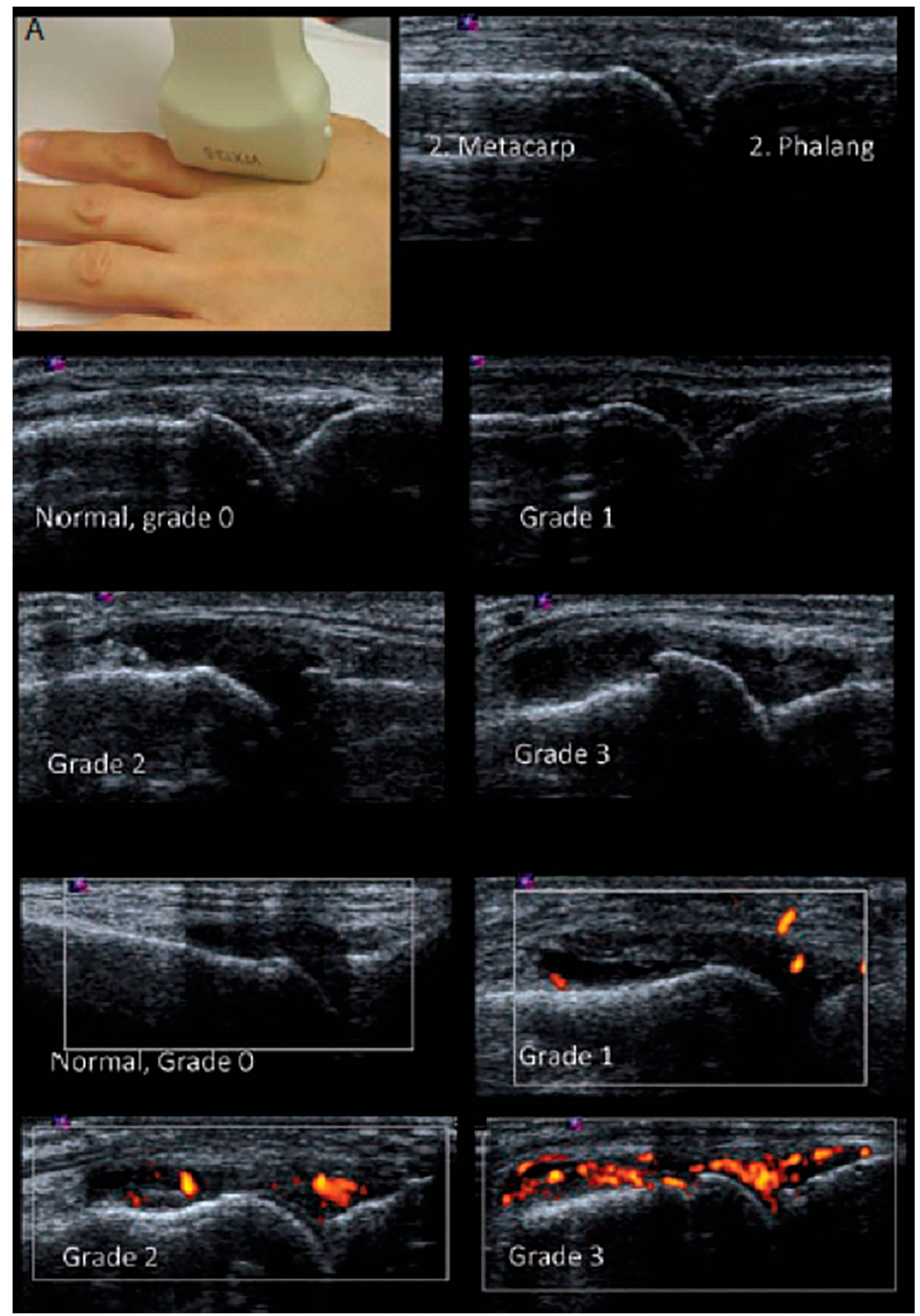

MCP2 joint, probe position and grade 0-3 for Grey scale and power Doppler ultrasound (95). Image courtesy of Dr. Hilde Berner Hammer. 


\subsubsection{Conventional radiographs}

Radiographs of hands, wrists, and feet were performed at $0,3,6,12,16$, and 24 months. Radiographs were scored chronologically and according to vdHSS, by two independent readers blinded for patient identity and clinical information. The average of the two readings were used in all analyses.

\subsection{Statistics}

All statistical analyses in paper I-III were performed by LBN in collaboration with a statistician, using Stata v14 (StataCorp. 2015. Stata Statistical Software: Release 14. College Station, TX, USA). Statistical tests were two-sided and p-values less than 0.05 were considered statistically significant.

\subsubsection{Descriptive statistics}

In all papers continuous variables are presented as means (SD) or medians (25th, 75 th percentiles) according to distribution, and dichotomous variables are presented as frequencies and percentages. Disease characteristics were compared between subgroups using independent samples t-test, Mann-Whitney $U$ test or chi-squared test as appropriate.

\subsubsection{Multivariate analyses}

A mixed effects model is a statistical model containing both fixed and random effects. This model is useful in settings with repeated measurements. In longitudinal analysis at the joint level in paper I, we used a logistic mixed-effects model with random intercepts for patient and joint in order to account for within-patient and within-joint dependencies. We adjusted for age, gender, ACPA status and strategy arm (follow-up with or without ultrasound) in the models. We also adjusted for whether the patient was assessed at the baseline visit or at subsequent visits, since patients started bridging therapy with $15 \mathrm{mg}$ prednisolone at 
baseline. In order to compare the efficacy of intra-articular injections performed by ultrasound versus palpation guidance we added the interaction between injection (yes/no) and strategy arm (ultrasound/conventional). We then used marginal means to describe the difference in treatment success between ultrasound-guided and palpation-guided injections.

In paper III, we used linear mixed-effects models when we compared disease measures over time between subgroups in order to account for within-patient dependencies. We used robust variance estimates for ultrasound scores and radiographic progression due to skewed distributions.

In paper I we used logistic regression to compare the proportions of patients with any injection between groups, adjusting for gender due to gender imbalance between the groups. In paper III, we assessed treatment response using logistic regression models with EULAR good/moderate response at 3 and 6 months as dependent variables and serology status (seronegative/seropositive), baseline SJC44, baseline DAS, baseline Ritchie articular index, sex and age as independent variables. We performed the same analyses with ACR50 response at 3 and 6 months as dependent variables.

\subsubsection{Cumulative probability plot}

A cumulative probability plot depicts data from each individual patient ranked from lowest to highest observed score within each subgroup. In paper II we used cumulative probability plots in order to illustrate the number of swollen joints and ultrasound scores in patients with low and high levels of RF and ACPA. In paper III we used a cumulative probability plot of radiographic change between baseline and 24 months to illustrate the differences between seronegative and seropositive patients.

\subsubsection{Missing data}

Overall, missing data were less than $10 \%$ in the ARCTIC trial. In paper I, the main analyses were at the joint level. Patients with missing data at the selected point of assessment were not included in the analyses. In paper II, only baseline data were analysed. For all variables, less than $5 \%$ of data were missing, thus no imputation of data was done. In paper III, we used a conservative approach for missing data. If categorical values were missing at 24 months, they were imputed with worst outcome. If values were missing before the last visit, 
we imputed them with the last known value. Missing values for continuous variables were replaced by multiple imputation, with 10 imputations drawn from the observed distribution, using the Markov chain Monte Carlo method (172).

\subsection{Legal and ethical aspects}

The ARCTIC trial was conducted according the principles of the Declaration of Helsinki (173). All patients provided written, informed consent before inclusion. The study protocol and consent documents were approved by the Regional Committee for Medical and Health Research Ethics South East (reference number 2010/744) and appropriate institutional review boards at participating centres.

The trial followed the principles in "Guidelines for Good Clinical Practice" (GCP) developed by the International Conference on Harmonisation (174). GCP is an international ethical and scientific quality standard for the performance of a clinical trial on medicinal products involving humans.

The trial was monitored by the Section for GCP, Oslo University Hospital and Innovest AS. Their mission was to ensure that the trial was conducted, recorded, and reported in accordance with the protocol, Standard Operating Procedures (SOPs), GCP, and the applicable regulatory requirements. 


\section{Summary of results}

\subsection{Paper I}

The impact of ultrasound on the use and efficacy of intra-articular glucocorticoid injections in early rheumatoid arthritis: Secondary analyses from a randomized trial examining the benefit of ultrasound in a clinical tight control regimen

Intra-articular glucocorticoid injections are common in RA treatment. The objective of this paper was to investigate whether ultrasound in combination with clinical examination is better at identifying joints that will benefit from intra-articular injections compared to identification by clinical examination alone, as well as to assess the efficacy of ultrasoundguided versus palpation-guided injections.

In the ARCTIC trial, early RA patients were randomised 1:1 to follow-up with or without ultrasound. In addition to DMARD treatment, inflamed joints were treated with intraarticular glucocorticoids. Distribution of injections was assessed in both arms. We examined how clinical and ultrasound findings at the time of injection were related to treatment efficacy, with non-swollen joint at next visit as outcome measure. Treatment success was compared across arms to test ultrasound-guided versus palpation-guided procedure.

More injections were observed in the ultrasound arm than in the conventional arm $(n=770$ vs. 548), especially in intercarpal ( $n=58$ vs. $n=5)$ and MTP joints ( $n=200$ vs. $n=104)$. Injecting clinically swollen joints without ultrasound power Doppler activity was not found efficacious compared to not injecting (OR 1.3, $\mathrm{p}=0.59$ ). The observed efficacy was best in swollen (OR 9.0, $\mathrm{p}=0.001)$ and non-swollen (OR 8.4, $\mathrm{p}=0.016)$ joints with moderate power Doppler activity. Treatment success was similar with ultrasound-guided and palpationguided procedure.

Our study indicates that the efficacy of intra-articular injections varies according to ultrasound findings at the time of injection, supporting the use of ultrasound as a tool for selecting joints that will benefit from intra-articular injections. However, ultrasound needleguidance was not superior to palpation-guidance. 


\subsection{Paper II}

\section{Patients with seronegative RA have more inflammatory activity compared with patients with seropositive $R A$ in an inception cohort of DMARD-naïve patients classified according to the 2010 ACR/EULAR criteria}

Implementation of 2010 classification criteria for RA has redefined the patient population, including classification of seronegative versus seropositive RA. The objective of this paper was to compare the presentation of seropositive and seronegative early RA patients classified according to the new criteria.

All patients had symptom duration from first swollen joint $<2$ years, and were DMARD naïve with indication for DMARD treatment. Patients were stratified as seropositive (RF+ and/or ACPA+) or seronegative (RF- and ACPA-), and disease characteristics were compared between groups.

A total of 234 patients were included, and 36 (15.4\%) were seronegative. Ultrasonography scores for joints (median 55 vs. 25, p<0.001) and tendons (median 3 vs. $0, p<0.001$ ), number of swollen joints (median 17 vs. 8, p<0.001), disease activity score (DAS; mean 3.9 vs. 3.4, $\mathrm{p}=0.03$ ) and physician global assessment (mean 49.1 vs. 38.9, $\mathrm{p}=0.006$ ) were significantly higher in seronegative patients compared to seropositive. Total vdHSS, Richie articular index and patient reported outcome measures were similar between groups.

Seronegative patients had higher levels of inflammation, assessed both clinically and by ultrasonography, than seropositive patients. These differences may reflect the high number of involved joints required for seronegative patients to fulfill the 2010 ACR/EULAR classification criteria for RA. 


\subsection{Paper III}

\section{Comparing the disease course of patients with seronegative and seropositive}

rheumatoid arthritis fulfilling the 2010 ACR/EULAR classification criteria in a treatto-target setting: 2-year data from the ARCTIC trial

In paper II, we found seronegative patients to have markedly higher inflammatory activity at time of diagnosis, compared to seropositive patients, possibly due to increased weighting of ACPA and RF in the classification criteria. The purpose of paper III was to assess the disease course over 2 years in these patients fulfilling the 2010 ACR/EULAR classification criteria. We compared disease activity, radiographic progression, treatment response and remission rates in seronegative and seropositive patients.

A total of 230 patients were included, mean (SD) age was 51.4 (13.7) years and $61.3 \%$ were female; 34 patients (14.8\%) were seronegative. At 24 months of follow-up, measures of disease activity, radiographic progression and remission rates were similar between groups. Treatment response was slower in seronegative patients and there was a tendency towards more radiographic damage in seronegative compared to seropositive patients. Treatment was similar between groups.

Our findings suggest that in RA patients classified according to the 2010 ACR/EULAR criteria, seronegative RA patients respond well to modern treatment strategies, however seronegative RA is not a mild form of the disease and requires intensive treat-to-target therapy similar to treatment of seropositive RA. 


\section{Discussion}

\subsection{Methodological aspects}

In the following sections, methodological limitations, strengths and possible sources of bias in the papers will be discussed.

\subsubsection{Study design}

The ARCTIC trial was designed as a randomised controlled trial, aiming to determine whether a treatment strategy based on ultrasound assessment would lead to improved outcomes in RA. In the papers of the current thesis, secondary analyses of the study were performed, and the ARCTIC study was mainly used as an inception cohort of early RA patients receiving modern treat to target therapy. A challenge in observational designs is to minimise confounding factors, as it is impossible to identify, measure and control for all possible confounding factors. Primarily association, and not causation, should be inferred from the results of an observational study (175).

\subsubsection{Representativeness of the study population}

The ARCTIC trial was a multi-centre study, recruiting patients from the majority of rheumatology clinics in Norway, aiming to include the vast majority of newly diagnosed patients with RA at the participating centres. The broad inclusion strengthens the external validity of our results. Strict inclusion and exclusion criteria, as usually applied in pharmaceutical RCTs, may lead to a study population that differs from a real-life patient population. The treatment protocol in the ARCTIC trial was very similar to the updated EULAR treatment recommendations for RA, increasing the generalisability of our results (14).

The ARCTIC trial is one of the first studies including patients based on the 2010 ACR/EULAR classification criteria for RA. This is a strength, as it makes our patient population representative for the modern definition of an early RA population. Comparisons 
of our results with previous studies based on the ACR 1987 criteria are interesting, but can be difficult to interpret. Compared to the 1987 criteria, it has been proposed that implementation of the new criteria result in an increased prevalence of classifiable RA, with a milder disease course (176). Most baseline patient characteristics in ARCTIC are in line with earlier inception cohorts of RA $(177,178)$, with the exception of a lower proportion of seronegative patients. The limited number of seronegative patients included in the ARCTIC trial, limits the statistical power in paper II and III.

\subsubsection{Data collection}

Strengths of our study include the extensive data collection with radiographic and ultrasonographic examinations of all patients. Data were collected at 11 rheumatology centres in Norway. A challenge of this approach is the use of different assessors and laboratories, and possible local preferences regarding choice of treatment (e.g. different practice regarding the use of intra-articular injections). However, the study nurses, rheumatologists and ultrasonographers were all experienced, and they were specifically trained prior to and during the study and instructed to use the pre-defined treatment algorithm. National investigator meetings were held regularly and study personnel from all the participating centres attended.

RF and ACPA were analysed centrally using the same methodology at the same laboratory (ELISA and fluorescence enzyme immunoassay, respectively). CRP and ESR were analysed locally at the time of assessment, and different laboratories may have yielded slightly differing results.

\subsubsection{Outcome measures}

DAS was the main composite outcome measure in the ARCTIC trial, whereas many other studies use DAS28. For easier comparisons of our results with other studies, it would have been an advantage if the 28 tender joint count had been registered in the ARCTIC trial, allowing us to calculate DAS28 without estimation of 28 tender joints based on the Ritchie articular index. This would have been useful for comparisons with other studies of disease activity levels in seronegative and seropositive patients (paper II and III). 
Our main outcome measure in paper I was joint swelling at the next visit. Another relevant outcome measure would have been joint pain. However, joint tenderness was assessed with Ritchie articular index in which some joints are assessed at the same time as a single unit (such as the MCP and PIP joints of each hand and the MTP joints of each foot) (68). The grouping of joints in the Ritchie articular index made it difficult to use joint tenderness as an outcome measure, as our analyses were at the single joint level. Another limitation of our main outcome measure is that joint swelling was assessed at the next visit (most often 4 or 8 weeks after the injection). Thus, we cannot exclude that the treatment effect in injected joints was faster than in joints only receiving systemic treatment. Previous studies have shown response of intra-articular glucocorticoids within two weeks $(150,156,179)$.

No consensus exists on the optimal ultrasound scoring system in RA, especially with respect to the optimal number of joints to assess. The EULAR-OMERACT combined score was proposed after the finalisation of the ARCTIC trial. This method is different than the one used in ARCTIC $(99,100)$, which could make our results more difficult to compare to future studies. However, the method we used has shown good intra- and inter-reader reliability (95), and are in line with the majority of scoring systems in conducted trials applying ultrasonography. All sonographers were trained in using the scoring system and the reference atlas.

Radiographs were scored by two trained readers blinded to clinical data, but with known chronological order, since this has been shown to be the most sensitive method for detecting changes over time $(180,181)$. This method may have introduced expectation bias (i.e. a higher proportion of patients could have been considered to progress radiographically than would be revealed with blinded chronology). This potential bias for radiographic progression would be similar in both seronegative and seropositive patients (compared in paper III).

\subsubsection{Selection of joints for analyses}

The number of joints examined during the ARCTIC study and the number of intra-articular injections administered were extensive. Over the two years of follow-up, more than 130000 joints were examined, of these 48480 joints were examined with ultrasound. More than 
1300 injections were performed. In paper I, we aimed to examine the possible benefit of selecting joints for injection therapy by use of ultrasound as well as the effect of applying an ultrasound-guided injection procedure. Planning of the analyses for this study, including selection of joints for analyses, was challenging. In the ARCTIC trial, the rheumatologists had been instructed to inject clinically swollen joints regardless of ultrasound findings in both groups. We therefore could not study the possible benefit of selecting joints with ultrasound simply by comparing efficacy of injections across study groups. We therefore aimed to assess whether the effect of injections depended on the grade of power Doppler activity in the joint at the time of injection. Our hypothesis was that if this was the case, then ultrasound could be useful when selecting joints for injection therapy.

Absence or presence of clinical joint swelling at the subsequent visit was chosen as a measure of the effect of injections. The patients were randomised to ultrasound-guided or palpation-guided injections, but the joints were not randomly assigned to being injected or not. A variety of factors may have affected the chance of a joint being injected and the outcome of joint swelling. We compared subsequent joint swelling in injected versus not injected joints with identical power Doppler score and joint swelling state at the time of injection, aiming to limit confounding. We discussed grouping the joints according to both power Doppler and grey scale score and according to joint size. This approach would have given a larger number of joint groups with a limited number of observations in each group. We attempted to balance the need for statistical power (number of joints in each group) and the risk of selection bias. Also, we tried to identify possible confounding factors and adjusted for these in the analyses (age, gender, ACPA status, strategy arm, visit (baseline visit or at subsequent visits), within-patient and within-joint dependencies). However, it is not possible to control for all factors that may have affected the exposure and the outcome.

\subsection{Discussion of main results}

In the following chapter, the main results of paper I-III will be discussed and the specific research questions of this thesis will be addressed. 


\subsubsection{Ultrasound power Doppler and subsequent clinical joint swelling}

We found power Doppler activity in non-swollen joints to be associated with clinical joint swelling at the next visit, and the risk of joint swelling increased with higher power Doppler activity. In the ARCTIC study patients received intensive DMARD treatment, the association would probably have been even stronger in less aggressively treated patients. It has previously been shown that power Doppler activity is a predictor for radiographic progression and a predictor for disease flare in RA patients in clinical remission $(182,183)$. However, we are not aware of previous studies examining the association between subclinical synovitis in a joint and subsequent clinical swelling in that joint. Our findings support the use of ultrasound as a tool to detect joints at risk for developing clinical synovitis.

The main results from the ARCTIC trial showed no advantage, on the group level, of systematic local and systemic treatment of subclinical synovitis. Patients may still benefit from treatment of subclinical synovitis in a joint. If a patient has a painful clinically nonswollen joint with the presence of power Doppler activity, this joint could be a target for intra-articular injection.

\subsubsection{Identification of joints that may benefit from intra-articular injections}

According to our results, the beneficial efficacy of intra-articular injections depends on grade of power Doppler activity at the time of injection. Our study supports the use of ultrasound as a tool to select joints for injections.

One previous study has shown that ultrasound findings frequently led the physician to change the decision on whether to perform an intra-articular injection or not in patients with rheumatic diseases (169). This study showed that such modifications were associated with a trend towards improved short-term symptomatic treatment effect. As far as we know, this is the only study examining whether ultrasound affects the decision on joint injection. This study did not specify which ultrasound findings made the physician decide to inject or not, or whether certain ultrasound findings could predict the outcome of an injection. In a clinical setting, it is important to know which joints to inject to achieve the best effect. 
In our study, injecting clinically swollen joints without ultrasound power Doppler activity was not efficacious compared to not injecting (OR 1.3, p=0.59). Efficacy of injecting compared to not injecting was better in swollen (OR 9.0, p=0.001) and non-swollen (OR $8.4, \mathrm{p}=0.016)$ joints with a power Doppler score of two. This observation may be explained by the background risk of joint swelling in joints with different grades of ultrasound synovitis. When power Doppler activity is low, the probability of non-swollen joint at the next visit is high also if the joint is not injected, leading to a lower OR. Injections in joints with the highest grade of inflammation (swollen and power Doppler=3) were not the most effective according to our estimates. A potential explanation might be that when inflammation is severe, one injection is not sufficient, but the limited number of observations in this group of joints (leading to wide confidence intervals) makes interpretations difficult.

In the ARCTIC trial, more injections were performed in the ultrasound arm than in the conventional strategy arm (770 vs 548 injections). The difference was largest in MTP joints (200 vs 104 injections) and intercarpal joints (58 vs 5 injections), possibly because clinical joint swelling can be difficult to ascertain in these joints. It was not unexpected that patients followed with ultrasound received more injections, as non-swollen joints with power Doppler activity should be injected in the ultrasound arm (in addition to clinically swollen joints) according to the study protocol. In a different setting, ultrasound may be used to restrict injections to the joints most likely to benefit, reducing rather than increasing, the number of injections.

Even if joints are selected optimally, the number of joints needed to treat/inject (NNT) to prevent one swollen joint may be high. Systemic treatment leads to reduction and prevention of joint swelling in most joints, also if they are not injected. Studies have shown high remission rates in early RA patients treated with a combination of intra-articular glucocorticoid injections and treat-to-target DMARD therapy $(128,155,184)$. These studies, however, did not include a control group not receiving injections. Thus, it is unknown whether treatment success is a result of systemic DMARD treatment in a treat-to target and tight control setting, or whether there is a clinically relevant additional effect of injections. In the ARCTIC trial more than 1300 intra-articular injections were performed over the two years of follow-up. As the extended use of injections is time-consuming and 
exposes patients to procedural discomfort and potential side effects, there is a need for randomised controlled trials examining the additional effect of injections in modern RA care.

In the ARCTIC trial injections were used in addition to systemic DMARD treatment. Current EULAR recommendations for pharmacological management of RA include intraarticular glucocorticoid injections for residual inflammation in one or a few joints before escalation of DMARD treatment (6). In a real-life setting, clinicians may choose to inject inflamed joints instead of adjusting systemic treatment. Injection therapy could in this setting cause a delay in step-up of DMARDs which may seem contradictory to the modern conceptual thinking in RA management, which aims for disease control and prevention, rather than treating flares.

\subsubsection{Ultrasound-guided compared to palpation-guided injection procedure}

In our study, the efficacy of injections was similar when performed with or without ultrasound needle guidance. Previous studies have shown that ultrasound guidance increases accuracy and there is some evidence of better clinical outcomes and less procedural pain with ultrasound guidance $(163,185)$. However, accuracy and clinical effect may depend on the joint injected and on the experience of the clinician. In one study, ultrasound did not increase the accuracy of wrist injections when palpation-guided injections were performed by experienced rheumatologists (186). In our study, injections were performed by experienced rheumatologists. For less experienced clinicians, ultrasound-guided injections may involve a steeper learning curve compared to that necessary to get the skills for an optimal palpation-guided procedure. A study has shown that a trainee performing ultrasound-guided injections rapidly achieved higher accuracy than experienced rheumatologists performing palpation-guided injections. In this study accurate injections did improve clinical outcomes, and ultrasound-guided injections were more accurate, but still ultrasound guidance did not improve the short-term outcome of joint injection (165).

The possible benefit of ultrasound guidance may depend on the joint injected. A Cochrane review was unable to show any advantage in terms of clinical outcomes of ultrasoundguided injection for shoulder disorders over palpation-guided injection (168). A review on 
knee injections concludes that ultrasound guidance resulted in better clinical outcomes (164). In our study, all joints were analysed together. If we had more observations for each joint, we may have been able to show a difference in the effect of the procedures for some joints.

\subsubsection{Clinical presentation of seronegative and seropositive RA}

We found that seronegative patients classified according to the 2010 ACR/EULAR criteria had higher levels of inflammation, assessed both clinically and by ultrasound, than seropositive patients at baseline. This is in contrast with previous studies where patients are included based on the 1987 criteria, showing similar disease activity in the subgroups or more severe disease in seropositive patients (187-189). However, higher baseline disease activity in seronegative patients has also been shown when patients were classified according to the 1987 criteria (12), but the new criteria seem to increase the differences between the subgroups. Two studies have shown that the baseline inflammatory activity in seronegative patients were higher when applying the 2010 criteria compared to the 1987 criteria, which is in line with our results $(190,191)$.

Serological markers are helpful in establishing a diagnosis of RA, and RF is included also in the 1987 criteria. In the absence of serological markers, clinicians may require more inflammatory activity to diagnose RA in daily practice. However, the new criteria may be too stringent when applied to seronegative patients. A seronegative patient with elevated CRP and ESR, synovitis in both wrist joints, four MCP joints, two PIP joints and two MTP joints, and a disease duration of six months, may not fulfill the criteria, while a seropositive patient can fulfill the criteria with one swollen PIP joint and normal CRP and ESR. It was not unexpected that seronegative patients classified according to the new criteria had more joint involvement compared to seropositive patients, but the differences were larger than expected. Seronegative patients in our study had a median number of swollen joints of 17 , while the criteria require 11 involved joints.

The new criteria aimed to increase the sensitivity for RA and at the same time preserve high specificity. By weighting ACPA and RF so heavily, this may have been achieved for seropositive patients. Our results suggest that this may not be the case for seronegative patients. The rate of seronegative patients in our study was low (15\%). One explanation for 
this, as we have hypothesised, could be inclusion of patients based on the 2010 criteria for RA. Higher numbers of seronegative patients in a previous Norwegian RA cohort based on 1987 ACR criteria (34.5\% seronegative) also indicate that the introduction of the 2010 criteria changed the ratio of patients with seronegative RA to patients with seropositive RA (110). It has previously been shown that the new criteria identify fewer patients with seronegative disease compared to the 1987 criteria (19). A study of undiagnosed patients with joint symptoms found a sensitivity of the 2010 criteria among seronegative patients of only $15.8 \%$ (192). However, in other studies examining the agreement and discordance between 1987 and 2010 criteria based on data from cohorts of early arthritis, the new criteria do not seem to alter the ratio of seronegative to seropositive patients $(176,193,194)$.

\subsubsection{Disease course of seronegative compared to seropositive RA}

In paper III we found that disease activity after two years of treat-to-target therapy was similar in seronegative and seropositive patients. Both seronegative and seropositive patients responded well to treatment, and outcomes were good in both subgroups. Seronegative patients did not have a less severe disease course than seropositive patients, with similar rates of remission and similar radiographic progression over 2 years. Treatment response was somewhat slower in seronegative patients.

Previous studies indicate that seronegative patients have a less severe disease course with less radiographic damage than seropositive patients $(8-12,188,195)$. Our study indicates that implementation of new criteria may change the prognosis of seronegative compared to seropositive patients in clinical trials. However, ARCTIC is one of the first studies of patients included based on the new criteria, and more studies are needed to confirm this assumption. One recently published study of RA patients fulfilling the 2010 criteria showed that patient reported outcomes, including physical functioning and restrictions at work, were similar in ACPA-positive and ACPA-negative patients after four years of follow-up (196). This is in line with our results.

The results in papers II and III indicate that seronegative RA patients might have a more severe disease than the historic perception of this RA subgroup, which has also been discussed previously (197). We believe that our results highlight the need for a discussion 
regarding the performance of the new criteria for seronegative patients and also the possibility that clinicians have become more reluctant to use the diagnosis of seronegative RA. 


\section{Conclusions}

\subsection{Answers to research questions}

With regard to the specific research questions of this thesis presented in section 3.2, we were able to draw the following conclusions:

- Ultrasound power Doppler activity predicted subsequent clinical joint swelling at the joint level.

- According to our results, ultrasound assessment and clinical examination is superior to clinical examination alone in identifying joints that may benefit from intraarticular injections.

- Efficacy of injections was similar when performed ultrasound-guided and palpationguided.

- We found that seronegative patients classified according to the 2010 ACR/EULAR criteria had higher inflammatory activity, assessed both clinically and by ultrasonography, than seropositive patients at the time of diagnosis. This finding may reflect a limitation in the performance of the new classification criteria.

- After two years of DMARD treatment, measures of disease activity and remission rates were similar between seronegative and seropositive patients classified according to the new criteria. There was a tendency towards more radiographic damage in seronegative patients. Radiographic progression was similar in seronegative and seropositive patients during two years of follow-up.

- Seronegative RA patients responded well to modern treatment, however treatment response was slower in seronegative compared to seropositive patients. Type of treatment was similar between groups. Our findings suggest that among RA patients classified according to the $2010 \mathrm{ACR} / \mathrm{EULAR}$ criteria, seronegative RA is not a mild form of the disease and requires intensive treat-to-target therapy similar to treatment of seropositive RA. 


\subsection{Clinical implications and further research}

This thesis examines clinically relevant research questions and our findings may be of importance for clinicians and patients.

The decision of whether to inject a joint or not is a frequent dilemma in rheumatology practice. According to our results, examining the grade of ultrasound power Doppler activity in the joint could be useful when making this decision (paper 1). Selection of joints for injections by use of ultrasound may lead to better effect of the injections performed and avoidance of unnecessary injections. Better selection of joints for injection can reduce costs associated with this treatment (e.g. time and material costs), as well as the discomfort for the patients.

As discussed above, in our study, most of the joint swelling resolved also without injection therapy, probably because patients received intensive systemic DMARD treatment. Our results highlight the need for randomised controlled trials regarding the efficacy of intraarticular injections in modern RA treatment, both in early and established disease.

It is possible that applying the 2010 classification criteria for diagnostic guidance could make clinicians more reluctant to make a diagnosis of seronegative RA. This may cause a delay in treatment initiation. Our results in papers II and III indicate that patients now classified as seronegative RA have a more serious disease than before, and require intensive therapy. We hope that our results can contribute to an increased focus on seronegative patients including a discussion of the performance of the 2010 ACR/EULAR criteria for these patients. 


\section{References}

1. Global, regional, and national incidence, prevalence, and years lived with disability for 310 diseases and injuries, 1990-2015: a systematic analysis for the Global Burden of Disease Study 2015. Lancet (London, England). 2016;388(10053):1545-602.

2. Smolen JS, Aletaha D, McInnes IB. Rheumatoid arthritis. Lancet (London, England). 2016;388(10055):2023-38.

3. Landre-Beauvais AJ. The first description of rheumatoid arthritis. Unabridged text of the doctoral dissertation presented in 1800. Joint, bone, spine : revue du rhumatisme. 2001;68(2):130-43.

4. Entezami P, Fox DA, Clapham PJ, Chung KC. Historical perspective on the etiology of rheumatoid arthritis. Hand clinics. 2011;27(1):1-10.

5. Waaler E. On the occurrence of a factor in human serum activating the specific agglutintion of sheep blood corpuscles. 1939. APMIS : acta pathologica, microbiologica, et immunologica Scandinavica. 2007;115(5):422-38; discussion 39.

6. Schellekens GA, de Jong BA, van den Hoogen FH, van de Putte LB, van Venrooij

WJ. Citrulline is an essential constituent of antigenic determinants recognized by rheumatoid arthritis-specific autoantibodies. The Journal of clinical investigation. 1998;101(1):273-81.

7. Klareskog L, Catrina AI, Paget S. Rheumatoid arthritis. Lancet (London, England). 2009;373(9664):659-72.

8. Syversen SW, Goll GL, van der Heijde D, Landewe R, Lie BA, Odegard S, et al. Prediction of radiographic progression in rheumatoid arthritis and the role of antibodies against mutated citrullinated vimentin: results from a 10-year prospective study. Annals of the rheumatic diseases. 2010;69(2):345-51.

9. Hecht C, Englbrecht M, Rech J, Schmidt S, Araujo E, Engelke K, et al. Additive effect of anti-citrullinated protein antibodies and rheumatoid factor on bone erosions in patients with RA. Annals of the rheumatic diseases. 2015;74(12):2151-6.

10. Ronnelid J, Wick MC, Lampa J, Lindblad S, Nordmark B, Klareskog L, et al. Longitudinal analysis of citrullinated protein/peptide antibodies (anti-CP) during 5 year follow up in early rheumatoid arthritis: anti-CP status predicts worse disease activity and greater radiological progression. Annals of the rheumatic diseases. 2005;64(12):1744-9. 11. Nell VP, Machold KP, Stamm TA, Eberl G, Heinzl H, Uffmann M, et al.

Autoantibody profiling as early diagnostic and prognostic tool for rheumatoid arthritis. Annals of the rheumatic diseases. 2005;64(12):1731-6.

12. van den Broek M, Dirven L, Klarenbeek NB, Molenaar TH, Han KH, Kerstens PJ, et al. The association of treatment response and joint damage with ACPA-status in recentonset RA: a subanalysis of the 8-year follow-up of the BeSt study. Annals of the rheumatic diseases. 2012;71(2):245-8.

13. Aletaha D, Neogi T, Silman AJ, Funovits J, Felson DT, Bingham CO, 3rd, et al. 2010 rheumatoid arthritis classification criteria: an American College of

Rheumatology/European League Against Rheumatism collaborative initiative. Annals of the rheumatic diseases. 2010;69(9):1580-8.

14. Smolen JS, Landewe R, Bijlsma J, Burmester G, Chatzidionysiou K, Dougados M, et al. EULAR recommendations for the management of rheumatoid arthritis with synthetic 
and biological disease-modifying antirheumatic drugs: 2016 update. Annals of the rheumatic diseases. 2017;76(6):960-77.

15. Arnett FC, Edworthy SM, Bloch DA, McShane DJ, Fries JF, Cooper NS, et al. The American Rheumatism Association 1987 revised criteria for the classification of rheumatoid arthritis. Arthritis Rheum. 1988;31(3):315-24.

16. Saraux A, Berthelot JM, Chales G, Le Henaff C, Thorel JB, Hoang S, et al. Ability of the American College of Rheumatology 1987 criteria to predict rheumatoid arthritis in patients with early arthritis and classification of these patients two years later. Arthritis and rheumatism. 2001;44(11):2485-91.

17. Banal F, Dougados M, Combescure C, Gossec L. Sensitivity and specificity of the American College of Rheumatology 1987 criteria for the diagnosis of rheumatoid arthritis according to disease duration: a systematic literature review and meta-analysis. Annals of the rheumatic diseases. 2009;68(7):1184-91.

18. Radner H, Neogi T, Smolen JS, Aletaha D. Performance of the 2010 ACR/EULAR classification criteria for rheumatoid arthritis: a systematic literature review. Annals of the rheumatic diseases. 2014;73(1):114-23.

19. Fautrel B, Combe B, Rincheval N, Dougados M. Level of agreement of the 1987 ACR and 2010 ACR/EULAR rheumatoid arthritis classification criteria: an analysis based on ESPOIR cohort data. Annals of the rheumatic diseases. 2012;71(3):386-9.

20. van der Heijde D, van der Helm-van Mil AH, Aletaha D, Bingham CO, Burmester GR, Dougados M, et al. EULAR definition of erosive disease in light of the 2010 ACR/EULAR rheumatoid arthritis classification criteria. Annals of the rheumatic diseases. 2013;72(4):479-81.

21. Aletaha D, Hawker G, Neogi T. Re:Clarification of the role of ultrasonography, magnetic resonance imaging and conventional radiography in the ACR/EULAR 2010 rheumatoid arthritis classification criteria - comment to the article by Aletaha et al. Annals of the rheumatic diseases. 2011.

22. Alamanos Y, Voulgari PV, Drosos AA. Incidence and prevalence of rheumatoid arthritis, based on the 1987 American College of Rheumatology criteria: a systematic review. Seminars in arthritis and rheumatism. 2006;36(3):182-8.

23. Kvien TK. Epidemiology and burden of illness of rheumatoid arthritis. PharmacoEconomics. 2004;22(2 Suppl 1):1-12.

24. Tobon GJ, Youinou P, Saraux A. The environment, geo-epidemiology, and autoimmune disease: Rheumatoid arthritis. Autoimmunity reviews. 2010;9(5):A288-92.

25. Cross M, Smith E, Hoy D, Carmona L, Wolfe F, Vos T, et al. The global burden of rheumatoid arthritis: estimates from the global burden of disease 2010 study. Annals of the rheumatic diseases. 2014;73(7):1316-22.

26. Kvien TK, Uhlig T, Odegard S, Heiberg MS. Epidemiological aspects of rheumatoid arthritis: the sex ratio. Annals of the New York Academy of Sciences. 2006;1069:212-22.

27. Crowson CS, Matteson EL, Myasoedova E, Michet CJ, Ernste FC, Warrington KJ, et al. The lifetime risk of adult-onset rheumatoid arthritis and other inflammatory autoimmune rheumatic diseases. Arthritis and rheumatism. 2011;63(3):633-9.

28. Viatte S, Plant D, Raychaudhuri S. Genetics and epigenetics of rheumatoid arthritis. Nature reviews Rheumatology. 2013;9(3):141-53.

29. Dougados M. Comorbidities in rheumatoid arthritis. Current opinion in rheumatology. 2016;28(3):282-8. 
30. Dadoun S, Zeboulon-Ktorza N, Combescure C, Elhai M, Rozenberg S, Gossec L, et al. Mortality in rheumatoid arthritis over the last fifty years: systematic review and metaanalysis. Joint, bone, spine : revue du rhumatisme. 2013;80(1):29-33.

31. van Nies JA, de Jong Z, van der Helm-van Mil AH, Knevel R, Le Cessie S, Huizinga TW. Improved treatment strategies reduce the increased mortality risk in early RA patients. Rheumatology (Oxford, England). 2010;49(11):2210-6.

32. Poppelaars PB, van Tuyl LHD, Boers M. Normal mortality of the COBRA early rheumatoid arthritis trial cohort after 23 years of follow-up. Annals of the rheumatic diseases. 2019.

33. Anquetil F, Clavel C, Offer G, Serre G, Sebbag M. IgM and IgA rheumatoid factors purified from rheumatoid arthritis sera boost the Fc receptor- and complement-dependent effector functions of the disease-specific anti-citrullinated protein autoantibodies. Journal of immunology (Baltimore, Md : 1950). 2015;194(8):3664-74.

34. Nishimura K, Sugiyama D, Kogata Y, Tsuji G, Nakazawa T, Kawano S, et al. Metaanalysis: diagnostic accuracy of anti-cyclic citrullinated peptide antibody and rheumatoid factor for rheumatoid arthritis. Annals of internal medicine. 2007;146(11):797-808.

35. Whiting PF, Smidt N, Sterne JA, Harbord R, Burton A, Burke M, et al. Systematic review: accuracy of anti-citrullinated Peptide antibodies for diagnosing rheumatoid arthritis. Annals of internal medicine. 2010;152(7):456-64; w155-66.

36. Dorner T, Egerer K, Feist E, Burmester GR. Rheumatoid factor revisited. Current opinion in rheumatology. 2004;16(3):246-53.

37. Ingegnoli F, Castelli R, Gualtierotti R. Rheumatoid factors: clinical applications. Disease markers. 2013;35(6):727-34.

38. Nienhuis RL, Mandema E. A new serum factor in patients with rheumatoid arthritis; the antiperinuclear factor. Annals of the rheumatic diseases. 1964;23:302-5.

39. Young BJ, Mallya RK, Leslie RD, Clark CJ, Hamblin TJ. Anti-keratin antibodies in rheumatoid arthritis. British medical journal. 1979;2(6182):97-9.

40. Schellekens GA, Visser H, de Jong BA, van den Hoogen FH, Hazes JM, Breedveld $\mathrm{FC}$, et al. The diagnostic properties of rheumatoid arthritis antibodies recognizing a cyclic citrullinated peptide. Arthritis and rheumatism. 2000;43(1):155-63.

41. Shi J, Knevel R, Suwannalai P, van der Linden MP, Janssen GM, van Veelen PA, et al. Autoantibodies recognizing carbamylated proteins are present in sera of patients with rheumatoid arthritis and predict joint damage. Proceedings of the National Academy of Sciences of the United States of America. 2011;108(42):17372-7.

42. Juarez M, Bang H, Hammar F, Reimer U, Dyke B, Sahbudin I, et al. Identification of novel antiacetylated vimentin antibodies in patients with early inflammatory arthritis.

Annals of the rheumatic diseases. 2016;75(6):1099-107.

43. McInnes IB, Schett G. The pathogenesis of rheumatoid arthritis. The New England journal of medicine. 2011;365(23):2205-19.

44. MacGregor AJ, Snieder H, Rigby AS, Koskenvuo M, Kaprio J, Aho K, et al. Characterizing the quantitative genetic contribution to rheumatoid arthritis using data from twins. Arthritis and rheumatism. 2000;43(1):30-7.

45. Frisell T, Holmqvist M, Kallberg H, Klareskog L, Alfredsson L, Askling J. Familial risks and heritability of rheumatoid arthritis: role of rheumatoid factor/anti-citrullinated protein antibody status, number and type of affected relatives, sex, and age. Arthritis and rheumatism. 2013;65(11):2773-82. 
46. Gregersen PK, Silver J, Winchester RJ. The shared epitope hypothesis. An approach to understanding the molecular genetics of susceptibility to rheumatoid arthritis. Arthritis and rheumatism. 1987;30(11):1205-13.

47. Okada Y, Wu D, Trynka G, Raj T, Terao C, Ikari K, et al. Genetics of rheumatoid arthritis contributes to biology and drug discovery. Nature. 2014;506(7488):376-81.

48. Derksen V, Huizinga TWJ, van der Woude D. The role of autoantibodies in the pathophysiology of rheumatoid arthritis. Seminars in immunopathology. 2017;39(4):437-46.

49. Kurreeman F, Liao K, Chibnik L, Hickey B, Stahl E, Gainer V, et al. Genetic basis of autoantibody positive and negative rheumatoid arthritis risk in a multi-ethnic cohort derived from electronic health records. American journal of human genetics. 2011;88(1):5769.

50. Eyre S, Bowes J, Diogo D, Lee A, Barton A, Martin P, et al. High-density genetic mapping identifies new susceptibility loci for rheumatoid arthritis. Nature genetics. 2012;44(12):1336-40.

51. Verpoort KN, van Gaalen FA, van der Helm-van Mil AH, Schreuder GM, Breedveld FC, Huizinga TW, et al. Association of HLA-DR3 with anti-cyclic citrullinated peptide antibody-negative rheumatoid arthritis. Arthritis and rheumatism. 2005;52(10):3058-62.

52. Bossini-Castillo L, de Kovel C, Kallberg H, van 't Slot R, Italiaander A, Coenen M, et al. A genome-wide association study of rheumatoid arthritis without antibodies against citrullinated peptides. Annals of the rheumatic diseases. 2015;74(3):e15.

53. Uhlig T, Hagen KB, Kvien TK. Current tobacco smoking, formal education, and the risk of rheumatoid arthritis. The Journal of rheumatology. 1999;26(1):47-54.

54. Sugiyama D, Nishimura K, Tamaki K, Tsuji G, Nakazawa T, Morinobu A, et al. Impact of smoking as a risk factor for developing rheumatoid arthritis: a meta-analysis of observational studies. Annals of the rheumatic diseases. 2010;69(1):70-81.

55. Klareskog L, Stolt P, Lundberg K, Kallberg H, Bengtsson C, Grunewald J, et al. A new model for an etiology of rheumatoid arthritis: smoking may trigger HLA-DR (shared epitope)-restricted immune reactions to autoantigens modified by citrullination. Arthritis and rheumatism. 2006;54(1):38-46.

56. Liao KP, Alfredsson L, Karlson EW. Environmental influences on risk for rheumatoid arthritis. Current opinion in rheumatology. 2009;21(3):279-83.

57. Pedersen M, Jacobsen S, Klarlund M, Pedersen BV, Wiik A, Wohlfahrt J, et al. Environmental risk factors differ between rheumatoid arthritis with and without autoantibodies against cyclic citrullinated peptides. Arthritis research \& therapy. 2006;8(4):R133.

58. Jacobsson LT, Jacobsson ME, Askling J, Knowler WC. Perinatal characteristics and risk of rheumatoid arthritis. BMJ (Clinical research ed). 2003;326(7398):1068-9.

59. Mandl LA, Costenbader KH, Simard JF, Karlson EW. Is birthweight associated with risk of rheumatoid arthritis? Data from a large cohort study. Annals of the rheumatic diseases. 2009;68(4):514-8.

60. Firestein GS, McInnes IB. Immunopathogenesis of Rheumatoid Arthritis. Immunity. 2017;46(2):183-96.

61. Reynisdottir G, Olsen H, Joshua V, Engstrom M, Forsslund H, Karimi R, et al. Signs of immune activation and local inflammation are present in the bronchial tissue of patients with untreated early rheumatoid arthritis. Annals of the rheumatic diseases. 2016;75(9):1722-7.

62. Roos K, Martinsson K, Ziegelasch M, Sommarin Y, Svard A, Skogh T, et al. Circulating secretory IgA antibodies against cyclic citrullinated peptides in early rheumatoid 
arthritis associate with inflammatory activity and smoking. Arthritis research \& therapy. 2016;18(1):119.

63. Felson DT, Anderson JJ, Boers M, Bombardier C, Chernoff M, Fried B, et al. The American College of Rheumatology preliminary core set of disease activity measures for rheumatoid arthritis clinical trials. The Committee on Outcome Measures in Rheumatoid Arthritis Clinical Trials. Arthritis and rheumatism. 1993;36(6):729-40.

64. Kirkham JJ, Boers M, Tugwell P, Clarke M, Williamson PR. Outcome measures in rheumatoid arthritis randomised trials over the last 50 years. Trials. 2013;14:324.

65. Fuchs HA, Brooks RH, Callahan LF, Pincus T. A simplified twenty-eight-joint quantitative articular index in rheumatoid arthritis. Arthritis and rheumatism. 1989;32(5):531-7.

66. Deandrade JR, Casagrande PA. A SEVEN-DAY VARIABILITY STUDY OF 499 PATIENTS WITH PERIPHERAL RHEUMATOID ARTHRITIS. Arthritis and rheumatism. 1965;8:302-34.

67. van der Heijde DM, van 't Hof M, van Riel PL, van de Putte LB. Development of a disease activity score based on judgment in clinical practice by rheumatologists. The Journal of rheumatology. 1993;20(3):579-81.

68. Ritchie DM, Boyle JA, McInnes JM, Jasani MK, Dalakos TG, Grieveson P, et al. Clinical studies with an articular index for the assessment of joint tenderness in patients with rheumatoid arthritis. Q J Med. 1968;37(147):393-406.

69. Anderson JK, Zimmerman L, Caplan L, Michaud K. Measures of rheumatoid arthritis disease activity: Patient (PtGA) and Provider (PrGA) Global Assessment of Disease Activity, Disease Activity Score (DAS) and Disease Activity Score with 28-Joint Counts (DAS28), Simplified Disease Activity Index (SDAI), Clinical Disease Activity Index (CDAI), Patient Activity Score (PAS) and Patient Activity Score-II (PASII), Routine Assessment of Patient Index Data (RAPID), Rheumatoid Arthritis Disease Activity Index (RADAI) and Rheumatoid Arthritis Disease Activity Index-5 (RADAI-5), Chronic Arthritis Systemic Index (CASI), Patient-Based Disease Activity Score With ESR (PDAS1) and Patient-Based Disease Activity Score without ESR (PDAS2), and Mean Overall Index for Rheumatoid Arthritis (MOI-RA). Arthritis care \& research. 2011;63 Suppl 11:S14-36. 70. Sokka T. Assessment of pain in rheumatic diseases. Clinical and experimental rheumatology. 2005;23(5 Suppl 39):S77-84.

71. Pincus T, Gibson KA, Shmerling RH. An evidence-based approach to laboratory tests in usual care of patients with rheumatoid arthritis. Clinical and experimental rheumatology. 2014;32(5 Suppl 85):S-23-8.

72. van der Heijde DM, van't Hof MA, van Riel PL, van Leeuwen MA, van Rijswijk $\mathrm{MH}$, van de Putte LB. Validity of single variables and composite indices for measuring disease activity in rheumatoid arthritis. Annals of the rheumatic diseases. 1992;51(2):17781.

73. Smolen JS, Breedveld FC, Burmester GR, Bykerk V, Dougados M, Emery P, et al. Treating rheumatoid arthritis to target: 2014 update of the recommendations of an international task force. Annals of the rheumatic diseases. 2016;75(1):3-15.

74. van der Heijde DM, van 't Hof MA, van Riel PL, Theunisse LA, Lubberts EW, van Leeuwen MA, et al. Judging disease activity in clinical practice in rheumatoid arthritis: first step in the development of a disease activity score. Ann Rheum Dis. 1990;49(11):916-20. 75. Prevoo ML, van 't Hof MA, Kuper HH, van Leeuwen MA, van de Putte LB, van Riel PL. Modified disease activity scores that include twenty-eight-joint counts. 
Development and validation in a prospective longitudinal study of patients with rheumatoid arthritis. Arthritis and rheumatism. 1995;38(1):44-8.

76. Smolen JS, Breedveld FC, Schiff MH, Kalden JR, Emery P, Eberl G, et al. A simplified disease activity index for rheumatoid arthritis for use in clinical practice. Rheumatology (Oxford). 2003;42(2):244-57.

77. Aletaha D, Nell VP, Stamm T, Uffmann M, Pflugbeil S, Machold K, et al. Acute phase reactants add little to composite disease activity indices for rheumatoid arthritis: validation of a clinical activity score. Arthritis Res Ther. 2005;7(4):R796-806.

78. Felson DT, Smolen JS, Wells G, Zhang B, van Tuyl LH, Funovits J, et al. American College of Rheumatology/European League against Rheumatism provisional definition of remission in rheumatoid arthritis for clinical trials. Annals of the rheumatic diseases. 2011;70(3):404-13.

79. Felson DT, Anderson JJ, Boers M, Bombardier C, Furst D, Goldsmith C, et al. American College of Rheumatology. Preliminary definition of improvement in rheumatoid arthritis. Arthritis and rheumatism. 1995;38(6):727-35.

80. van Gestel AM, Prevoo ML, van 't Hof MA, van Rijswijk MH, van de Putte LB, van Riel PL. Development and validation of the European League Against Rheumatism response criteria for rheumatoid arthritis. Comparison with the preliminary American College of Rheumatology and the World Health Organization/International League Against Rheumatism Criteria. Arthritis and rheumatism. 1996;39(1):34-40.

81. Bruce B, Fries JF. The Stanford Health Assessment Questionnaire: dimensions and practical applications. Health Qual Life Outcomes. 2003;1:20.

82. Oude Voshaar MA, Ten Klooster PM, Glas CA, Vonkeman HE, Taal E, Krishnan E, et al. Validity and measurement precision of the PROMIS physical function item bank and a content validity-driven 20 -item short form in rheumatoid arthritis compared with traditional measures. Rheumatology (Oxford). 2015;54(12):2221-9.

83. Ware JE, Jr., Sherbourne CD. The MOS 36-item short-form health survey (SF-36). I. Conceptual framework and item selection. Med Care. 1992;30(6):473-83.

84. Herdman M, Gudex C, Lloyd A, Janssen M, Kind P, Parkin D, et al. Development and preliminary testing of the new five-level version of EQ-5D (EQ-5D-5L). Qual Life Res. 2011;20(10):1727-36.

85. Gossec L, Paternotte S, Aanerud GJ, Balanescu A, Boumpas DT, Carmona L, et al. Finalisation and validation of the rheumatoid arthritis impact of disease score, a patientderived composite measure of impact of rheumatoid arthritis: a EULAR initiative. Annals of the rheumatic diseases. 2011;70(6):935-42.

86. Haavardsholm EA, Lie E, Lillegraven S. Should modern imaging be part of remission criteria in rheumatoid arthritis? Best practice \& research Clinical rheumatology. 2012;26(6):767-85.

87. Colebatch AN, Edwards CJ, Ostergaard M, van der Heijde D, Balint PV, d'Agostino MA, et al. EULAR recommendations for the use of imaging of the joints in the clinical management of rheumatoid arthritis. Ann Rheum Dis. 2013;72(6):804-14.

88. Boers M, Tugwell P, Felson DT, van Riel PL, Kirwan JR, Edmonds JP, et al. World Health Organization and International League of Associations for Rheumatology core endpoints for symptom modifying antirheumatic drugs in rheumatoid arthritis clinical trials. J Rheumatol Suppl. 1994;41:86-9.

89. van der Heijde D. How to read radiographs according to the Sharp/van der Heijde method. J Rheumatol. 1999;26(3):743-5. 
90. Odegard S, Landewe R, van der Heijde D, Kvien TK, Mowinckel P, Uhlig T. Association of early radiographic damage with impaired physical function in rheumatoid arthritis: a ten-year, longitudinal observational study in 238 patients. Arthritis and rheumatism. 2006;54(1):68-75.

91. Grassi W, Filippucci E. A brief history of ultrasound in rheumatology: where we were. Clinical and experimental rheumatology. 2014;32(1 Suppl 80):S3-6.

92. Hammer HB, Terslev L. Role of ultrasound in managing rheumatoid arthritis. Current rheumatology reports. 2012;14(5):438-44.

93. Schmidt WA, Backhaus M. What the practising rheumatologist needs to know about the technical fundamentals of ultrasonography. Best practice \& research Clinical rheumatology. 2008;22(6):981-99.

94. Moller I, Janta I, Backhaus M, Ohrndorf S, Bong DA, Martinoli C, et al. The 2017 EULAR standardised procedures for ultrasound imaging in rheumatology. Annals of the rheumatic diseases. 2017;76(12):1974-9.

95. Hammer HB, Bolton-King P, Bakkeheim V, Berg TH, Sundt E, Kongtorp AK, et al. Examination of intra and interrater reliability with a new ultrasonographic reference atlas for scoring of synovitis in patients with rheumatoid arthritis. Annals of the rheumatic diseases. 2011;70(11):1995-8.

96. Szkudlarek M, Court-Payen M, Jacobsen S, Klarlund M, Thomsen HS, Ostergaard M. Interobserver agreement in ultrasonography of the finger and toe joints in rheumatoid arthritis. Arthritis Rheum. 2003;48(4):955-62.

97. Tan YK, Allen JC, Lye WK, Conaghan PG, D’Agostino MA, Chew L-C, et al. Novel Ultrasound Joint Selection Methods Using a Reduced Joint Number Demonstrate Inflammatory Improvement when Compared to Existing Methods and Disease Activity Score at 28 Joints. The Journal of Rheumatology. 2016;43(1):34-7.

98. Cheung PP, Lahiri M, Teng GG, Lim AYN, Lau TC, Lateef A, et al. A randomized controlled trial for improving patient self-assessment of synovitis in rheumatoid arthritis with education by ultrasonography: the RAEUS Study. Rheumatology. 2015;54(7):1161-9. 99. D'Agostino MA, Terslev L, Aegerter P, Backhaus M, Balint P, Bruyn GA, et al. Scoring ultrasound synovitis in rheumatoid arthritis: a EULAR-OMERACT ultrasound taskforce-Part 1: definition and development of a standardised, consensus-based scoring system. RMD open. 2017;3(1):e000428.

100. Terslev L, Naredo E, Aegerter P, Wakefield RJ, Backhaus M, Balint P, et al. Scoring ultrasound synovitis in rheumatoid arthritis: a EULAR-OMERACT ultrasound taskforcePart 2: reliability and application to multiple joints of a standardised consensus-based scoring system. RMD open. 2017;3(1):e000427.

101. Mandl P, Naredo E, Wakefield RJ, Conaghan PG, d'Agostino MA. A systematic literature review analysis of ultrasound joint count and scoring systems to assess synovitis in rheumatoid arthritis according to the OMERACT filter. J Rheumatol. 2011;38(9):2055-62. 102. Backhaus M, Ohrndorf S, Kellner H, Strunk J, Backhaus TM, Hartung W, et al. Evaluation of a novel 7-joint ultrasound score in daily rheumatologic practice: a pilot project. Arthritis Rheum. 2009;61(9):1194-201.

103. Dougados M, Jousse-Joulin S, Mistretta F, d'Agostino MA, Backhaus M, Bentin J, et al. Evaluation of several ultrasonography scoring systems for synovitis and comparison to clinical examination: results from a prospective multicentre study of rheumatoid arthritis. Ann Rheum Dis. 2010;69(5):828-33.

104. Naredo E, Rodriguez M, Campos C, Rodriguez-Heredia JM, Medina JA, Giner E, et al. Validity, reproducibility, and responsiveness of a twelve-joint simplified power doppler 
ultrasonographic assessment of joint inflammation in rheumatoid arthritis. Arthritis Rheum. 2008;59(4):515-22.

105. Perricone C, Ceccarelli F, Modesti M, Vavala C, Di FM, Valesini G, et al. The 6joint ultrasonographic assessment: a valid, sensitive-to-change and feasible method for evaluating joint inflammation in RA. Rheumatology (Oxford). 2012;51(5):866-73.

106. Scheel AK, Hermann KG, Kahler E, Pasewaldt D, Fritz J, Hamm B, et al. A novel ultrasonographic synovitis scoring system suitable for analyzing finger joint inflammation in rheumatoid arthritis. Arthritis Rheum. 2005;52(3):733-43.

107. Aga AB, Hammer HB, Olsen IC, Uhlig T, Kvien TK, van der Heijde D, et al. First step in the development of an ultrasound joint inflammation score for rheumatoid arthritis using a data-driven approach. Annals of the rheumatic diseases. 2016;75(8):1444-51.

108. Haavardsholm EA, Aga AB, Olsen IC, Lillegraven S, Hammer HB, Uhlig T, et al. Ultrasound in management of rheumatoid arthritis: ARCTIC randomised controlled strategy trial. BMJ (Clinical research ed). 2016;354:i4205.

109. Dale J, Stirling A, Zhang R, Purves D, Foley J, Sambrook M, et al. Targeting ultrasound remission in early rheumatoid arthritis: the results of the TaSER study, a randomised clinical trial. Annals of the rheumatic diseases. 2016;75(6):1043-50.

110. Haavardsholm EA, Boyesen P, Ostergaard M, Schildvold A, Kvien TK. Magnetic resonance imaging findings in 84 patients with early rheumatoid arthritis: bone marrow oedema predicts erosive progression. Annals of the rheumatic diseases. 2008;67(6):794-800.

111. Hetland ML, Stengaard-Pedersen K, Junker P, Ostergaard M, Ejbjerg BJ, Jacobsen $\mathrm{S}$, et al. Radiographic progression and remission rates in early rheumatoid arthritis - MRI bone oedema and anti-CCP predicted radiographic progression in the 5-year extension of the double-blind randomised CIMESTRA trial. Annals of the rheumatic diseases.

2010;69(10):1789-95.

112. Ostergaard M, Peterfy C, Conaghan P, McQueen F, Bird P, Ejbjerg B, et al. OMERACT Rheumatoid Arthritis Magnetic Resonance Imaging Studies. Core set of MRI acquisitions, joint pathology definitions, and the OMERACT RA-MRI scoring system. J Rheumatol. 2003;30(6):1385-6.

113. Ostergaard M, Peterfy CG, Bird P, Gandjbakhch F, Glinatsi D, Eshed I, et al. The OMERACT Rheumatoid Arthritis Magnetic Resonance Imaging (MRI) Scoring System: Updated Recommendations by the OMERACT MRI in Arthritis Working Group. The Journal of rheumatology. 2017;44(11):1706-12.

114. Moller-Bisgaard S, Horslev-Petersen K, Ejbjerg B, Hetland ML, Ornbjerg LM, Glinatsi D, et al. Effect of Magnetic Resonance Imaging vs Conventional Treat-to-Target Strategies on Disease Activity Remission and Radiographic Progression in Rheumatoid Arthritis: The IMAGINE-RA Randomized Clinical Trial. Jama. 2019;321(5):461-72. 115. Singh JA, Saag KG, Bridges SL, Jr., Akl EA, Bannuru RR, Sullivan MC, et al. 2015 American College of Rheumatology Guideline for the Treatment of Rheumatoid Arthritis. Arthritis \& rheumatology (Hoboken, NJ). 2016;68(1):1-26.

116. Cush JJ. Early rheumatoid arthritis -- is there a window of opportunity? J Rheumatol Suppl. 2007;80:1-7.:1-7.

117. Boers M. Understanding the window of opportunity concept in early rheumatoid arthritis. Arthritis Rheum. 2003;48(7):1771-4.

118. Furst DE. Window of opportunity. J Rheumatol. 2004;31(9):1677-9.

119. Anderson JJ, Wells G, Verhoeven AC, Felson DT. Factors predicting response to treatment in rheumatoid arthritis: the importance of disease duration. Arthritis and rheumatism. 2000;43(1):22-9. 
120. Emery P, Breedveld FC, Dougados M, Kalden JR, Schiff MH, Smolen JS. Early referral recommendation for newly diagnosed rheumatoid arthritis: evidence based development of a clinical guide. Annals of the rheumatic diseases. 2002;61(4):290-7.

121. Aletaha D, Eberl G, Nell VP, Machold KP, Smolen JS. Attitudes to early rheumatoid arthritis: changing patterns. Results of a survey. Annals of the rheumatic diseases. 2004;63(10):1269-75.

122. Aga AB, Lie E, Uhlig T, Olsen IC, Wierod A, Kalstad S, et al. Time trends in disease activity, response and remission rates in rheumatoid arthritis during the past decade: results from the NOR-DMARD study 2000-2010. Annals of the rheumatic diseases. 2015;74(2):381-8.

123. Allaart CF, Goekoop-Ruiterman YP, de Vries-Bouwstra JK, Breedveld FC, Dijkmans BA. Aiming at low disease activity in rheumatoid arthritis with initial combination therapy or initial monotherapy strategies: the BeSt study. Clin Exp Rheumatol. 2006;24(6 Suppl 43):S-82.

124. Verstappen SM, Jacobs JW, Van D, V, Heurkens AH, Schenk Y, ter Borg EJ, et al. Intensive treatment with methotrexate in early rheumatoid arthritis: aiming for remission. Computer Assisted Management in Early Rheumatoid Arthritis (CAMERA, an open-label strategy trial). Ann Rheum Dis. 2007;66(11):1443-9.

125. Mottonen T, Hannonen P, Leirisalo-Repo M, Nissila M, Kautiainen H, Korpela M, et al. Comparison of combination therapy with single-drug therapy in early rheumatoid arthritis: a randomised trial. FIN-RACo trial group. Lancet. 1999;353(9164):1568-73. 126. Goekoop-Ruiterman YP, de Vries-Bouwstra JK, Allaart CF, van ZD, Kerstens PJ, Hazes JM, et al. Comparison of treatment strategies in early rheumatoid arthritis: a randomized trial. Ann Intern Med. 2007;\%20;146(6):406-15.

127. Bijlsma JW, Weinblatt ME. Optimal use of methotrexate: the advantages of tight control. Ann Rheum Dis. 2007;66(11):1409-10.

128. Grigor C, Capell H, Stirling A, McMahon AD, Lock P, Vallance R, et al. Effect of a treatment strategy of tight control for rheumatoid arthritis (the TICORA study): a singleblind randomised controlled trial. Lancet. 2004;364(9430):263-9.

129. Bukhari MA, Wiles NJ, Lunt M, Harrison BJ, Scott DG, Symmons DP, et al. Influence of disease-modifying therapy on radiographic outcome in inflammatory polyarthritis at five years: results from a large observational inception study. Arthritis Rheum. 2003;48(1):46-53.

130. Lard LR, Visser H, Speyer I, vander Horst-Bruinsma IE, Zwinderman AH, Breedveld FC, et al. Early versus delayed treatment in patients with recent-onset rheumatoid arthritis: comparison of two cohorts who received different treatment strategies. Am J Med. 2001;111(6):446-51.

131. Nell VP, Machold KP, Eberl G, Stamm TA, Uffmann M, Smolen JS. Benefit of very early referral and very early therapy with disease-modifying anti-rheumatic drugs in patients with early rheumatoid arthritis. Rheumatology (Oxford). 2004;43(7):906-14.

132. Smolen JS, Landewe R, Breedveld F, Buch M, Burmester G, Dougados M, et al. EULAR recommendations for the management of rheumatoid arthritis with synthetic and biological disease-modifying antirheumatic drugs: 2013 update. Ann Rheum Dis doi:10 1136/annrheumdis-2013-204573. 2013.

133. Smolen JS, Aletaha D, Koeller M, Weisman MH, Emery P. New therapies for treatment of rheumatoid arthritis. Lancet (London, England). 2007;370(9602):1861-74. 
134. Stoffer MA, Schoels MM, Smolen JS, Aletaha D, Breedveld FC, Burmester G, et al. Evidence for treating rheumatoid arthritis to target: results of a systematic literature search update. Annals of the rheumatic diseases. 2016;75(1):16-22.

135. Kersley GD. Amethopterin (methotrexate) in connective tissue disease-psoriasis and polyarthritis. Annals of the rheumatic diseases. 1968;27(1):64-6.

136. Lopez-Olivo MA, Siddhanamatha HR, Shea B, Tugwell P, Wells GA, SuarezAlmazor ME. Methotrexate for treating rheumatoid arthritis. The Cochrane database of systematic reviews. 2014(6):Cd000957.

137. Brown PM, Pratt AG, Isaacs JD. Mechanism of action of methotrexate in rheumatoid arthritis, and the search for biomarkers. Nature reviews Rheumatology. 2016;12(12):731-42.

138. Meier FM, Frerix M, Hermann W, Muller-Ladner U. Current immunotherapy in rheumatoid arthritis. Immunotherapy. 2013;5(9):955-74.

139. Smolen JS, Han C, Bala M, Maini RN, Kalden JR, van der Heijde D, et al. Evidence of radiographic benefit of treatment with infliximab plus methotrexate in rheumatoid arthritis patients who had no clinical improvement: a detailed subanalysis of data from the anti-tumor necrosis factor trial in rheumatoid arthritis with concomitant therapy study. Arthritis and rheumatism. 2005;52(4):1020-30.

140. Landewe R, van der Heijde D, Klareskog L, van Vollenhoven R, Fatenejad S. Disconnect between inflammation and joint destruction after treatment with etanercept plus methotrexate: results from the trial of etanercept and methotrexate with radiographic and patient outcomes. Arthritis and rheumatism. 2006;54(10):3119-25.

141. de Punder YM, Hendrikx J, den Broeder AA, Valls Pascual E, van Riel PL, Fransen J. Should we redefine treatment targets in rheumatoid arthritis? Low disease activity is sufficiently strict for patients who are anticitrullinated protein antibody-negative. The Journal of rheumatology. 2013;40(8):1268-74.

142. Wevers-de Boer K, Visser K, Heimans L, Ronday HK, Molenaar E, Groenendael $\mathrm{JH}$, et al. Remission induction therapy with methotrexate and prednisone in patients with early rheumatoid and undifferentiated arthritis (the IMPROVED study). Annals of the rheumatic diseases. 2012;71(9):1472-7.

143. Gottenberg JE, Ravaud P, Cantagrel A, Combe B, Flipo RM, Schaeverbeke T, et al. Positivity for anti-cyclic citrullinated peptide is associated with a better response to abatacept: data from the 'Orencia and Rheumatoid Arthritis' registry. Annals of the rheumatic diseases. 2012;71(11):1815-9.

144. Lal P, Su Z, Holweg CT, Silverman GJ, Schwartzman S, Kelman A, et al.

Inflammation and autoantibody markers identify rheumatoid arthritis patients with enhanced clinical benefit following rituximab treatment. Arthritis and rheumatism. 2011;63(12):368191.

145. Cappelli LC, Palmer JL, Kremer J, Bingham CO, 3rd. Tocilizumab treatment leads to improvement in disease activity regardless of CCP status in rheumatoid arthritis.

Seminars in arthritis and rheumatism. 2017;47(2):165-9.

146. Gorter SL, Bijlsma JW, Cutolo M, Gomez-Reino J, Kouloumas M, Smolen JS, et al. Current evidence for the management of rheumatoid arthritis with glucocorticoids: a systematic literature review informing the EULAR recommendations for the management of rheumatoid arthritis. Annals of the rheumatic diseases. 2010;69(6):1010-4.

147. Kirwan JR, Bijlsma JW, Boers M, Shea BJ. Effects of glucocorticoids on radiological progression in rheumatoid arthritis. The Cochrane database of systematic reviews. 2007(1):Cd006356. 
148. Strehl C, Bijlsma JW, de Wit M, Boers M, Caeyers N, Cutolo M, et al. Defining conditions where long-term glucocorticoid treatment has an acceptably low level of harm to facilitate implementation of existing recommendations: viewpoints from an EULAR task force. Annals of the rheumatic diseases. 2016;75(6):952-7.

149. Mandl P, Naredo E, Conaghan PG, D'Agostino MA, Wakefield RJ, Bachta A, et al. Practice of ultrasound-guided arthrocentesis and joint injection, including training and implementation, in Europe: results of a survey of experts and scientific societies. Rheumatology (Oxford, England). 2012;51(1):184-90.

150. Hetland ML, Ostergaard M, Ejbjerg B, Jacobsen S, Stengaard-Pedersen K, Junker P, et al. Short- and long-term efficacy of intra-articular injections with betamethasone as part of a treat-to-target strategy in early rheumatoid arthritis: impact of joint area, repeated injections, MRI findings, anti-CCP, IgM-RF and CRP. Annals of the rheumatic diseases. 2012;71(6):851-6.

151. Kuusalo LA, Puolakka KT, Kautiainen H, Alasaarela EM, Hannonen PJ, Julkunen HA, et al. Intra-articular glucocorticoid injections should not be neglected in the remission targeted treatment of early rheumatoid arthritis: a post hoc analysis from the NEO-RACo trial. Clinical and experimental rheumatology. 2016.

152. Menon N, Kothari SY, Gogna A, Sharma R. Comparison of intra-articular glucocorticoid injections with DMARDs versus DMARDs alone in rheumatoid arthritis. The Journal of the Association of Physicians of India. 2014;62(8):673-6.

153. Furtado RN, Oliveira LM, Natour J. Polyarticular corticosteroid injection versus systemic administration in treatment of rheumatoid arthritis patients: a randomized controlled study. The Journal of rheumatology. 2005;32(9):1691-8.

154. Gvozdenovic E, Dirven L, van den Broek M, Han KH, Molenaar ET, Landewe RB, et al. Intra articular injection with corticosteroids in patients with recent onset rheumatoid arthritis: subanalyses from the BeSt study. Clinical rheumatology. 2014;33(2):263-7.

155. Horslev-Petersen K, Hetland ML, Junker P, Podenphant J, Ellingsen T, Ahlquist P, et al. Adalimumab added to a treat-to-target strategy with methotrexate and intra-articular triamcinolone in early rheumatoid arthritis increased remission rates, function and quality of life. The OPERA Study: an investigator-initiated, randomised, double-blind, parallel-group, placebo-controlled trial. Annals of the rheumatic diseases. 2014;73(4):654-61.

156. Filippucci E, Farina A, Carotti M, Salaffi F, Grassi W. Grey scale and power Doppler sonographic changes induced by intra-articular steroid injection treatment. Annals of the rheumatic diseases. 2004;63(6):740-3.

157. Terslev L, Torp-Pedersen S, Qvistgaard E, Danneskiold-Samsoe B, Bliddal H. Estimation of inflammation by Doppler ultrasound: quantitative changes after intra-articular treatment in rheumatoid arthritis. Annals of the rheumatic diseases. 2003;62(11):1049-53. 158. Boesen M, Boesen L, Jensen KE, Cimmino MA, Torp-Pedersen S, Terslev L, et al. Clinical outcome and imaging changes after intraarticular (IA) application of etanercept or methylprednisolone in rheumatoid arthritis: magnetic resonance imaging and ultrasoundDoppler show no effect of IA injections in the wrist after 4 weeks. The Journal of rheumatology. 2008;35(4):584-91.

159. Haugeberg G, Morton S, Emery P, Conaghan PG. Effect of intra-articular corticosteroid injections and inflammation on periarticular and generalised bone loss in early rheumatoid arthritis. Annals of the rheumatic diseases. 2011;70(1):184-7.

160. Jensen TW, Hansen MS, Horslev-Petersen K, Hyldstrup L, Abrahamsen B, Langdahl $\mathrm{B}$, et al. Periarticular and generalised bone loss in patients with early rheumatoid arthritis: 
influence of alendronate and intra-articular glucocorticoid treatment. Post hoc analyses from the CIMESTRA trial. Annals of the rheumatic diseases. 2014;73(6):1123-9.

161. Courtney P, Doherty M. Joint aspiration and injection. Best practice \& research Clinical rheumatology. 2005;19(3):345-69.

162. Koski JM. Ultrasound guided injections in rheumatology. The Journal of rheumatology. 2000;27(9):2131-8.

163. Kane D, Koski J. Musculoskeletal interventional procedures: With or without imaging guidance? Best practice \& research Clinical rheumatology. 2016;30(4):736-50. 164. Berkoff DJ, Miller LE, Block JE. Clinical utility of ultrasound guidance for intraarticular knee injections: a review. Clinical interventions in aging. 2012;7:89-95.

165. Cunnington J, Marshall N, Hide G, Bracewell C, Isaacs J, Platt P, et al. A randomized, double-blind, controlled study of ultrasound-guided corticosteroid injection into the joint of patients with inflammatory arthritis. Arthritis and rheumatism. 2010;62(7):1862-9.

166. Sibbitt WL, Jr., Band PA, Chavez-Chiang NR, Delea SL, Norton HE, Bankhurst AD. A randomized controlled trial of the cost-effectiveness of ultrasound-guided intraarticular injection of inflammatory arthritis. The Journal of rheumatology. 2011;38(2):252-63.

167. Naredo E, Cabero F, Beneyto P, Cruz A, Mondejar B, Uson J, et al. A randomized comparative study of short term response to blind injection versus sonographic-guided injection of local corticosteroids in patients with painful shoulder. The Journal of rheumatology. 2004;31(2):308-14.

168. Bloom JE, Rischin A, Johnston RV, Buchbinder R. Image-guided versus blind glucocorticoid injection for shoulder pain. The Cochrane database of systematic reviews. 2012(8):Cd009147.

169. d'Agostino MA, Ayral X, Baron G, Ravaud P, Breban M, Dougados M. Impact of ultrasound imaging on local corticosteroid injections of symptomatic ankle, hind-, and midfoot in chronic inflammatory diseases. Arthritis and rheumatism. 2005;53(2):284-92. 170. Dougados M, Devauchelle-Pensec V, Ferlet JF, Jousse-Joulin S, D'Agostino MA, Backhaus M, et al. The ability of synovitis to predict structural damage in rheumatoid arthritis: a comparative study between clinical examination and ultrasound. Annals of the rheumatic diseases. 2013;72(5):665-71.

171. Torp-Pedersen ST, Terslev L. Settings and artefacts relevant in colour/power Doppler ultrasound in rheumatology. Annals of the rheumatic diseases. 2008;67(2):143-9.

172. Hamra G, MacLehose R, Richardson D. Markov chain Monte Carlo: an introduction for epidemiologists. International journal of epidemiology. 2013;42(2):627-34.

173. Rickham PP. Human Experimentation. Code of Ethics of the World Medical Association. Declaration of Helsinki. Br Med J. 1964;2(5402):177.

174. ICH Harmonised Tripartite Guideline: guideline for good clinical practice. Journal of postgraduate medicine. 2001;47(2):121-30.

175. Sedgwick P. Prospective cohort studies: advantages and disadvantages. BMJ :

British Medical Journal. 2013;347.

176. Burgers LE, van Nies JA, Ho LY, de Rooy DP, Huizinga TW, van der Helm-van Mil AH. Long-term outcome of rheumatoid arthritis defined according to the 2010-classification criteria. Annals of the rheumatic diseases. 2014;73(2):428-32.

177. Schipper LG, Vermeer M, Kuper HH, Hoekstra MO, Haagsma CJ, Den Broeder AA, et al. A tight control treatment strategy aiming for remission in early rheumatoid arthritis is 
more effective than usual care treatment in daily clinical practice: a study of two cohorts in the Dutch Rheumatoid Arthritis Monitoring registry. Ann Rheum Dis. 2012;71(6):845-50. 178. Goekoop-Ruiterman YP, de Vries-Bouwstra JK, Allaart CF, van ZD, Kerstens PJ, Hazes JM, et al. Clinical and radiographic outcomes of four different treatment strategies in patients with early rheumatoid arthritis (the BeSt study): A randomized, controlled trial. Arthritis Rheum. 2008;58(2 Suppl):S126-S35.

179. Furtado RN, Machado FS, Luz KR, Santos MF, Konai MS, Lopes RV, et al. Intraarticular injection with triamcinolone hexacetonide in patients with rheumatoid arthritis: prospective assessment of goniometry and joint inflammation parameters. Revista brasileira de reumatologia. 2017;57(2):115-21.

180. Boini S, Guillemin F. Radiographic scoring methods as outcome measures in rheumatoid arthritis: properties and advantages. Ann Rheum Dis. 2001;60(9):817-27.

181. van der Heijde DM. Plain X-rays in rheumatoid arthritis: overview of scoring methods, their reliability and applicability. Baillieres Clin Rheumatol. 1996;10(3):435-53. 182. Han J, Geng Y, Deng X, Zhang Z. Subclinical Synovitis Assessed by Ultrasound Predicts Flare and Progressive Bone Erosion in Rheumatoid Arthritis Patients with Clinical Remission: A Systematic Review and Metaanalysis. The Journal of rheumatology. 2016;43(11):2010-8.

183. Nguyen H, Ruyssen-Witrand A, Gandjbakhch F, Constantin A, Foltz V, Cantagrel A. Prevalence of ultrasound-detected residual synovitis and risk of relapse and structural progression in rheumatoid arthritis patients in clinical remission: a systematic review and meta-analysis. Rheumatology (Oxford, England). 2014;53(11):2110-8.

184. Hetland ML, Horslev-Petersen K. The CIMESTRA study: intra-articular glucocorticosteroids and synthetic DMARDs in a treat-to-target strategy in early rheumatoid arhtritis. Clinical and experimental rheumatology. 2012;30(4 Suppl 73):S44-9.

185. Sibbitt WL, Jr., Peisajovich A, Michael AA, Park KS, Sibbitt RR, Band PA, et al. Does sonographic needle guidance affect the clinical outcome of intraarticular injections? The Journal of rheumatology. 2009;36(9):1892-902.

186. Luz KR, Furtado RN, Nunes CC, Rosenfeld A, Fernandes AR, Natour J. Ultrasoundguided intra-articular injections in the wrist in patients with rheumatoid arthritis: a doubleblind, randomised controlled study. Annals of the rheumatic diseases. 2008;67(8):1198-200. 187. Forslind K, Ahlmen M, Eberhardt K, Hafstrom I, Svensson B. Prediction of radiological outcome in early rheumatoid arthritis in clinical practice: role of antibodies to citrullinated peptides (anti-CCP). Annals of the rheumatic diseases. 2004;63(9):1090-5. 188. Kastbom A, Strandberg G, Lindroos A, Skogh T. Anti-CCP antibody test predicts the disease course during 3 years in early rheumatoid arthritis (the Swedish TIRA project). Annals of the rheumatic diseases. 2004;63(9):1085-9.

189. van der Helm-van Mil AH, Verpoort KN, Breedveld FC, Toes RE, Huizinga TW. Antibodies to citrullinated proteins and differences in clinical progression of rheumatoid arthritis. Arthritis research \& therapy. 2005;7(5):R949-58.

190. Choi S, Lee KH. Clinical management of seronegative and seropositive rheumatoid arthritis: A comparative study. PloS one. 2018;13(4):e0195550.

191. Barra L, Pope JE, Orav JE, Boire G, Haraoui B, Hitchon C, et al. Prognosis of seronegative patients in a large prospective cohort of patients with early inflammatory arthritis. The Journal of rheumatology. 2014;41(12):2361-9.

192. Kaneko Y, Kuwana M, Kameda H, Takeuchi T. Sensitivity and specificity of 2010 rheumatoid arthritis classification criteria. Rheumatology (Oxford, England).

2011;50(7):1268-74. 
193. Cader MZ, Filer A, Hazlehurst J, de Pablo P, Buckley CD, Raza K. Performance of the 2010 ACR/EULAR criteria for rheumatoid arthritis: comparison with 1987 ACR criteria in a very early synovitis cohort. Annals of the rheumatic diseases. 2011;70(6):949-55.

194. de Hair MJ, Lehmann KA, van de Sande MG, Maijer KI, Gerlag DM, Tak PP. The clinical picture of rheumatoid arthritis according to the 2010 American College of

Rheumatology/European League Against Rheumatism criteria: is this still the same disease? Arthritis and rheumatism. 2012;64(2):389-93.

195. Katchamart W, Koolvisoot A, Aromdee E, Chiowchanwesawakit P, Muengchan C. Associations of rheumatoid factor and anti-citrullinated peptide antibody with disease progression and treatment outcomes in patients with rheumatoid arthritis. Rheumatology international. 2015.

196. Boer AC, Boonen A, van der Helm van Mil AHM. Is ACPA-positive RA still a more severe disease than ACPA-negative RA? A longitudinal cohort study in RA-patients diagnosed from 2000 onwards. Arthritis care \& research. 2017.

197. Ajeganova S, Huizinga TW. Rheumatoid arthritis: Seronegative and seropositive RA: alike but different? Nature reviews Rheumatology. 2015;11(1):8-9. 

8. Papers I-III 


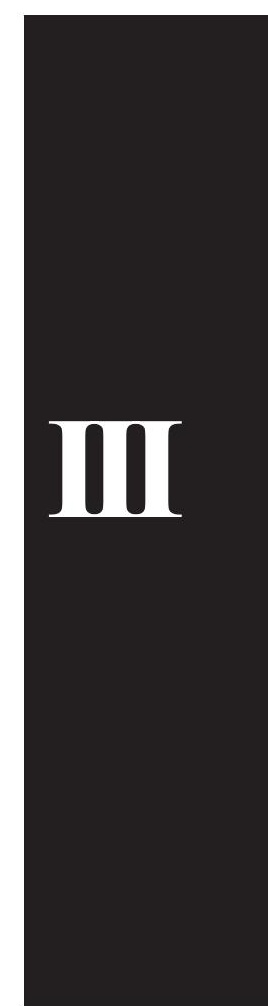





\section{RMD Open}

Rheumatic \& Musculoskeletal Diseases
To cite: Nordberg LB,

Lillegraven S, Aga A-B, et al. Comparing the disease course of patients with seronegative and seropositive rheumatoid arthritis fulfilling the 2010 ACR/EULAR classification criteria in a treatto-target setting: 2-year data from the ARCTIC trial. RMD Open 2018:4:e000752. doi:10.1136/ rmdopen-2018-000752

- Prepublication history and additional material for this paper are available online. To view these files, please visit the journal online (http://dx.doi. org/10.1136/rmdopen-2018000752)

Some of the findings in this article were presented as a poster presentation at the EULAR and ACR 2017 annual meetings.

Received 25 June 2018 Revised 2 0ctober 2018 Accepted 4 October 2018

\section{Check for updates}

(C) Author(s) (or their employer(s)) 2018. Re-use permitted under CC BY-NC. No commercial re-use. See rights and permissions. Published by BMJ.

For numbered affiliations see end of article.

Correspondence to Dr Lena Bugge Nordberg; lenabuggenordberg@gmail.com

Comparing the disease course of patients with seronegative and seropositive rheumatoid arthritis fulfilling the 2010 ACR/EULAR classification criteria in a treat-to-target setting: 2-year data from the ARCTIC trial

Lena Bugge Nordberg, ${ }^{1,2}$ Siri Lillegraven, ${ }^{1}$ Anna-Birgitte Aga, ${ }^{1}$ Joseph Sexton, ${ }^{1}$ Inge Christoffer Olsen, ${ }^{1,3}$ Elisabeth Lie, ${ }^{1}$ Hilde Berner Hammer, ${ }^{1}$ Till Uhlig, ${ }^{1}$ Desirée van der Heijde, ${ }^{1,4}$ Tore K Kvien, ${ }^{1}$ Espen A Haavardsholm ${ }^{1,2}$

\section{ABSTRACT}

Objectives Recent studies suggest that implementation of the 2010 American College of Rheumatology (ACR)/ European League Against Rheumatism (EULAR) classification criteria for rheumatoid arthritis (RA) leads to higher inflammatory activity in seronegative compared with seropositive patients at time of diagnosis. Our aim was to compare the disease course in seronegative and seropositive patients classified according to the 2010 criteria.

Methods DMARD-naïve patients with RA fulfilling the 2010 criteria were included in the treat-to-target ARCTIC trial and followed for 24 months. We stratified patients as seropositive (rheumatoid factor (RF)+, anticitrullinated protein antibodies (ACPA)+ or both) or seronegative (RFand ACPA-) and compared disease activity, radiographic progression, treatment response and remission rates across groups.

Results 230 patients were included with mean (SD) age 51.4 (13.7) years, and 61\% were female. 34 patients $(15 \%)$ were seronegative. At 24 months, disease activity measures, radiographic progression and remission rates were similar between groups, despite more inflammatory activity in seronegative patients at baseline. Treatment response was slower in seronegative compared with seropositive patients. The groups received similar treatment.

Conclusion Our findings suggest that among patients with RA classified according to the 2010 ACR/EULAR criteria, seronegative patients respond well to modern treatment strategies. However, treatment response was somewhat slower in seronegative patients and radiographic progression was similar in seronegative and seropositive patients. Our results indicate that seronegative $\mathrm{RA}$ is not a mild form of the disease and requires intensive treat-to-target therapy similar to treatment of seropositive RA.

\section{Key messages}

What is already known about this subject?

- Seronegative rheumatoid arthritis (RA) has been considered to represent a less severe disease subset than seropositive RA, with less radiographic damage.

- Recent studies indicate that the implementation of the 2010 classification criteria for RA, which put strong emphasis on serological status, leads to higher inflammatory activity in seronegative compared with seropositive patients at time of diagnosis.

What does this study add?

- Disease activity, remission rates and radiographic progression were similar in patients with seronegative and seropositive RA after 2 years of follow-up.

- Treatment response was slower in seronegative than in seropositive patients, although all patients were treated according to the same algorithm.

How might this impact on clinical practice?

- These results indicate that patients now classified as seronegative RA might have a more serious disease than the historic perception of this subgroup and require intensive therapy similar to treatment of seropositive RA.

\section{INTRODUCTION}

Rheumatoid arthritis (RA) is an autoimmune, potentially disabling joint disease. ${ }^{1}$ RA is currently classified as seropositive or seronegative based on the presence or absence of rheumatoid factor (RF) and anticitrullinated protein antibodies 
(ACPA), and serological status has become important in diagnosis, prognostication and treatment decisions. Seronegative RA has been considered to represent a less severe disease subset than seropositive RA, with less radiographic damage. ${ }^{2-6}$ It has been suggested that seronegative patients should be treated less aggressively than seropositive patients, which is also reflected in the 2016 update of the European League Against Rheumatism (EULAR) treatment recommendations. ${ }^{78}$

Implementation of the 2010 American College of Rheumatology (ACR)/EULAR classification criteria for RA redefined the patient population, including the classification of seronegative patients. ${ }^{9}$ In our recently published study of disease-modifying antirheumatic drug (DMARD)-naïve patients with early RA fulfilling the new classification criteria, we found that seronegative patients had markedly higher inflammatory activity at the time of diagnosis compared with seropositive patients. ${ }^{10}$ Based on follow-up data in this cohort, we aimed to examine the disease course of seronegative patients with early RA fulfilling the 2010 ACR/EULAR criteria compared with seropositive patients.

\section{METHODS}

\section{Patients and study design}

Patients with RA fulfilling the 2010 ACR/EULAR classification criteria were included in the ARCTIC trial (ClinicalTrials.gov identifier NCT01205854). ${ }^{11}$ All patients had symptom duration less than 2 years and were DMARD naïve with indication for DMARD treatment. We stratified the patients as seropositive (RF+ (IgM or IgA), ACPA+ or both) or seronegative (both RF- and ACPA-). Patients were randomised 1:1 to a treat-to-target strategy with or without ultrasound examinations to guide treatment decisions and joint injections during follow-up. The same DMARD escalation algorithm was applied in both arms, and inflamed joints were treated with intra-articular glucocorticoids (triamcinolone hexacetonide). Patients were assessed at 13 visits within 24 months. Data from the two strategy arms were pooled and analysed together for the current study, as clinical and radiographic outcomes were similar in the two strategy arms after 2 years. ${ }^{11}$ The study was approved by the regional ethics committee, and all patients provided written informed consent.

\section{Data collection}

The data collection included demographic data, erythrocyte sedimentation rate $(\mathrm{mm} /$ hour $)$, $\mathrm{C}$ reactive protein $(\mathrm{mg} / \mathrm{L})$, Ritchie Articular Index, 44 swollen joint count (SJC), the patient's and physician's global assessment of disease activity on $0-100 \mathrm{~mm}$ visual analogue scales, patient-reported outcome measures and radiographs of hands and feet which were scored according to the van der Heijde-modified Sharp score by two independent readers blinded for patient identity and clinical information. The Disease Activity Score (DAS) was calculated. ${ }^{12}$

Ultrasound examinations were performed by trained rheumatologists according to a validated 0-3 semiquantitative scoring system for grey scale and power Doppler. ${ }^{13}$ Thirty-two joints were included, giving ranges from 0 to 96 for grey scale and power Doppler.

Sera were collected in a biobank, and RF and ACPA were analysed at the same laboratory by enzyme-linked immunosorbent assay ELISA and fluorescence enzyme immunoassay, respectively. A positive test was defined as any value $\geq 10 \mathrm{IU} / \mathrm{mL}$ for ACPA and $\geq 25 \mathrm{IU} / \mathrm{mL}$ for RF.

\section{Statistical analyses}

Continuous variables are presented as means (SD) or medians (25th-75th percentile) according to distribution. Dichotomous variables are presented as frequencies and percentages. At baseline and 24 month follow-up, measures of disease activity were compared across groups using independent samples t-test, MannWhitney $U$ test or $\chi^{2}$ test as appropriate. We also compared the change from baseline in these measures between groups. Measures of disease activity at baseline and 24-month follow-up were also compared between seronegative patients and subgroups of seropositive patients (single ACPA+, single RF+ and double-positive patients).

Radiographic progression, DAS, SJC44 and ultrasound scores over time were compared between seronegative and seropositive patients by linear mixed-effects models with random intercept for patient in order to account for within-patient dependencies. We used robust variance estimates for ultrasound scores and radiographic progression due to skewed distributions. Finally, we compared response and remission rates across serology status at 3, 6, 12 and 24 months using $\chi^{2}$ tests. We also assessed treatment response in logistic regression models with EULAR good/moderate response at 3 and 6 months as dependent variables and serology status (seronegative/seropositive) baseline SJC44, baseline DAS, baseline Ritchie articular index, sex and age as independent variables. We performed the same analyses with ACR 50 response at 3 and 6 months as dependent variables.

Statistical tests were two-sided and $\mathrm{p}<0.05$ were considered statistically significant. Three seronegative and 23 seropositive patients did not attend the 24 month visit, with missing values imputed as described elsewhere. ${ }^{11}$ Statistical analyses were performed using Stata 14.

\section{RESULTS}

Patients

A total of 238 patients were initially included in the ARCTIC trial; of these, 230 attended follow-up visits and were thus included in the current study; 34 patients $(15 \%)$ were seronegative. In the seronegative/ 
seropositive groups, mean (SD) age was 55.4 (15.7) / 50.8 (13.2) years $(\mathrm{p}=0.07)$, mean $(\mathrm{SD})$ disease duration was $7.7(6.8) / 7.0(5.1)$ months $(\mathrm{p}=0.46)$ and $56 \% / 62 \%$ were women $(p=0.48)$.

\section{Disease severity}

At baseline, measures of disease activity were higher in seronegative compared with seropositive patients. ${ }^{10}$ Seronegative patients had a significantly greater reduction in disease activity measures (DAS, number of swollen joints, physician global and ultrasonography scores) resulting in no differences between the groups at 24-month follow-up. There was a trend towards more radiographic damage in seronegative compared with seropositive patients, both at baseline and 24 months (table 1).

Measures of disease activity and severity at baseline and 24-month follow-up were also compared between seronegative patients and subgroups of seropositive patients (single ACPA+, single RF+ and double-positive patients). These analyses did not substantially change the results. At baseline, RF positive (ACPA negative) and seronegative (both ACPA and RF negative) patients had similar levels of inflammatory activity, however, the low number of patients in this subgroup makes interpretations difficult (online supplementary table 1).

During the first 6 months following DMARD initiation, the number of swollen joints and DAS were higher in seronegative compared with seropositive patients. From month six, they were similar across groups (figure 1A,B). Ultrasound scores were not statistically significantly different between groups after 1 and 2 years (figure 1C,D). Radiographic progression was similar between the groups (figure 1E,F).

\section{Response and remission rates}

Three months after treatment start, response and remission rates were lower in seronegative patients, and $6 \%$ of seronegative patients $(2 / 34)$ were in ACR/ EULAR Boolean remission compared with $30 \%$ of seropositive patients $(58 / 196)(\mathrm{p}=0.004)$. From 6 months onwards, response and remission rates were similar between groups. After 6 months of follow-up, 32\% of seronegative $(11 / 34)$ and $35 \%$ of seropositive patients (69/196) were in ACR/EULAR Boolean remission $(\mathrm{p}=0.75)$ (table 2). Analyses adjusted for age, gender, baseline DAS, baseline SJC44 and baseline Ritchie articular index showed that seropositivity was associated with achieving treatment response at 3 months, both for ACR 50 response (OR 3.8 (1.5 to 9.8)) and EULAR good/moderate response (OR 3.9 (1.4 11.2)). Serology status did not predict treatment response at 6 months. Higher baseline DAS was associated with treatment response at 6 months, but not at 3 months (data not shown).

\section{Treatment}

Treatment was similar across groups during the study, with similar rates of seronegative and seropositive patients receiving methotrexate monotherapy, triple therapy and biological treatment at 6 months and 24 months (data not shown). There was a trend towards a higher rate of biological treatment in seronegative patients at the 6 month visit, as $11.8 \%$ of the seronegative patients $(4 / 34)$ received biological treatment, compared with $5.1 \%$ of the seropositive patients $(10 / 196, p=0.13)$.

\section{DISCUSSION}

In this follow-up study of patients with early RA classified according to the 2010 ACR/EULAR criteria, disease activity after 2 years of treat-to-target therapy was similar in seronegative and seropositive patients, despite markedly more inflammatory activity and a tendency towards more radiographic damage in seronegative patients at baseline. Treatment response was somewhat slower in seronegative patients and radiographic progression was similar in seronegative and seropositive patients. Our findings suggest that in patients RA classified according to the new criteria, seronegative RA is not a mild form of the disease and requires intensive treat-to-target therapy similar to treatment of seropositive RA.

Several studies of patients classified according to the 1987 criteria for RA indicate that seronegative patients have a less severe disease course with less radiographic damage than seropositive patients. ${ }^{2-6} 14$ Studies have also shown more inflammatory activity in seropositive patients, with fewer patients achieving remission, ${ }^{414} 15$ although evidence is somewhat conflicting. ${ }^{61617}$ There is very limited information about the disease course of seronegative patients classified according to the 2010 criteria. One recently published study in patients with RA fulfilling the 2010 criteria showed that patient-reported outcomes including physical functioning and restrictions at work were similar in ACPA-positive and ACPA-negative patients after 4 years of follow-up. ${ }^{18}$ This is in line with our study where seronegative patients did not have a less severe disease course than seropositive patients, with similar rates of remission and similar radiographic progression over 2 years. In our study, there was a trend towards more radiographic damage in seronegative compared with seropositive patients, both at baseline and 24 months. The numerical differences may not have reached statistical significance due to the small number of patients in the seronegative group.

An aim for the ACR/EULAR 2010 RA classification criteria was to increase sensitivity for patients with early disease. However, the low number of seronegative patients included in the ARCTIC trial and, on average, high inflammatory activity in seronegative patients at baseline, indicate that the increased sensitivity may be confined to patients with seropositive disease. ${ }^{19}$ 


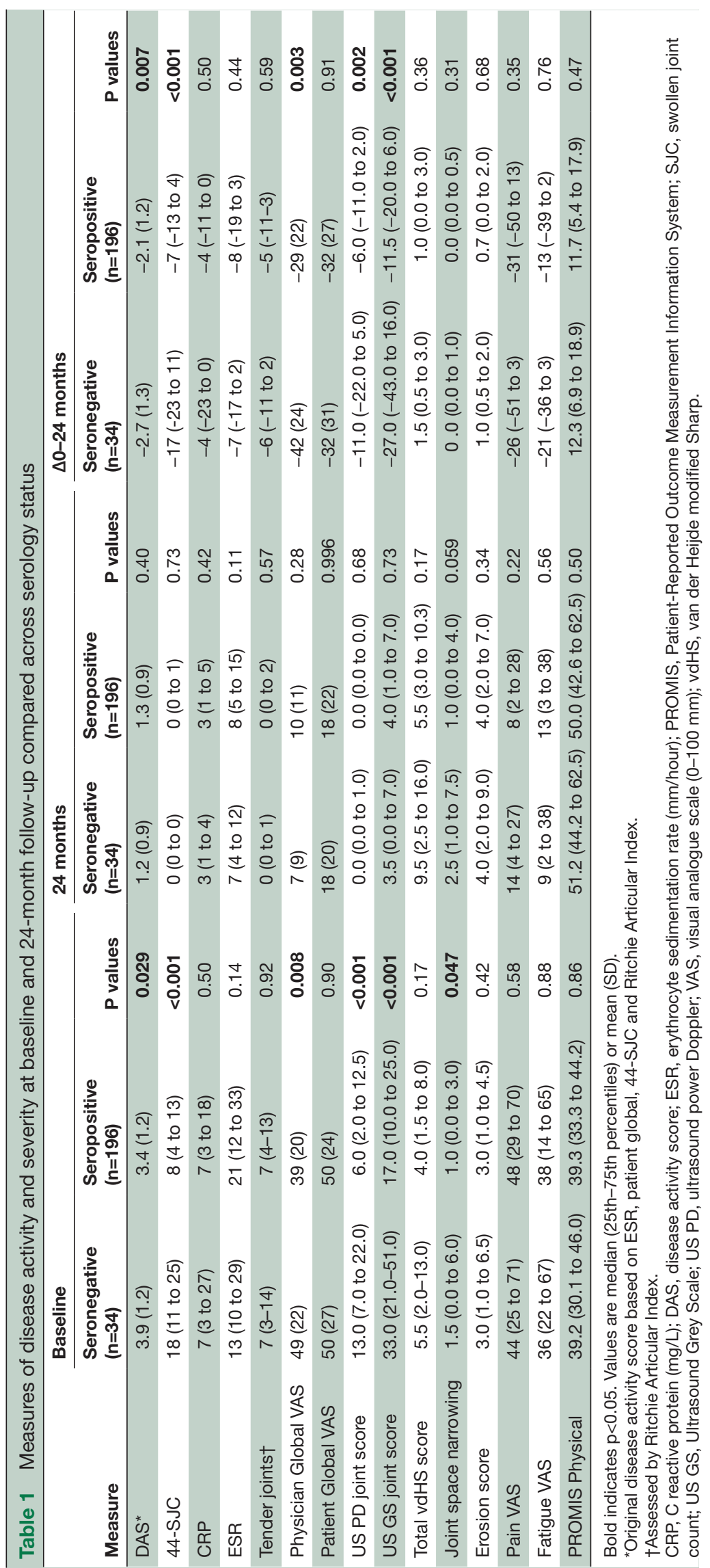



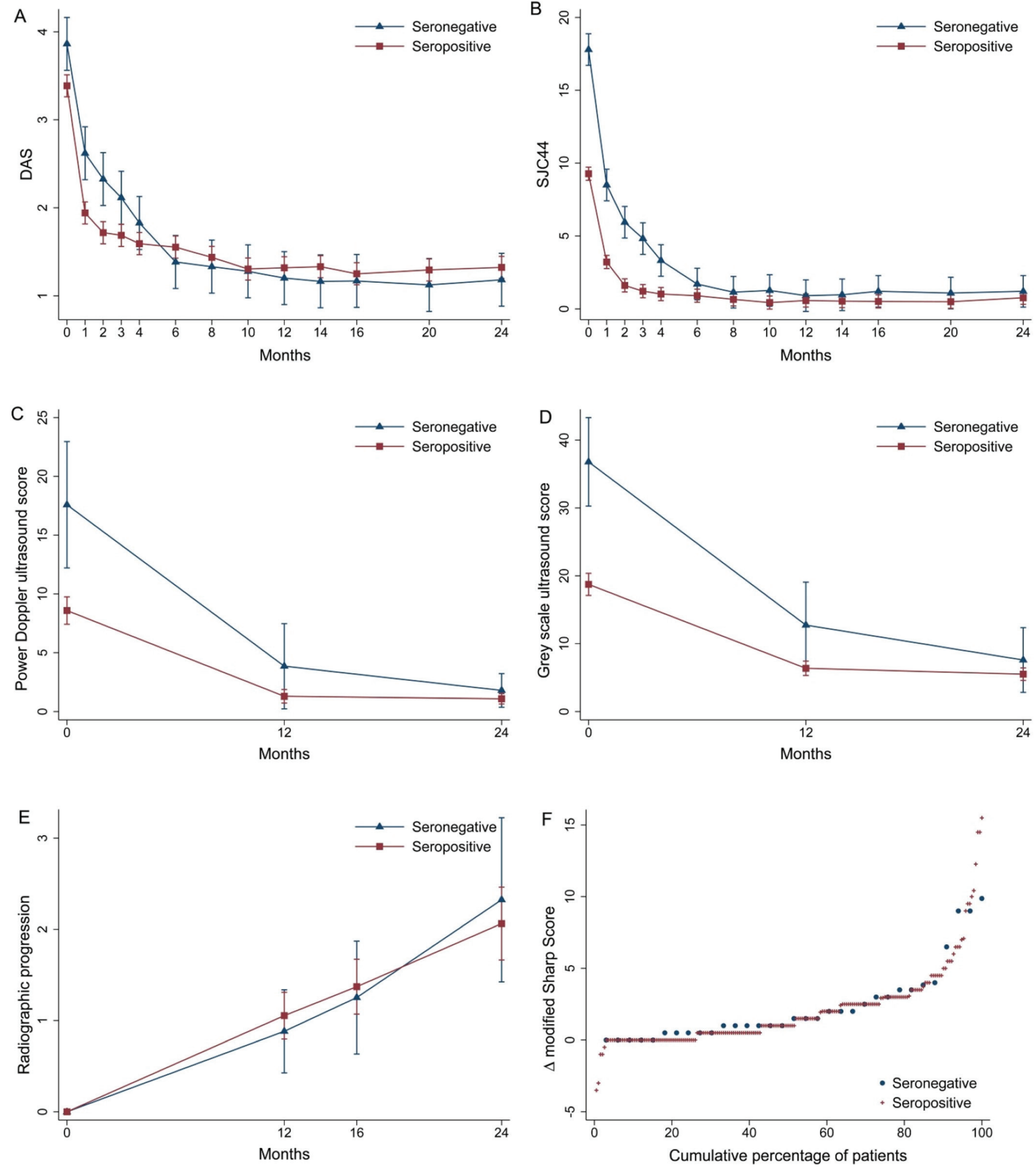

Figure 1 (A-F) Disease activity measures and radiographic progression 0-24 months in seronegative and seropositive patients. (A-E) Margins plot over 24 months of DAS, SJC44, ultrasound power Doppler score, ultrasound grey scale Score and radiographic progression. Bars represent 95\% Cls. (F) Cumulative probability plot of change between baseline and 24 months in Van der Heijde modified sharp score. DAS, Disease Activity Score; SJC, swollen joint count.

When patients were included in the ARCTIC trial, the ACR/EULAR 2010 classification criteria for RA were used. At this time, the erosion criteria had not yet been defined, and patients who did not otherwise fulfil the criteria may have been included if we had applied the later published erosion criteria. ${ }^{20}$ However, a recently published study has shown that the clinical and radiographic course in ACR/EULAR 2010 negative patients 


\begin{tabular}{|c|c|c|c|}
\hline & $\begin{array}{l}\text { Seronegative } \\
(n=34)\end{array}$ & $\begin{array}{l}\text { Seropositive } \\
(n=196)\end{array}$ & $P$ values \\
\hline EULAR good/moderate response & n (\%) & n (\%) & \\
\hline At 3 months & $23(68)$ & $159(81)$ & 0.07 \\
\hline At 6 months & $29(85)$ & $161(82)$ & 0.66 \\
\hline \multicolumn{4}{|l|}{ ACR50 response } \\
\hline At 3 months & $10(29)$ & $99(51)$ & 0.023 \\
\hline At 6 months & $17(50)$ & $109(56)$ & 0.54 \\
\hline \multicolumn{4}{|l|}{ ACR/EULAR Boolean remission } \\
\hline At 3 months & $2(6)$ & $58(30)$ & 0.004 \\
\hline At 6 months & $11(32)$ & $69(35)$ & 0.75 \\
\hline At 12 months & $14(41)$ & $83(42)$ & 0.90 \\
\hline At 24 months & $18(53)$ & $94(48)$ & 0.59 \\
\hline
\end{tabular}

Bold indicates $p<0.05$.

ACR, American Collage of Rheumatology; EULAR, European League Against Rheumatism.

under treatment was not dependent on the presence of erosions at diagnosis. $^{21}$

Studies have shown that patients who do not respond significantly to treatment within 3 months have a low chance of attaining remission within 6 months. ${ }^{22} 23$ According to the current EULAR recommendations for management of RA, treatment adjustment should be considered in patients with less than $50 \%$ improvement in disease activity 3 months after treatment start. ${ }^{8}$ In our study, the treatment response at 3 months was better in seropositive than seronegative patients, whereas the number of patients in remission at the end of the study was similar across groups. This observation may indicate that seronegative patients might respond well to treat-to-target strategies even if the initial treatment response is delayed compared with seropositive patients.

Seronegative RA has been considered to represent a less severe disease subset than seropositive RA. ${ }^{2-6}$ This assumption could possibly lead to less intensive treatment of seronegative patients in usual care. Our results highlight that both patients with seronegative and seropositive RA should receive intensive treat-totarget DMARD therapy. The updated EULAR treatment recommendations are more or less the same as the treatment protocol in the ARCTIC trial, increasing the generalisability of our results.

A limitation of our study is the small number of seronegative patients included, which limits the statistical power. Strengths of our study include the extensive data collection with radiographic and ultrasonographic examinations of all patients. To our knowledge, this is the first study to examine the disease course of seronegative RA in an inception cohort of DMARD-naïve patients classified according to the 2010 ACR/EULAR criteria.
In conclusion, patients with seronegative RA classified according to the 2010 ACR/EULAR criteria respond well to modern treatment strategies, but seronegative $\mathrm{RA}$ is not a mild form of the disease and requires as intensive treat-to-target therapy as seropositive RA.

\section{Author affiliations}

${ }^{1}$ Department of Rheumatology, Diakonhjemmet Hospital, Oslo, Norway ${ }^{2}$ Faculty of medicine, University of Oslo, Oslo, Norway

${ }^{3}$ Research Support Services CTU, Oslo University hospital, Oslo, Norway ${ }^{4}$ Leiden University Medical Center, Leiden, The Netherlands

Acknowledgements The authors wish to thank the patients for participating in this study and the ARCTIC investigators: Hallvard Fremstad, Tor Magne Madland, Åse Stavland Lexberg, Hilde Haukeland, Erik Rødevand, Christian Høili, Hilde Stray, Anne Lindter Noraas, Dag Magnar Soldal, Gunnstein Bakland.

Contributors All authors were involved in drafting the article or revising it critically for important intellectual content and approved the final manuscript to be submitted and agreed to be accountable for all aspects of the work. Conception and design of the study: EAH, SL, LBN, A-BA, EL, ICO, HBH, TU, DvdH, JS and TKK. Acquisition of data: EAH, A-BA, HBH, TU and the ARCTIC investigators. Analysis and interpretation of data: LBN, ICO, JS, EAH, SL, EL, A-BA, DvdH and TKK.

Funding The study has received grants from the Norwegian Research Council, the South-East Health Region in Norway, The Norwegian Rheumatism Association and unrestricted grant support from AbbVie, Pfizer, MSD, Roche and UCB.

Competing interests EAH has received research funding from Pfizer, UCB, Roche, MSD and AbbVie for the submitted work, honorariums as a speaker from Pfizer, UCB, Roche and AbbVie and honorariums for development of educational materia from Pfizer and Eli Lilly and has sat on advisory boards for Pfizer, Eli Lilly, Celgene and Janssen-Cilag. A-BA has sat on advisory boards for UCB, AbbVie and Pfizer and received honorariums for development of educational material for UCB. HBH has received honorariums as a speaker from AbbVie, Bristol-Myers Squibb, Roche, UCB Pharma, Novartis and Pfizer. DvdH has received consultancy honorariums from AbbVie, Amgen, Astellas, AstraZeneca, Bristol-Myers Squibb, Celgene, Daiichi, Eli Lilly, Galapagos, Merck, Novartis, Pfizer, Roche, Sanofi Aventis, Janssen and UCB and is owner of Imaging Rheumatology. TKK has received consultancy honorariums from AbbVie, Bristol-Myers Squibb, Celltrion, Epirus, Hospira, Merck-Serono, MSD, Orion Pharma, Pfizer, Roche and UCB. TU has received honorariums as a speaker from AbbVie, Bristol-Myers Squibb, Lilly, Roche, Novartis, UCB Pharma and Pfizer. ICO has received consultancy honorarium from Pfizer.

\section{Patient consent Not required.}

Ethics approval The Norwegian Regional ethics committee.

Provenance and peer review Not commissioned; externally peer reviewed. 
Data sharing statement The authors commit to making the relevant anonymised patient level data available on reasonable request.

Open access This is an open access article distributed in accordance with the Creative Commons Attribution Non Commercial (CC BY-NC 4.0) license, which permits others to distribute, remix, adapt, build upon this work non-commercially, and license their derivative works on different terms, provided the original work is properly cited, appropriate credit is given, any changes made indicated, and the use is non-commercial. See: http://creativecommons.org/licenses/by-nc/4.0

\section{REFERENCES}

1. Smolen JS, Aletaha D, Mclnnes IB. Rheumatoid arthritis. Lancet 2016;388:2023-38

2. Syversen SW, Goll GL, van der Heijde D, et al. Prediction of radiographic progression in rheumatoid arthritis and the role of antibodies against mutated citrullinated vimentin: results from a 10year prospective study. Ann Rheum Dis 2010;69:345-51.

3. Hecht C, Englbrecht M, Rech J, et al. Additive effect of anticitrullinated protein antibodies and rheumatoid factor on bone erosions in patients with RA. Ann Rheum Dis 2015;74:2151-6.

4. Rönnelid J, Wick MC, Lampa J, et al. Longitudinal analysis of citrullinated protein/peptide antibodies (anti-CP) during 5 year follow up in early rheumatoid arthritis: anti-CP status predicts worse disease activity and greater radiological progression. Ann Rheum Dis 2005;64:1744-9.

5. Nell VP, Machold KP, Stamm TA, et al. Autoantibody profiling as early diagnostic and prognostic tool for rheumatoid arthritis. Ann Rheum Dis 2005;64:1731-6.

6. van den Broek M, Dirven L, Klarenbeek NB, et al. The association of treatment response and joint damage with ACPA-status in recentonset RA: a subanalysis of the 8-year follow-up of the best study. Ann Rheum Dis 2012;71:245-8.

7. de Punder YM, Hendrikx J, den Broeder AA, et al. Should we redefine treatment targets in rheumatoid arthritis? Low disease activity is sufficiently strict for patients who are anticitrullinated protein antibody-negative. J Rheumatol 2013;40:1268-74.

8. Smolen JS, Landewé R, Bijlsma J, et al. EULAR recommendations for the management of rheumatoid arthritis with synthetic and biological disease-modifying antirheumatic drugs: 2016 update. Ann Rheum Dis 2017;76:960-77.

9. Aletaha D, Neogi T, Silman AJ, et al. 2010 rheumatoid arthritis classification criteria: an American college of rheumatology/ European league against rheumatism collaborative initiative. Ann Rheum Dis 2010;69:1580-8.

10. Nordberg LB, Lillegraven S, Lie E, et al. Patients with seronegative RA have more inflammatory activity compared with patients with seropositive RA in an inception cohort of DMARD-naïve patients classified according to the 2010 ACR/EULAR criteria. Ann Rheum Dis 2017;76:341-5.

11. Haavardsholm EA, Aga AB, Olsen IC, et al. Ultrasound in management of rheumatoid arthritis: ARCTIC randomised controlled strategy trial. BMJ 2016;354:i4205.

12. van der Heijde DM, van 't Hof M, van Riel PL, et al. Development of a disease activity score based on judgment in clinical practice by rheumatologists. J Rheumatol 1993;20:579-81.

13. Hammer HB, Bolton-King P, Bakkeheim V, et al. Examination of intra and interrater reliability with a new ultrasonographic reference atlas for scoring of synovitis in patients with rheumatoid arthritis. Ann Rheum Dis 2011;70:1995-8.

14. Katchamart W, Koolvisoot A, Aromdee E, et al. Associations of rheumatoid factor and anti-citrullinated peptide antibody with disease progression and treatment outcomes in patients with rheumatoid arthritis. Rheumatol Int 2015;35:1693-9.

15. Kastbom A, Strandberg G, Lindroos A, et al. Anti-CCP antibody test predicts the disease course during 3 years in early rheumatoid arthritis (the Swedish TIRA project). Ann Rheum Dis 2004;63:1085-9.

16. Barra L, Pope JE, Orav JE, et al. Prognosis of seronegative patients in a large prospective cohort of patients with early inflammatory arthritis. J Rheumatol 2014;41:2361-9.

17. Choi ST, Lee KH. Clinical management of seronegative and seropositive rheumatoid arthritis: a comparative study. PLoS One 2018;13:e0195550

18. Boer AC, Boonen A, van der Helm van Mil AHM. Is ACPApositive RA still a more severe disease than ACPA-negative RA? A longitudinal cohort study in RA-patients diagnosed from 2000 onwards. Arthritis care \& research 2017.

19. van der Helm-van Mil AH, Zink $A$. What is rheumatoid arthritis? Considering consequences of changed classification criteria. Ann Rheum Dis 2017:76:315-7.

20. van der Heijde D, van der Helm-van Mil AH, Aletaha D, et al. EULAR definition of erosive disease in light of the $2010 \mathrm{ACR}$ EULAR rheumatoid arthritis classification criteria. Ann Rheum Dis 2013;72:479-81.

21. Mueller RB, Kaegi T, Haile SR, et al. Clinical and radiographic course of early undifferentiated arthritis under treatment is not dependent on the number of joints with erosions at diagnosis: results from the Swiss prospective observational cohort. RMD Open 2018:4:e000673.

22. Aletaha D, Alasti F, Smolen JS. Optimisation of a treat-to-target approach in rheumatoid arthritis: strategies for the 3-month time point. Ann Rheum Dis 2016;75:1479-85.

23. Aletaha D, Funovits J, Keystone EC, et al. Disease activity early in the course of treatment predicts response to therapy after one yea in rheumatoid arthritis patients. Arthritis Rheum 2007;56:3226-35. 


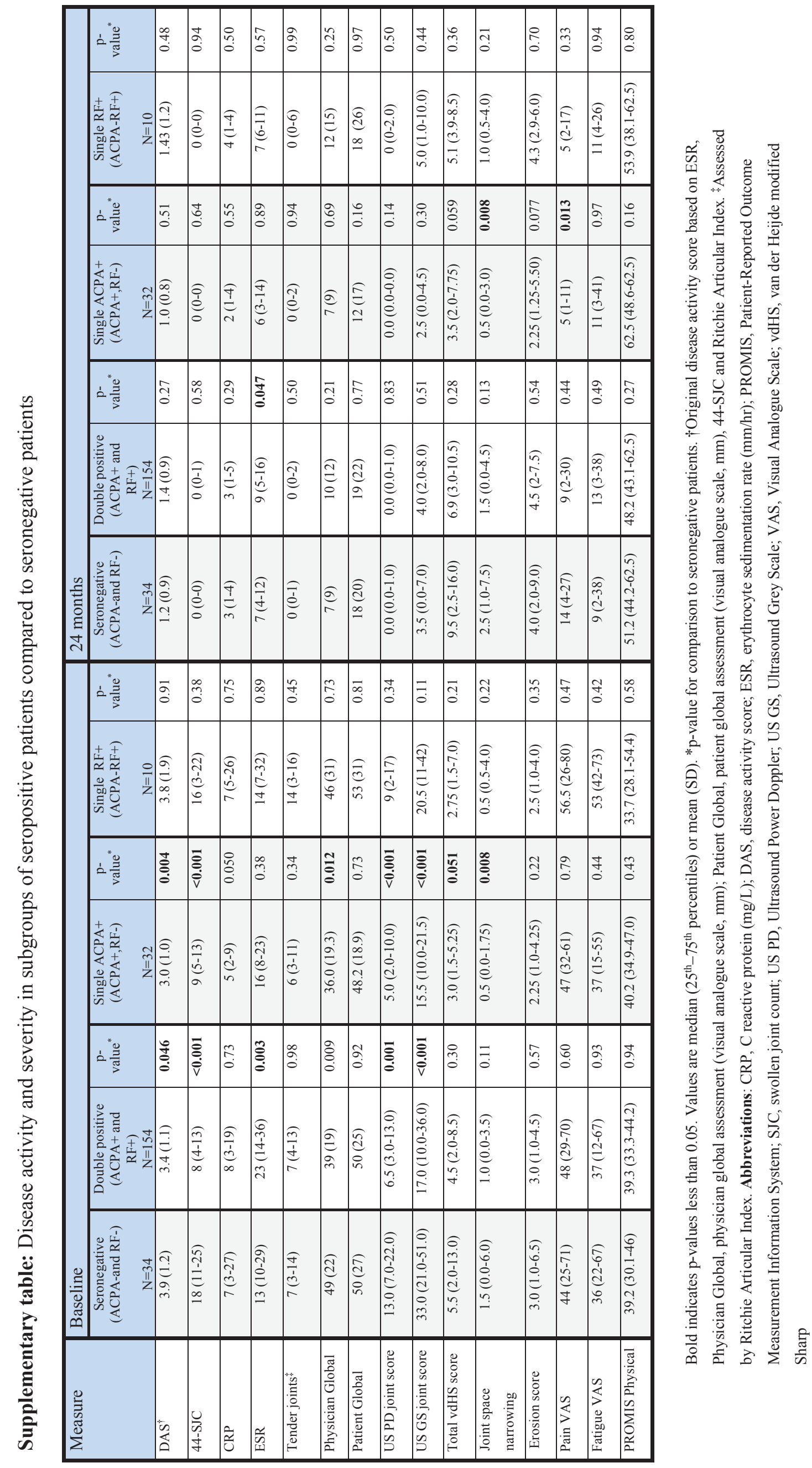

